Florida International University FIU Digital Commons

$11-1-2017$

\title{
Exploring the Efficacy of Social Media Based HIV Prevention Strategies for Hispanic College Students
}

Sofia B. Fernandez

Florida International University, sofernan@fiu.edu

DOI: $10.25148 /$ etd.FIDC004027

Follow this and additional works at: https://digitalcommons.fiu.edu/etd

Part of the Social Work Commons

\section{Recommended Citation}

Fernandez, Sofia B., "Exploring the Efficacy of Social Media Based HIV Prevention Strategies for Hispanic College Students" (2017). FIU Electronic Theses and Dissertations. 3539.

https://digitalcommons.fiu.edu/etd/3539 


\title{
FLORIDA INTERNATIONAL UNIVERSITY \\ Miami, Florida
}

\section{EXPLORING THE EFFICACY OF SOCIAL MEDIA BASED HIV PREVENTION STRATEGIES FOR HISPANIC COLLEGE STUDENTS}

\author{
A dissertation submitted in partial fulfillment of the \\ requirements for the degree of \\ DOCTOR OF PHILOSOPHY \\ in \\ SOCIAL WELFARE \\ By
}

Sofia B. Fernandez

2017 
To: Dean Tómas Guilarte

Robert Stempel College of Public Health and Social Work

This dissertation, written by Sofia B. Fernandez, and entitled Exploring the Efficacy of Social Media Based HIV Prevention Strategies for Hispanic College Students, having been approved in respect to style and intellectual content, is referred to you for judgment.

We have read this dissertation and recommend that it be approved.

Miriam Potocky

$\begin{array}{r}\hline \text { Melissa Howard } \\ \hline \text { Michelle Hospital } \\ \hline\end{array}$

Eric F. Wagner, Major Professor

Date of Defense: November 1, 2017

The dissertation of Sofia B. Fernandez is approved.

Dean Tómas Guilarte Robert Stempel College of Public Health and Social Work

Andrés G. Gil

Vice President for Research and Economic Development and Dean of the University Graduate School

Florida International University, 2017 
Copyright 2017 by Sofia B. Fernandez

All rights reserved. 


\section{DEDICATION}

I dedicate this dissertation to my parents. Your support and love have inspired and encouraged me to complete this endeavor. 


\section{ACKNOWLEDGMENTS}

I would like to acknowledge, first and foremost, Dr. Eric Wagner for his mentorship throughout my education and research training. You provided me with a tremendous opportunity to work on a federal health promotion grant, without which none of this work would have been possible. Thank you for trusting me with great responsibility and encouraging me to step out of my comfort zone. I will be always grateful for your generous and continuous mentorship and for the example of your visionary leadership.

I would also like to acknowledge and thank my three committee members: Dr.

Michelle Hospital, Dr. Melissa Howard, and Dr. Miriam Potocky. Each of you has guided and taught me through your tireless commitment to excellence. Thank you for showing me persistence, determination, and balance. I would also like to thank (my honorary committee member) Dr. Staci Morris for being a strong female example in my growth as a student and researcher. Additionally, I want to acknowledge Dr. Hui Huang for her leadership. Thank you for including me in meaningful research projects and for giving me the opportunity to learn alongside you.

None of this would have been possible without the encouragement, support, and dedication of FIU-BRIDGE staff, students, and volunteers. Growing and working with each of you has been an honor and I am so thankful to have shared this experience with you.

To my cohort, thank you for inspiring me every day with your selfless work and for always managing to make any situation — no matter how challenging — memorable. 
I also attribute much of my educational growth and success to my friend and family. First, I would like to acknowledge my grandparents: living, Virgina Bru, and deceased, Francisco Bru, Luis Fernandez-Caubi, and Maria del Carmen Arenas. Thank you to my sister and brothers, sister-in-law, nephews, cousins, uncles, aunts, and loving friends. You have given me unconditional support. 


\title{
ABSTRACT OF THE DISSERTATION \\ EXPLORING THE EFFICACY OF SOCIAL MEDIA BASED HIV PREVENTION STRATEGIES FOR HISPANIC COLLEGE STUDENTS
}

\author{
by \\ Sofia B. Fernandez \\ Florida International University, 2017 \\ Miami, Florida \\ Professor Eric F. Wagner, Major Professor
}

Hispanics now constitute the largest ethnic minority group in the U.S. As the country's fastest growing demographic, social welfare and public health professionals should focus on ameliorating health issues affecting this population. However, Hispanics continue to experience health disparities including high rates of HIV infection. Moreover, South Florida, is home to two counties with the highest per capita incidence of HIV in the U.S. Risks for HIV are heightened in college settings where individuals may have multiple partners and inconsistent condom use. As such, Hispanic college students in a minority serving institution in Miami, FL comprise an ideal group for the implementation of targeted prevention efforts to decrease health disparities related to HIV.

This dissertation evaluated the implementation of an HIV prevention effort that utilized social media based technologies to engage Hispanic college students in HIV prevention conversations and services. This dissertation (1) evaluated the effectiveness of exposure to a social media based campaign using an experimental design and (2) provided a systematic review of the campaign's content and user interactivity. 
Participants were recruited from students electing to receive free HIV testing on-campus as part of a SAMHSA-funded project.

Hispanic young adults (ages 18-24 years) completed baseline and follow-up assessments - reporting demographic and background characteristics as well as perceptions and incorporation of HIV preventive behaviors. Participants were randomized to social media exposure $(n=30)$ or control $(n=30)$ conditions. The exposure condition received three updates per week in the form of social media post updates. Follow-up assessments occurred 4 weeks after HIV testing.

Mixed ANOVA and logistic regression analysis were used to examine the impact of exposure over time by comparing mean scores of baseline and follow-up responses between conditions. This dissertation examined the following outcomes: awareness of HIV testing and prevention services, confidence of using condoms, perceived benefits of using condoms, and frequency of reported protected sex acts.

While analyses revealed no statistically significant differences between groups, McNemar's test results indicated a statistically significant increase in awareness of HIV prevention services on the university campus for participants in both study conditions $(\mathrm{p}<.001)$. These exploratory results indicate further research is needed to determine the effectiveness of social media based strategies and how such technologies should be harnessed to achieve HIV prevention goals. 


\section{TABLE OF CONTENTS}

CHAPTER

PAGE

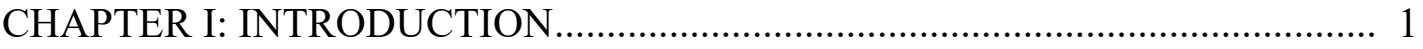

Purpose of the Research ............................................................................ 3

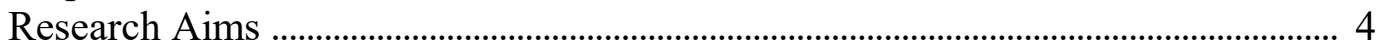

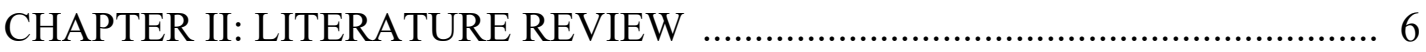

Hispanics in the United States ...................................................................... 6

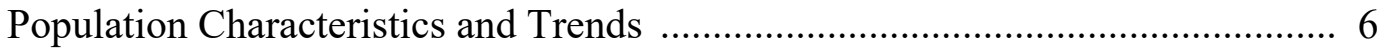

Young Adult Hispanics in the U.S ......................................................... 7

Native Versus Foreign Born ................................................................. 9

Hispanic College Students ..........................................................................10

Historical Background of Addressing Health Disparities ......................................12

HIV State of the Knowledge among Hispanics ...................................................13

Prevalence among Hispanic Young Adults ...............................................14

Cultural context and HIV prevention challenges............................................15

University context and HIV prevention challenges .....................................19

Evidence-Based HIV Prevention ..................................................................20

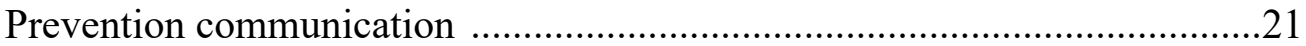

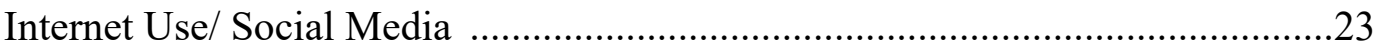

Social media use among Hispanic young adults …………….......................25

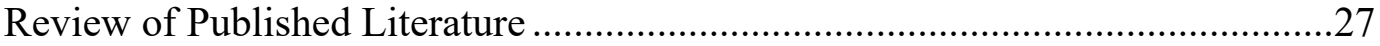

Social Media Delivered HIV Prevention …………….............................29

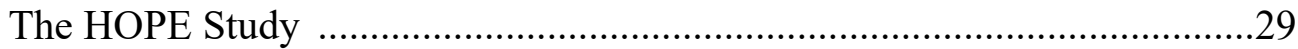

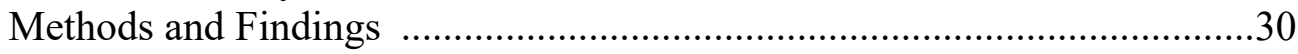

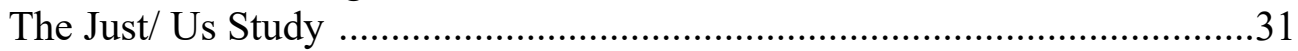

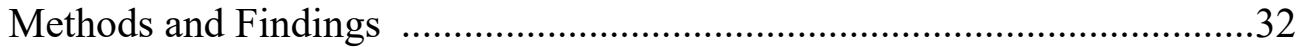

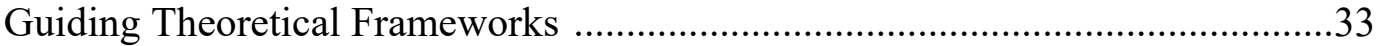

Developmental Lifespan Perspectives ......................................................33

Ethnic Minority Identity Formation ..............................................................34

Empirically Tested Model and Supporting Theories ………….....................36

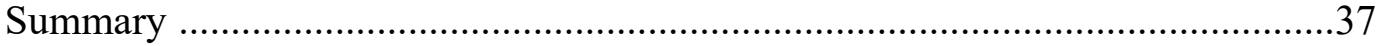

CHAPTER III: RESEARCH DESIGN AND METHODOLOGY …………….........39

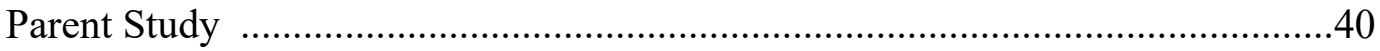

Population and Setting ...........................................................................40

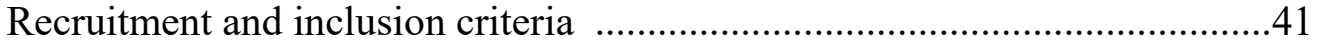

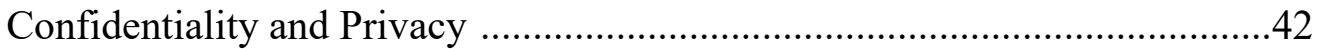

Protection of Human Subjects ....................................................................42

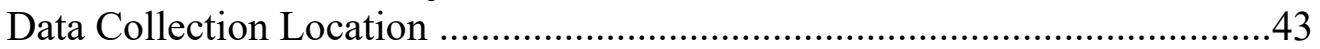

Contributions of researcher to parent study ……………............................4

Overview of Design and Procedures ............................................................44

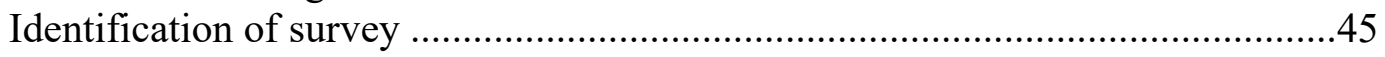




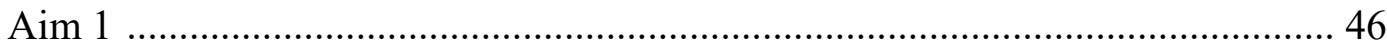

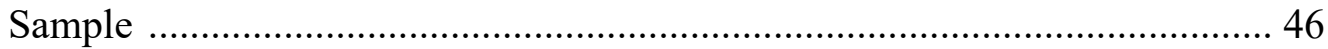

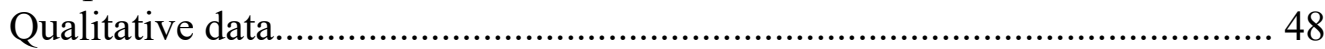

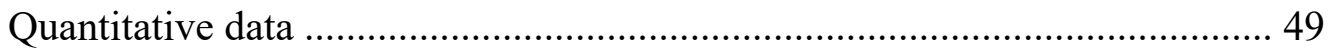

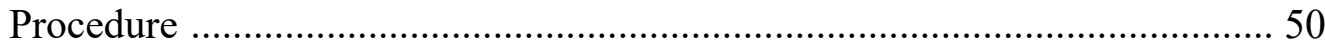

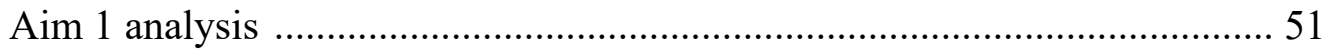

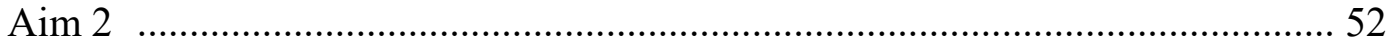

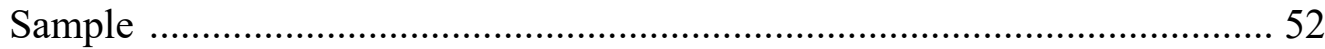

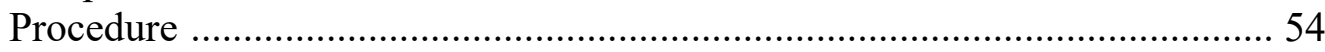

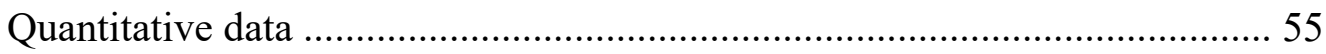

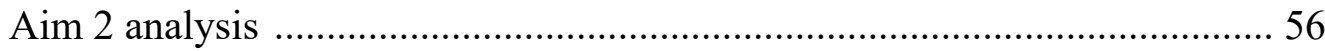

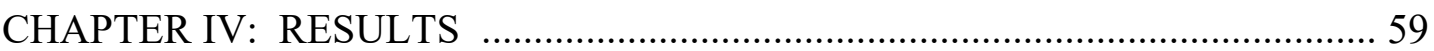

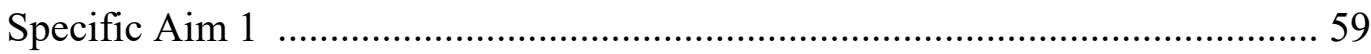

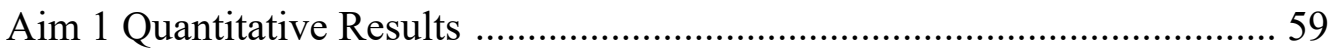

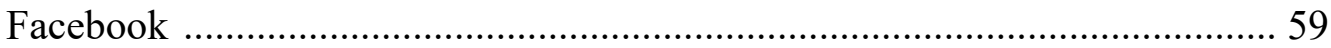

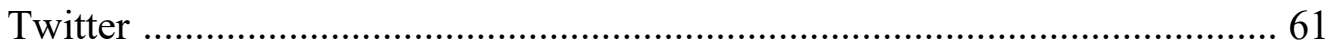

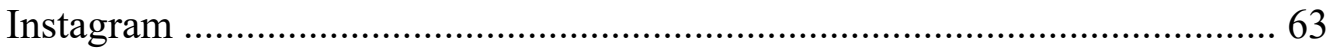

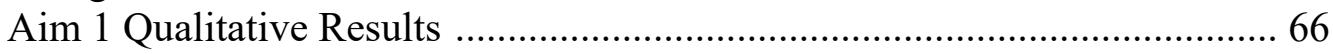

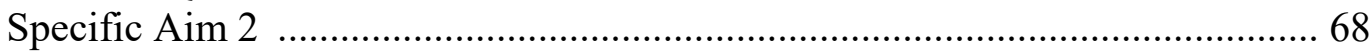

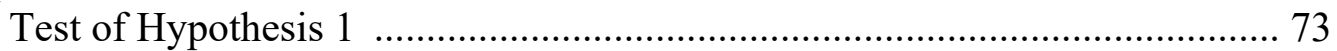

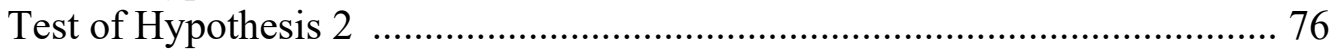

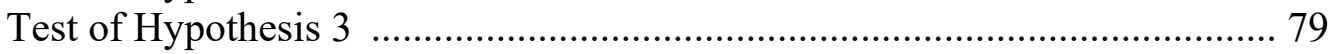

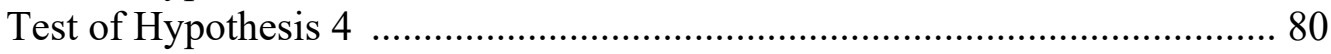

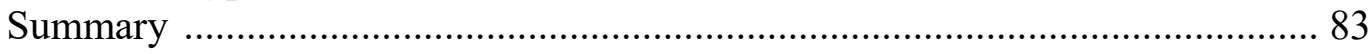

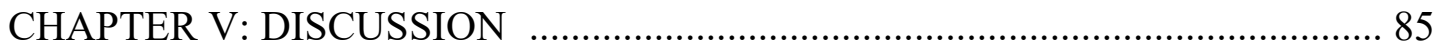

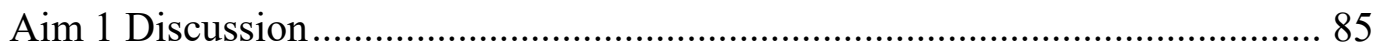

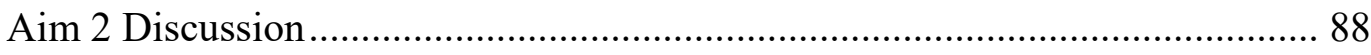

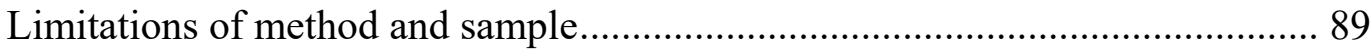

Ethical Considerations …………………………………………………..... 91

Significance to Social Work ……………………………….......................... 92

Implications for Social Work Practice ......................................................... 93

Implications for Future Research...................................................................... 94

Conclusions \& Recommendations ................................................................... 98

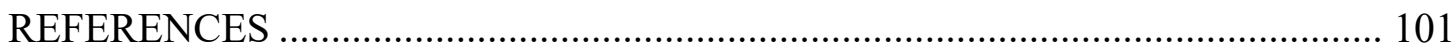

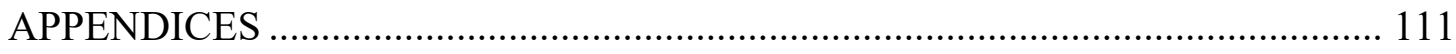

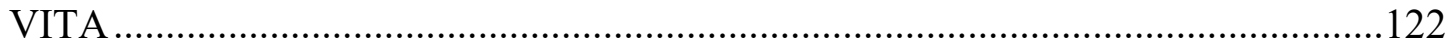




\section{LIST OF TABLES}

TABLE

1. Mixed Method Research Design Overview ..............................................46

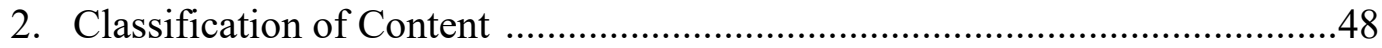

3. Social Media Key Performance Metrics ....................................................49

4. Overview of Top Posts per Social Networking Site ..................................65

5. Key Performance Metrics Overview of Study Period .................................65

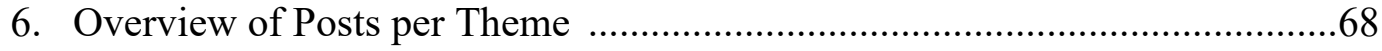

7. Demographic and Background Characteristics of Sample ..........................70

8. Descriptive Statistics of Variables of Interest at Baseline ...........................72

9. Descriptive Statistics for Awareness Outcome Variables ............................73

10. Binary Logistic Regression for awareness of where to receive HIV test in

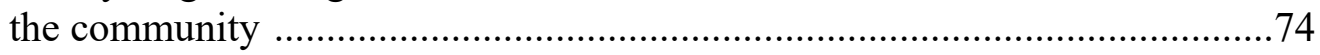

11. Binary Logistic Regression for awareness of prevention services in the community

12. Binary Logistic Regression for awareness of prevention services on campus 75

13. Mc Nemar's Test Statistics for awareness variables .76

14. Descriptive Statistics for perceived benefits and confidence of condom use .77

15. Tests of within-subject effects for benefits of condom use during sexual

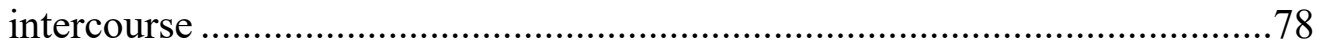

16. Tests of Between-Subjects Effects for benefits of condom use during sexual intercourse 78

17. Tests of Within-Subjects Effects for confidence of condom use during sexual act

18. Tests of Between-Subjects Effects for confidence of condom use during 
sexual act

19. Descriptive Statistics for frequency of protected sex acts.

20. Tests of Within-Subjects Effects for condom use with primary partner

21. Tests of Between-Subjects Effects for condom use with primary partner .....82

22. Tests of Within-Subjects Effects of condom use with someone other than a primary partner.

23. Tests of Between-Subjects Effects of condom use with someone other than a

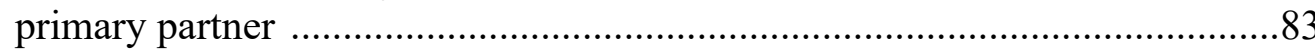




\section{CHAPTER I: INTRODUCTION}

Prevention efforts to eliminate the spread of HIV have had widespread impact in the United States over the past two decades. However, groups of individuals continue to be disproportionately affected by incidence of HIV infection, as increases in the number of new HIV cases are concentrated in certain racial, ethnic, sexual, and gender minority groups (Centers for Disease Control and Prevention [CDC], 2015). Although researchers, service providers, and federal agencies have gathered considerable evidence to identify effective preventive strategies, implementation challenges persist for groups who are in most need of services. Not all groups of individuals have benefited equally from advances in reducing HIV, as certain groups of individuals continue to be more at risk (Mann et al., 2014).

Despite national declining rates of HIV infection, rates of HIV in Florida are on the rise (CDC, 2016; Florida Department of Health, 2016). Specifically in the south east of the United States, Miami, FL, is identified as one of the areas hardest hit by the HIV epidemic and, in 2014, had the distinction of ranking number one in the number of new HIV cases per capita in the U.S. (Florida Department of Health, 2015). In addition, approximately $67 \%$ of Miami's residents identify as Hispanic (United States Census, 2016). Prevention challenges arise among Hispanics who may face cultural, social and structural barriers to HIV prevention services (CDC, 2017; Florida Department of Health, 2016). This has contributed to the characterization of Hispanics as a "high risk" or "hard to reach" group (CDC, 2017).

Researchers and practitioners are increasingly utilizing social media technologies to facilitate widespread dissemination of HIV prevention information, primarily because 
use and accessibility of social media continue to grow. Social media is a cost-effective method to achieve widespread impact, and it is now being used in health promotion as a platform, to promote community conversation in a manner that can effectively reach specific audiences. In accordance with the goals of the Division of HIV/AIDS Prevention, a leading force in HIV prevention within the CDC, the present research aims to evaluate a social media campaign designed to raise awareness about HIV through a communication campaign and a community partnership to ensure that young adults - specifically, Hispanic young adults in Miami, FL— know the facts about HIV prevention and available, local prevention services (CDC, 2015). Ultimately, the intent of this campaign is to assist in helping individuals change their health behaviors to reduce their health risks (Glasgow, 2007).

The use of social media in health promotion is not a novel idea, but it is one that is still largely underdeveloped in terms of evaluation and assessment for reach and impact. The use of social media is increasing globally — across ethnicities and socioeconomic backgrounds - and it is proving to be an efficient way to communicate with populations that have traditionally been hard to reach (Bennet \& Glasgow, 2009). Communities that continue to be at high risk of HIV are in need of meaningful and authentic strategies designed to meet their unique needs and reduce barriers to adoption of prevention strategies. Progressive methods, such as social media based interventions, may be needed to effectively keep up with new generations at risk of HIV, specifically in geographic areas hardest hit and among groups at greatest risk.

While various initiatives have used the Internet to conduct HIV prevention programs online, this is among the few studies to date to utilize an experimental design to 
evaluate the use of social networking sites as a platform in which to disseminate information about HIV prevention and locally available services to Hispanic young adults. Regarding the utility of social media in public health, researchers such as Jaganath, Gill, Cohen, Carl, and Young (2012) have stated:

The growing popularity, decreasing digital divide, and multi-functionality of social networking sites, such as Facebook, which promote interactive communication, make it an ideal time to develop innovative ways to use online social networking sites to facilitate HIV prevention interventions among high-risk groups. (p. 593)

Innovative and progressive prevention efforts are needed to further HIV prevention efforts among high risk groups; it is important for modern researchers to keep pace with younger populations who are using social media not only to communicate with each other, but also to obtain health related information (Voisin et al., 2013).

\section{Purpose of the Research}

The research at hand aims to evaluate the social media based prevention efforts of a community based research project titled, "The Miami-Dade Partnership for Preventing Health Risks among Young Adults," under the leadership of Principal Investigator, Dr.

Eric Wagner. This project (Grant \# 5H79SP020653), funded by the Substance Abuse and Mental Health Services Administration (SAMHSA), brings together a) Florida International University (FIU), a large Hispanic serving institution; b) Union Positiva, a grass roots, minority serving, community based organization that provides HIV services in nonclinical settings; c) Banyan Health Systems, the largest provider of outpatient substance abuse, mental health, and behavioral health care treatment in Miami-Dade; d) 
Mixto Music, a high visibility Hispanic market media production company; and e) Dieste, the largest Hispanic market advertising company in the US. The overall goals of the SAMHSA funded project include: a) building environmental prevention capacities, b) providing direct point of care HIV testing, and c) the implementation of media advocacy and awareness campaigns for Hispanic young adults at FIU and in Miami-Dade.

Specifically, the research at hand focused on evaluating the social media campaign that takes place online on the campaign's Facebook, Instagram, and Twitter pages. This research will evaluate the campaign for its goals of the provision of information, specifically information about locally available HIV testing and prevention services, and the increasing of preventive HIV behaviors, specifically condom use among Hispanic college students at FIU in Miami, FL. Also, because the evaluation of health promotion efforts conducted online is still in early stages of development, this study will contribute to evaluation knowledge, as well as explore the utility of conceptual measurements which are currently in use to evaluate such efforts (i.e., key performance metrics). This study is exploratory in nature and provides suggestions for implementation enhancement and directions for future research.

This study is comprised of two phases. The first phase involves a mixed methods data gathering process to answer Specific Aim 1. The second phase involves a solely quantitative data collection process to answer Specific Aim 2.

\section{Research Aims}

Specific aim 1: Provide a systematic examination of the social media based campaign content. Examine the relationship between the social media campaign inputs or presence and the responsive reach and interactivity on the campaign pages. 
campaign inputs?

Research question: Do reach and interactivity differ according to

Specific aim 2: Examine the relationship between exposure to the social media campaign and a participants' knowledge of locally available HIV prevention services, his/her condom use, and his/her perceived benefits and confidence of condom use.

Hypothesis: Participants' knowledge of available prevention services will increase after 4 week exposure to the social media campaign.

Hypothesis: Participants' perceived benefits of condom use will increase after 4 week to the social media campaign.

Hypothesis: Participants' confidence of condom use will increase after 4 week exposure to the social media campaign.

Hypothesis: Participants' frequency of protected sexual acts will increase after 4 week exposure to the social media campaign. 


\section{CHAPTER II: LITERATURE REVIEW}

\section{Hispanics in the United States}

The United States (U.S.) has the second largest Hispanic population in the world; with approximately 56.6 million Hispanic individuals, the U.S. is second only to Mexico, which has a Hispanic population of 120 million individuals (U.S. Census Bureau, 2016). As of 2015, nine U.S. states had over one million Hispanic residents. These states include Arizona, California, Colorado, Florida, Illinois, New Jersey, New Mexico, New York, and Texas (U.S. Census Bureau, 2016). The 56.6 million Hispanics living in the United States today represent approximately $17 \%$ of the U.S. total population. This makes people of Hispanic origin the nation's largest ethnic minority (CDC, 2016). The Office of Management and Budget (OMB) defines Hispanic or Latino as a person of Cuban, Mexican, Puerto Rican, South or Central American, or other Spanish culture or origin, regardless of race (OMB, 1997).

\section{Population Characteristics and Trends}

The term Hispanic encompasses more than 20 nationalities that are grouped together. Although this term refers to a group of individuals that differ by history, nationality, social class, legal status, and generation, perhaps the two most important factors that unite this diverse group are a common language, Spanish, and the social class disadvantages resulting from immigration to the U.S. (Tienda \& Mitchelle, 2006). Hispanics in the U.S. include the descendants of early Spanish settlers and also immigrants and their descendants from Spanish-speaking countries in the Caribbean, Central America, and South America (Tienda \& Mitchelle, 2006). Today, the majority of Hispanics in the U.S. identify as Mexican (63\%), Puerto Rican (9.5\%), Salvadorian 
(3.8\%), Cuban (3.7\%), Dominican (3.3\%), or Guatemalan $(2.4 \%)$. The remaining percentage are those who identify as of other Hispanic or Latino origins (CDC, 2016). As previously noted, even though Hispanics already comprise the nation's largest ethnic minority group, (17\% of the total U.S. population) it is predicted that the Hispanic population in the U.S. will continue to increase because of the sizable population already living in the U.S. and its current youthful age composition as well as higher than average fertility rates (Tienda \& Mitchelle, 2006).

Examining population growth trends, it is notable that in 1960, Hispanics comprised only 4\% on the U.S. population (Tienda \& Mitchelle, 2006). In 1980, they comprised 5.4\% of the U.S. population; in 1990, they comprised $9.0 \%$, and in 2000 , 12.5\% (Tienda \& Mitchelle, 2006). These numbers have steadily increased and are projected to continue increasing. In 2060, it is projected that the U.S. Hispanic population will increase to 119 million individuals, constituting nearly $30 \%$ of the nation's population by that date (U.S. Census Bureau, 2016). Some researchers such as Tienda and Mitchelle (2006) argue that the emergence of Hispanics as the largest minority group is one of the most significant demographic changes of the 20th century for the U.S. With numbers and projected trends such as these, it is apparent that the needs and accompanying special considerations of such a growing population be a priority for the common good and future public health of the U.S. as a whole.

\section{Young Adult Hispanics in the U.S.}

Young or emerging adults are considered those individuals who fall in between the ages of 18 and 24 years and are in the transition from adolescence to adulthood (Arnett, 2000). As of 2012, there were 31.2 million people in the United States who fell 
within this age bracket (Federal Interagency Forum on Child and Family Statistics, 2014). Of these 31.2 million young adults aged 18 to 24 in the U.S., 6 million, or $21 \%$, were Hispanic (Federal Interagency Forum on Child and Family Statistics, 2014). These numbers, too, have increased exponentially, when considering that in 1972, just $5 \%$ of the nation's 18-24 year olds were Hispanic.

Furthermore, Hispanics are the youngest racial or ethnic group in the U.S. Of those individuals who identify as Hispanic in the U.S., a larger percentage fall under the young adult bracket when compared to those that fall in older adult categories ( 25 years and older) (Patten, 2016). In 2014, about one-third, of the nation's Hispanic population was younger than 18 and about a quarter, or 14.6 million, of all Hispanics were between the ages of 18 and 33 (Patten, 2016). Thus a greater portion of the Hispanic population is currently at a youth or young adult age, and for this reason, youth is a defining characteristic of the Hispanic population in the U.S (Patten, 2016). Special considerations should be placed on the needs of youth and young adults in this ethnic group, as they comprise a substantial portion of Hispanics in the U.S.

The current Hispanic young adult population is comprised of a mixture of both foreign born and native born individuals (Krogstad \& Lopez, 2014). Some are individuals who arrived in the U.S. during childhood and others are individuals born in the U.S. to foreign-born parents. Nonetheless, Vega, Rodriguez, and Gruskin (2009) report that Hispanic young adults constitute the heart of the demographic transition of Hispanics in the U.S. These young adult Hispanics represent the future of the Hispanic population in the U.S. and, as stated previously, constitute a larger percentage of individuals than other subgroups of the U.S. Hispanic population. 


\section{Native Versus Foreign Born}

Over the past four decades, increases in the number of Hispanics in the U.S. have mainly been attributed to immigration (Krogstad \& Lopez, 2014). However, since 2000, the U.S. born, or native, Hispanic population has continued to grow at a faster rate than the growth of foreign born Hispanic individuals in the U.S (Krogstad \& Lopez, 2014). This is attributed to a number of factors including decreasing numbers of new Mexican immigrants who make up the current majority of the Hispanic population in the U.S., of which more than half are currently foreign born (Brown, 2015). Increased border enforcement, deportation laws, and growing dangers with illegal border crossings have contributed to a decrease in new Mexican immigration (Brown, 2015).

With the decreases in numbers of incoming Hispanic immigrants in the U.S., the primary source of Hispanic population growth is now attributed to increases in native born individuals (Krogstad \& Lopez, 2014). Between 2000 and 2010, there were 9.6 million Hispanic births in the U.S., while the number of newly arrived immigrants was 6.5 million (Krogstad \& Lopez, 2014). Overall, U.S. births alone account for 78\% of Hispanic population growth (Brown, 2015). Thus, even as the share of incoming Hispanic immigrants decreases, high fertility rates and the subsequent rapid growth in the number of native born Hispanic individuals in the U.S., coupled with the youthful age composition of the current Hispanic population indicate that the Hispanic population will continue to grow steadily (Tienda \& Mitchelle, 2006).

Changing demographic trends have begun to reshape the U.S. Hispanic population and will result in an increase in the number of Hispanic individuals reaching young adulthood in the coming years. Approximately 800,000 native born Hispanics turn 
18 each year, and in the coming decades, that number is expected to rise by more than one million annually (Taylor, Gonzalez-Barrera, Passel \& Lopez, 2012). As a whole, the Hispanic population in the U.S. has a median age of 27 years and, among native born Hispanics, the median age is 18 years. This is a remarkably lower age compared to the median age of the White non-Hispanic population in the U.S., which has a median of 42 years of age (Taylor, Gonzalez-Barrera, Passel \& Lopez, 2012). Thus, these trends indicate that, in the coming decades, the number of young adult Hispanic individuals in the U.S. will increase significantly (Taylor, Gonzalez-Barrera, Passel \& Lopez, 2012).

\section{Hispanic College Students}

One of the most significant changes over the past four decades among the Hispanic young adult population has been the number of individuals who enroll in postsecondary or higher education. Hispanic young adults now have the fastest growing rates of enrollment in higher education (Excelencia in Education, 2015). Although Hispanics still have alarmingly high high-school drop-out rates and the share of all Hispanics aged 18 to 24 in college lags behind that of non-Hispanic whites (37\% and $42.1 \%$ respectively), the rapid growth in the number of Hispanic young adults enrolled in college makes this a diminishing margin (Lopez \& Fry, 2013).

Among Hispanics in the U.S., the number of individuals earning associate's degrees more than doubled from 2000 to 2010, an increase of $118 \%$. As a result, Hispanics earned 13\% of all associate's degrees awarded in 2010 (U.S. Department of Education, 2012). During the same time period, the number of bachelor's degrees awarded to Hispanic students increased by $87 \%$ (U.S. Department of Education, 2012). Similarly, the numbers of master's degrees earned by Hispanic students more than 
doubled in this same time period (U.S. Department of Education, 2012). The number of doctoral degrees awarded to Hispanic students increased by $60 \%$ (U.S. Department of Education, 2012).

As of 2011, the number of 18 to 24 year old Hispanics enrolled in college exceeded 2 million, making up $16.5 \%$ of all college enrollments in both two or four year colleges (Fry, 2011). This new milestone reflects a number of continuing upward trends. These rapidly growing numbers of college enrollment are not simply due to population growth but are also linked with slowly increasing high school completion rates among Hispanics. As such, there is an increasing number of young adult Hispanics who are eligible to attend college (Fry, 2011). The increase in number of native born Hispanics who enter the educational system at a young age also contributes to the increasing numbers of educational eligibility. In 2011, 76.3\% of all Hispanics ages 18 to 24 had a high school diploma or a General Educational Development (GED) degree and among Hispanic high school completers, nearly half (49\%) enrolled in two-year or four-year colleges (Lopez \& Fry, 2013). Thus, both population increase and greater eligibility to enroll in higher education have contributed to growth in the number of Hispanic young adults enrolled in college (Fry, 2011). Furthermore, the number of Hispanic high school graduates is projected to increase $64 \%$ from 2010 to 2023 and it is predicted that there will be a $27 \%$ increase in the number of students enrolled in post-secondary education who are Hispanic within that same time frame (Hussar \& Bailey, 2014). Thus, Hispanic college students are becoming an increasingly substantial portion of the young adult, college student population in the U.S. 


\section{Historical Background of Addressing Health Disparities}

The World Health Organization (WHO) defines disparities as "differences in health, which are not only unnecessary and avoidable but, in addition, are considered unfair and unjust" (p. 7). The Department of Health and Human Services (DHHS) defines a health disparity as a health difference that is linked with social or economic disadvantage (U.S. DHHS, 2011). According to the U.S. DHHS, health disparities adversely affect groups of people who have experienced "social and/or economic obstacles to health based on their racial or ethnic group, religion, socioeconomic status, gender, age, mental health status, physical disability, sexual orientation, geographic location, or other characteristics historically linked to systematic discrimination or exclusion" (U.S. DHHS, 2011). For decades, the U.S. has recognized the impact of health disparities among certain racial, ethnic, and socieconomic groups and has considered these disparities a national priority.

Attention given to health disparities in the U.S. came as a result of the first largescale epidemiological studies that highlighted differences in morbidity and mortality among grouips in the earlier 1980s (Gibbons, 2005). In 1984, the U.S. Department of Health and Human Services released a report entitled Health, United States, 1983, which documented that major disparities existed in morbidity and mortality between AfricanAmericans and other minority groups in the U.S. when compared with the nation's majority (Gibbons, 2005). Researchers found that a significant amount of nonrandom variability existed between different geographic locations, despite treating patients with similar health issues (Gibbons, 2005). In response, the Department of Health and Human Services established a task force on black and minority health. This was the first time in 
U.S. history that the federal government convened a group of experts to conduct a comprehensive study of minority health. The U.S. continues to place considerable effort on addressing growing disparities in health among racial and ethnic minority groups. The health disparities that exist within the Hispanic community in the U.S. are well documented, persistent and, as noted below, certain disparities have more negative impacts then others.

\section{HIV State of the Knowledge among Hispanics}

Globally, more than 36 million people are living with HIV (WHO, 2017). The CDC estimates that 1.2 million of these individuals (13 years or older) live in the United States (2015). This number increases by approximately $4 \%$ each year with 50,000 new infections annually (CDC, 2015). Of the 1.2 million people in the U.S. living with the virus, about one in eight are unaware of their infection (CDC, 2016). While the increase in numbers of persons living with HIV is largely due to the founding of an antiretroviral therapy, which has increased the average lifespan of persons living with HIV, the steady increase of new cases is also a large and concerning factor (Zeglin \& Stein, 2015). Currently, in the U.S., HIV remains mainly an urban disease with the majority of new cases coming from areas with 500,000 people or more. Geographical locations of greatest concern in the U.S. include Atlanta, GA, Washington, DC, and Miami, FL (CDC, 2015).

While HIV is a disease that affects all people, certain groups of individuals are at a higher risk for contracting the disease. Among these groups are gay and bisexual men, intravenous drug users, and certain ethnic minority groups. The estimated new HIV infection rates among Hispanics in 2010 was more than 3 times higher than that of nonHispanic whites (CDC, 2015). There are a number of factors that contribute to this 
disproportionate representation of Hispanics including growing numbers of Hispanic groups in the U.S., cultural, social, economic, environmental, and risk behavior factors, as well as stigma-related and other barriers to prevention information and services (CDC, 2015). Below is a brief discussion of these factors as they relate to Hispanics in the U.S.

\section{Prevalence among Hispanic Young Adults}

HIV is a serious threat to the health and well-being of the Hispanic community in

the U.S. (CDC, 2016). In 2014, Hispanics accounted for almost a quarter $(24 \%$ or 10,887$)$ of all new HIV infections in the U.S. and 6 dependent areas (CDC, 2016). This is disproportionate, as Hispanics represent only about $17 \%$ of the total U.S. population and are, therefore, overrepresented in rates of infection (CDC, 2016). Data estimates from the Office of Minority Health in 2011 also indicate that Hispanics are more than twice as likely to die from complications from HIV when compared to non-Hispanic Whites (U.S. DHHS, 2013). HIV Stage III, formerly known as AIDS or acquired immune deficiency syndrome, is the final and most serious stage of HIV and, in 2013, was the eighth leading cause of death for Hispanics between the ages of 25 and 34 years and was among the top 10 causes of death for Hispanics aged 35 to 54 years (CDC, 2015).

Among Hispanics, $26 \%$ of new HIV infection cases are predicted to be among young adults (CDC, 2015). In addition, approximately half of the 12-24 year olds who are currently infected with HIV in the U.S. do not know their status, and are, therefore, more likely to spread their infection (CDC, 2015). Research also indicates that the presence of sexually transmitted infections (STIs) make it easier to contract HIV. About half of the 20 million STIs occurring annually in the U.S. affect a young adult group between the ages of 15 and 24 (Satterwhite et al., 2013). Hispanics have high rates for 
numerous STIs including chlamydia, gonorrhea, and syphilis when compared to nonHispanic Whites (CDC, 2016). For example, in 2014, the gonorrhea rate among Hispanics was 1.9 times the rate of that among non-Hispanic Whites, and the rate of congenital syphilis was 2.2 times the rate of that among non-Hispanic Whites (CDC, 2016).

The CDC and other major health organizations have identified individuals in the young adult age group as a high-risk group in terms of acquiring sexually transmitted infections, and have made young adults a priority in sexual health promotion and prevention. HIV and STI prevalence is especially high in young adult ethnic minority groups, and incidences of HIV are increasing in these populations (Kann et al., 2014). Current rates of STI infection among ethnic minority young adult groups range from 8 to 21 times the rates found among non-Hispanic Whites (Thomas, Yarandi, Dalmida, Frados $\&$ Klienert, 2015). For this reason, ethnic minority youth and young adults, are at the forefront of public health research concerning HIV/STI infection and increased efforts are needed to promote preventive behaviors among ethnic minority groups, particularly Hispanic young adults (Kann et al., 2014).

\section{Cultural context and HIV prevention challenges}

A lack of culturally appropriate, evidence-based HIV prevention interventions contributes to the elevated risk of HIV among the Hispanic community (CDC, 2015). Despite widespread awareness of the overrepresentation of HIV infections among Hispanics, culturally sensitive, evidence-based prevention services rarely are available to these populations. Hispanics comprise a group that has not benefited from the strides made in HIV prevention as other majority groups have in the U.S. Over the past decade, 
there has been an increasing push for HIV prevention services that are uniquely tailored to better address the specific needs of this at-risk community (Sanchez, De La Rosa, \& Serna, 2013). Specifically, the National Standards for Culturally and Linguistically Appropriate Services (CLAS), first developed in 2010 by the Office of Minority Health, provide guidelines for health care organizations and researchers to ensure "effective, equitable, understandable, and respectful quality care and services that are responsive to diverse cultural health beliefs and practices, preferred languages, health literacy, and other communication needs" (US DHHS, 2013, p.13). These standards include a push for establishing culturally and linguistically appropriate goals, programs, and policies, conducting assessments of community needs to integrate needs into the planning and development of services, and partnering with the community agencies and members to ensure program appropriateness (US DHHS, 2013).

Furthermore, in line with CLAS recommendations, understanding characteristics, needs, and strengths of the Hispanic community is essential to further the impact and efficacy of HIV prevention strategies. Various culture specific factors affect the risk of HIV infection among the Hispanic community. Gender specific cultural norms such as machismo and marianismo contribute to elevated HIV risk behaviors and barriers to effectively receiving prevention services (CDC, 2015). Machismo is the cultural factor related to a male's strong sense of masculine pride and honor. This cultural enforced norm to prove masculinity is linked with homophobia, the desire to seek multiple sexual partners, and the desire to take various risks (Marín, 2003). While homophobia and stigma related factors are a challenge for any group in HIV prevention, these challenges are particularly highlighted among Hispanics because of noted cultural concepts that 
reinforce common barriers to effective HIV prevention. Furthermore, machismo may lead to reluctance of utilizing services as Hispanic men are often reluctant to participate in activities, especially health promotional ones that may challenge their pride or do not reinforce their masculinity (Wilson et al., 2012). If infected with HIV, Hispanic individuals often avoid seeking testing, counseling, or treatment because of the discrimination and shame present, linked to the stigma associated with HIV. Furthermore, the majority of new HIV infection cases among Hispanics are attributed to sexual contact with men because of their higher tendency for having multiple sex partners, unprotected sex, and intravenous drug use. Therefore, being unaware of a partners' risk factors, especially a male partner, may place Hispanic women and men who have sex with men at increased risk for HIV (CDC, 2015).

Marianismo is a term used to identify another gender specific cultural idea that women should be sexually pure and non-confrontational in Hispanic communities (Wilson et al., 2012). This may contribute to the fears of stigma surrounding a woman being viewed as "easy" or may leave a woman disempowered to get tested or ask her partner to do so. Familismo and respeto also play a role in prevention challenges as Hispanics tend to have a strong attachment to their nuclear families and strong family pride. These two cultural concepts are closely tied as familismo emphasizes trust and loyalty to the family and respeto relates to respect and obedience within the family, especially between a child and their parent. Individuals may be reluctant to reveal a positive status in order to protect their family from associated stigma or shame. Fatalist views also may negatively contribute to the perception of HIV among the Hispanic community. Fatalismo is the idea that conditions, such as HIV, are inevitable. This is 
closely tied with religiosity, specifically Catholicism and a "resignation to God's will" (Wilson et al., 2012). Fatalismo may also be associated with a decreased sense of empowerment to seek help (Wilson et al., 2012).

Socioeconomic factors that contribute to an increased risk of HIV infection among Hispanics include poverty, migration patterns, lower educational achievement, language barriers and overall acculturation (CDC, 2015). In 2015, 21.4\% of the Hispanics in the U.S. were living in poverty. Living in poverty can limit access to health care, which includes HIV testing as well as access to prophylactic medications that could lower chances of contracting or spreading HIV. Furthermore, in 2015, $16.2 \%$ of Hispanics in the U.S. lacked health insurance, making Hispanics the minority group with the highest uninsured rate when compared to African Americans and Asians minority groups (Barnett \& Vornovitsky, 2016). Moreover, living in the U.S. as an undocumented citizen comes with additional prevention challenges such as fear of disclosing immigration status because of fear ofb deportation. Although numbers of undocumented Hispanics in the U.S. have slightly decreased, Mexican immigrants still make up half of all undocumented immigrants in the U.S. (Krogstad, Passel, \& Cohn, 2017). These factors can lead to reluctance of getting tested, especially when an individual is an undocumented immigrant. Lack of social support or connectedness for recent immigrants can also contribute to lack of linkage to services. Finally, acculturation, or the process by which an individual integrates the practices and values of the dominant culture also plays a substantial role, as more acculturated Hispanics who have adopted similar values, norms and the language of U.S. culture may be more willing to enroll or participate in 
U.S. prevention services and programs than those who are less acculturated (Warner et al., 2006; Wilson et al., 2012).

\section{University context and HIV prevention challenges}

Hispanic young adults in a university or college setting face contextual challenges that put them at heightened risk of engaging in risky HIV behaviors. College students, overall, are at particular risk for contracting HIV and other sexually transmitted diseases because of their high frequency of sexual activity, inconsistent and infrequent condom use, and general attitude of denial regarding their risk (Jones, Patsdaughter, Jorda, Hamilton, \& Malow, 2008). Because of heightened sexual risk behaviors in a university environment, the Healthy People 2020 initiative includes a focus on the prevention of associated health consequences among individuals in a university setting. The objective, specific to sexually transmitted diseases, includes increasing the proportion of postsecondary students who receive information form their institution regarding unintended pregnancy, and the spread of HIV and STIs (U.S. DHHS, 2010). Furthermore, The Sexuality Information and Education Council of the United States (SIECUS) states that it is the responsibility of professionals serving young adults to provide accurate information and education about sexuality, and to assure access to sexual reproductive health care in order to reduce risk factors for young adults (SIECUS, 2012). Both of these national level actions highlight the importance of targeting college students in sexual health promotion and prevention efforts and place considerable responsibility on institutions and professionals who work with young adults in such settings.

Data reflect that the use of condoms declines considerably between ages 19-20 (Johnston et al., 2015). Findings from a cross sectional sample of young adults in a 
university setting revealed that fewer than $20 \%$ of college students, across all ethnicities, consistently use condoms (Thomas et al., 2015). Findings from Monitoring the Future (MTF), a long-term study of American adolescents, college students and adult high school graduates also reflect concerning decreases in reports of ever having been tested among this age group in recent years. In 2004, 33\% of 21-22 year olds reported having been tested for HIV in their lifetime, while only $27 \%$ of the same age group reported so in 2014 (Johnston et al., 2015). Similarly, among 23-24 year olds, the percentage of individuals who had been tested for HIV in their lifetime dropped from $37 \%$ to $31 \%$ over the past 10 years (Johnston et al., 2015). These risk factors add to the existing normative behaviors, gender roles, and cultural beliefs that may affect Hispanic college students' safer sex practices (Jones et al., 2008).

\section{Evidence-Based HIV Prevention}

Systematic reviews of HIV prevention efforts highlight the need for multiple strategies for the current and future generations of HIV prevention. Researchers such as Rotheram-Borus, Swendeman, and Chovnick (2009) state that prevention efforts must integrate behavioral, biomedical, and structural intervention strategies in multilevel programs to increase chances of success, and ultimately, eliminate the spread of HIV. There is a push for multi-pronged approaches to prevention. Biomedical and behavioral evidence based prevention strategies that reduce the spread of HIV include increasing condom use and HIV testing among cultural groups (Thomas et al., 2015). Additional behavioral and biomedical interventions include the human papillomavirus (HPV) vaccine, male circumcision, and treatment of both HIV and STIs (Rotheram-Borus et al., 2009). These evidence-based biomedical and behavioral prevention interventions, 
though, are no "magic bullet" for this issue and are dependent on environmental and structural intervention components for their effectiveness (Rotheram-Borus et al., 2009).

Structural or environmental considerations in HIV prevention include the marginalization of at risk populations that limits access to relevant risk information, treatment, and prevention resources (Rotheram-Borus et al., 2009). Ethnic minority young adults face barriers to receiving relevant HIV prevention information. Therefore, it is important to focus on the relevance of tailored messaging in order to ensure uptake of testing and other prevention behaviors.

\section{Prevention communication}

In HIV research, prevention communication uses strategic, evidence based messaging, advertising, and social marketing techniques to increase the provision of information, to raise awareness, and to influence behavior. Specifically, current prevention communication efforts develop and disseminate scientific and statistical materials on HIV for researchers, health care providers, people at risk for HIV, and the general public at large (CDC, 2015). Prevention communication is tailored according to audience. SAMHSA recognizes that the development of communication campaigns and partnerships is necessary to reach high-risk groups of individuals and to provide them with relevant and accurate facts about HIV prevention. SAMHSA also identifies

prevention communication and education as a necessary part of environmental prevention strategies and supports innovative communication strategies to increase awareness and community support for prevention. Prevention communication does more than provide information to individuals, rather, it persuades people to increase preventive behaviors by influencing their knowledge and motivation to carry them out (SAMHSA, 2016). 
Traditionally, communication methods in health promotion have been characterized by their one-way flow of information. This is typically referred to as a "top down" form of communication, where experts provide health messages to those in need of services or behavioral health changes. Contrastingly, in a culture-centered approach to health communication, the role of the researcher shifts from that of an expert who disseminates information, to a participator who engages in conversation with members of a community (Airhihenbuwa, 1995). Employing a culture-centered approach highlights the need to develop communication strategies that are consistent with a community's cultural identity to facilitate successful uptake and incorporation into daily life. This requires a change in focus from disseminating generalized messages to broad audiences to customized prevention communication for specific groups of people (Ems \& Gonzalez, 2016). When dealing with HIV disparities that are concentrated among certain cultural and ethnic groups, this deliberate approach is critical for public health officials to employ (i.e., both top down and bottom up communication strategies), to ensure that HIV prevention efforts provide interventions and strategies that are relevant and authentic to at risk groups (Ems \& Gonzalez, 2016).

Researchers have found social media as an avenue to make these necessary communication changes possible (Ems \& Gonzalez, 2016). It is possible that social media provides a new opportunity for health communication in which both top down and bottom up methods of communication are employed. Allowing for a participant-involved approach to communication increases connection between researchers or public health officials and the population of focus. Using social media as a new setting of communication can minimize cultural barriers between members of public health 
institutions and those who are in need of critical information and services (Ems \& Gonzalez, 2016).

The innovative use of social media in HIV prevention is largely understudied, but is an endeavor that is imperative for future generations of HIV prevention research that focus on young adult ethnic minority populations. Social media based HIV prevention efforts serve as a platform to deliver structural or environmental intervention strategies that are needed to complement evidence based behavioral and biomedical ones. The widespread use of social media across race, ethnicity, and economic status offers support for its use to promote health interventions and messaging in order to minimize prevention communication inequalities and subsequent health related knowledge gaps and disparities among high risk minority groups (Kontos, Emmons, Puleo, \& Viswanath, 2010).

\section{Internet Use/ Social Media}

The exponential growth and adoption of Web 2.0 technologies has dramatically changed the way that individuals use the Internet in the U.S. and across the globe. Web 2.0 refers to a collection of web-based technologies and services where users interact and collaborate as content creators rather than solely as content consumers on the web (Neiger, Thackeray, Burton, Giraud-Carrier \& Fagen, 2012). This contrasts to the previous Web 1.0 platform, which was characterized by a one-way information flow. This change in functionality has dramatically changed the way and the reasons why individuals, especially young adults, use the internet.

A key technology that characterizes Web 2.0 functions is social media. Social media refers to the interaction among people in which they create, share and or exchange information and ideas online in virtual communities and in virtual networks (Smith \& 
Denali, 2014). Usually this takes place in the form of words, pictures, videos, and audio clips through posts, shares, likes, and comments. Social media is characterized by interactive, user-generated and user-controlled content. Social media can be considered an umbrella term that encompasses different forms including forums, message boards, blogging, social networking, and media sharing sites (Thackeray, Neiger, Smith, \& Van Wagenen, 2012). Social networking sites are the most popular forms of social media and, today, the most commonly used social networking platform is Facebook. In fact, Facebook is the most popular website nationwide after Google and YouTube (Alexa Internet, Inc., 2017).

A social networking site is distinguished from other forms of social media for its distinct functionality. Social networking sites are characterized by the unique ability for users to construct a public or semi-public profile, form a list of users with whom they share a connection, and view the list of connections of those made by others within the system (Boyd \& Ellison, 2010). Specifically, Facebook is a social networking site where users can connect with a variety of close and loose personal and professional ties, send messages, and receive and share content with other individuals who typically have some commonalities to themselves (Paek, Hove, \& Cole, 2013). Other popular social networking sites include Instagram, a mobile application established in 2010 that allows users to upload images which are shared with others on their network, and Twitter, a micro-blogging site that links users with trending topics.

Social media includes a variety of communication tools that can provide an online avenue for social support and facilitate a sense of connectedness among individuals, as well as a channel for gathering and sharing information among groups of individuals 
(Adzharuddina \& Ramly, 2015). Today, many young adults use the Internet to seek health information (Bennet \& Glasgow, 2009). In health promotion and prevention research, social media has proven to offer easy, cost effective access to large numbers of people across geographic distances (Thackeray et al., 2012). Health promotion recognizes the potential of social media for reaching broad audiences through health promotion campaigns in order to enable and empower individuals in their health through prevention communication (Thackeray, Neiger, Hanson, \& Mckenzie, 2008). Because social networking sites, in particular, are widely accessible across geographical barriers, and they are increasingly being used as a daily part of individuals' lives, they are increasingly attractive as public health opportunities, particularly in behavioral health efforts that aim to influence daily lifestyle choices (Laranjo et al., 2014).

\section{Social media use among Hispanic young adults}

Today, $90 \%$ of young adult Americans aged 18-29 use social media sites (Perrin, 2015). In a recent report titled "Social Media Update: 2016," researchers from Pew Research Center (2016) found that Facebook remains, by far, the most popular social media site today as $88 \%$ of online young adults ages $18-29$ report using Facebook (Greenwood, Perrin \& Duggan, 2016). Other social networking sites such as Instagram, Twitter, Pinterest and LinkedIn have gained popularity and have seen significant increases over the past year in the proportion of online adults who now use their sites. Multiplatform usage is on the rise with $52 \%$ of online individuals aged 18 years or older reporting two or more social media site use, a significant increase from 2013 (42\%) (Duggan, Ellison, Lampe, Lenhart, \& Madden, 2015). Researchers suggest Facebook acts as "home base" as it remains the most popular site for those who only use only one social 
media site, and has significant overlap with other platforms for those who use multiple sites (Duggan, Ellison, Lampe, Lenhart, \& Madden, 2015).

In a study conducted by Kontos, Emmons, Puleo, \& Viswanath (2010), using the Health Information National Trends Survey (HINTS), a nationally representative data source that provides data on the prevalence and characteristics of social media users, age emerged as the single strongest predictor of both social networking and blogging sites. Regardless of household income, or race, youth and young adults represent the biggest demographic using the Internet with the highest frequency (Kontos et al., 2010). Given the immense use of social networking sites among young adults, these sites have become a part of their everyday lives and an integral part of their health and safety (Yager \& O’ Keefe, 2012).

The HINTS survey contained specific follow-up questions for all Internet users, which allowed researchers to compare the use of different types of social media. Among the three forms of social media listed, social networking sites attracted the most users, making social networking sites a target for maximizing reach among young adults regardless of geographical or economic characteristics. Although Hispanic, African American, and non-Hispanic White youth and young adults use social media equally, Hispanics report spending more time on social media sites than any other ethnic minority group in the U.S. On average, $26.8 \%$ of Hispanic Internet users spend six or more hours on social media sites per day versus $20.4 \%$ of African American users and $8.5 \%$ of nonHispanic White users (Smith \& Denali, 2014). Furthermore, rates of use tend to be higher across all social media platforms in urban settings (Perrin, 2015). These findings 
highlight the potential for influencing the health of Hispanic young adults in urban settings by delivering content and engaging them through social networking sites.

\section{Review of the Published Literature}

The potential application of social media in health promotion is well documented in the literature, yet there are fewer studies confirming or negating its effectiveness. It is said that the use of social media in public health communication is still in the "Wild West" phase of development, where little order or structure for evaluation is in place, let alone, enforced (Ems \& Gonzales, 2016, p. 1762). There is a desperate need for further research to rigorously evaluate social media approaches in public health and to ensure that researchers are employing these social media strategies responsibly and effectively.

To date, there are two systematic reviews that provide rigorous assessments of the use of social media in health promotion (Maher et al., 2014; Laranjo et al., 2014). Both have offered encouraging findings in pursue of using such strategies to implement positive change in public and behavioral health.

Laranjo et al. (2014) provided a strong systematic review and meta-analysis that analyzed the effectiveness of social networking sites that were primarily used as a means of providing education and social support to change health behaviors. This study was the first meta-analysis to evaluate the effectiveness of the use of social networking sites in changing health behavior related outcomes (Laranjo et al., 2014). Twelve studies were included in this review but only eight provided enough information to be combined for a meta-analysis. The health topics covered in the twelve studies included fitness, sexual health, food safety, smoking, and health promotion. Although slight, researchers found a statistically significant positive effect of social networking site based interventions on 
behavior change outcomes (Hedges' g 0.24; $95 \%$ CI 0.04 to 0.43 ), encouraging future research in this area (Laranjo et al., 2014). In this meta-analysis, two studies focused on sexual health and both are described in detail below (Bull, Levine, Black, Schmiege, \& Santelli, 2012; Young et al., 2013).

Another review conducted by Maher et al. (2014), included 10 studies that were interventions that either wholly or in part used social networking sites to influence behavior change. Four of the reviewed studies reported significant improvement in an outcome measure, specifically related to weight loss, physical activity or dietary awareness. Four other published studies reported evidence suggestive of improvement where both groups in randomized controlled conditions improved significantly over time, but no significant differences were found between groups. Although these findings reveal promising results, the systematic review provided by Maher et al. (2014) was limited to including interventions that targeted one of the following health behaviors: tobacco smoking, alcohol use, physical inactivity, or diet. Thus, the review contributed to the literature surrounding the evaluation of interventions delivered via social networking sites, but it did not contribute to the knowledge specifically surrounding those interventions aimed to impact behavior change related to sexual health or HIV prevention.

Although these reviews are limited in their utility when focusing on HIV prevention, the findings provide valuable contributions that can be applied to further research evaluating the use of social media in health promotion, regardless of health topic. Regarding dissemination of findings, the importance of reporting consistent engagement metrics is stressed. Consistent and clearly defined engagement metrics 
should be used so future reviewers are able to provide recommendations for high impact interventions. Further, researchers recommended that effect sizes should be interpreted in terms of their potential clinical relevance whenever possible (Laranjo et al., 2014). Last, reviews highlight the need to include multiple aspects of the intervention in evaluations ranging from reach and engagement to effectiveness, as all are interdependent on one another for successful implementation and maintenance of interventions. In order to cover all evaluation domains, mixed method evaluation designs should be used whenever possible (Lim, Wright, Carrotte, \& Pedrana, 2016).

To date, only two research studies have published the results of experiments using social networking sites in HIV prevention communication research. Below are the main findings of both studies that presented with goals of delivering HIV prevention and education programs online through the commonly used social networking site, Facebook.

\section{Social Media Delivered HIV Prevention}

\section{The HOPE Study}

The HOPE (Harnessing Online Peer Education) Study was presented as a randomized controlled trial examining the efficacy of an HIV prevention intervention delivered on a social networking platform (Young et al., 2013). The intervention was primarily designed for African American and Latino men who have sex with men. Utilizing a community popular opinion leader (C-POL) model, the study entailed a 12week intervention program. The purpose of the HOPE Study was to determine whether social networking communities could increase HIV testing among African American and Latino men who have sex with men (MSM) in Los Angeles, CA. The study tested whether participants who received peer delivered information on HIV prevention over 
Facebook ( $\mathrm{n}=57$ intervention group) were more likely to request a home-based HIV testing kit and report decreased sexual risk behaviors compared with those who received peer delivered information on general health over Facebook $(n=55$ general health control; total $\mathrm{n}=112$ ). Researchers also aimed to examine the relationship between HIVrelated online discussions on the HOPE intervention Facebook page and requests for a home based HIV testing kit. This study was funded by the National Institute of Mental Health (S.D.Y.; K01 MH 090884) as well as the UCLA AIDS Institute and related articles were published in the Journal AIDS Care and the Annals of Internal Medicine (Young et al., 2013).

\section{Methods and Findings}

Primary intervention outcome measures were based on behavior change from baseline to follow-up, primarily the request for a home-based testing kit. Secondary outcome measures were self-reported reduction in number of sexual partners and observed communication using the social networking community. Findings from this study revealed that almost $95 \%$ of those individuals exposed to the intervention voluntarily communicated using the social networking platform. $73 \%$ of the control participants voluntarily participated. Twenty-five of the 57 intervention participants (44\%) requested home-based HIV testing kits, compared with $20 \%$ or 11 of the 55 control participants. Nine of the 25 intervention participants $(36 \%)$ who requested the test took it and mailed it back compared with 2 of the 11 control participants (18\%) who requested the test. Both intervention and control groups experienced a decrease in the median number of sexual partners from baseline to follow up (Young et al., 2013). 
Over the 12-week exposure period, there were 485 conversations posted on the HIV intervention Facebook page. Using grounded theory to code participant conversations, the following themes were identified by researchers: prevention and testing, knowledge, stigma, and advocacy. Multivariate analysis showed that participants posting about HIV prevention and testing were significantly more likely to request an HIV testing kit (OR 11.14, $p=.001$ ) when compared to those who did not. These effects remained significant when adjusting for age and race. Intervention participants were more likely to request home-based HIV testing kits when compared with control participants, suggesting that this intervention strategy was an effective way to reach HIV prevention goals. In this study, findings suggest that social networking can change health behaviors and increase HIV testing among at-risk populations (Young et al., 2013).

\section{The Just/ Us Study}

The Just/Us Study conducted by Bull et al. (2012) entailed a clustered randomized controlled trial testing the efficacy of an HIV prevention-education study delivered on Facebook for young adult community members and college students. The purpose of the study was to determine whether STI prevention messages delivered via Facebook were effective in preventing increases in sexual risk behavior at 2 and 6 month follow up points. Researchers hypothesized that exposure to social media content would mitigate typical declines in condom use among young adults. Their attempt was to reach young adults at highest risk of HIV which included a particular focus on African American and Hispanic youth and young adult recruitment. This project was funded by the National Institute of Nursing Research (Grant: R01NR01492) and is the first published study to present the results of an RCT using Facebook aimed to influence sexual health risk 
behaviors (Bull et al., 2012). Findings from this study are published in the American Journal of Preventive Medicine.

\section{Methods and Findings}

Primary outcome measures were condom use at last sex act (dichotomized as yes or no) and proportion of sex acts protected by condoms in the past 60 days. In total there were 1578 participants enrolled in this study ( $\mathrm{n}=942 \mathrm{Just} / \mathrm{Us}$ intervention group; $\mathrm{n}=636$ control group). Changes from baseline and 2 and 6 month follow up were assessed for time by treatment effects (Bull et al., 2012).

Time by treatment effects were observed at 2 months for condom use (intervention $68 \%$ vs control $56 \%, p=0.04$ ) and proportion of sex acts protected by condoms (intervention $63 \%$ vs control $57 \%, p=0.03$ ), where intervention participation reduced the tendency for condom use to decrease over time. No effects were seen at 6 months. The proportion of protected acts significantly decreased from baseline to 2 months in the control group and the subsequent increase at 6 months was not significant. Contrastingly, proportion of protected acts remained stable from baseline to 2 months in the intervention group and decreased by the 6-month follow-up (Bull et al., 2012).

Data on participant engagement in the Just/Us Facebook page was gathered using Google analytics and indicated that there were an average of 43 unique visitors per week during the study period (range $=37-101)$. The average time spent on the Facebook page was 3.16 minutes (range $=<1$ minute to 7.3 minutes). There were a total of 227 posts by visitors to the page during the entire study period.

Researchers successfully recruited 1578 diverse participants aged 16-24 years and retained $69 \%$ of them for a two-month follow-up, suggesting that Facebook was an 
outlet to aid in successful recruitment and short-term retention of a diverse sample (Bull et al., 2012). Researchers reported that the effect size of the short-term outcomes matched those observed in previous meta-analysis, suggesting that social networking sites such as Facebook can be, at least, equally effective as traditional HIV prevention programs delivered in a real world setting (Bull et al., 2012).

Both the above studies provide the results of research employing experimental designs to evaluate the use of social networking sites in HIV prevention. The study at hand aims to add to these findings in order to contribute to evidence based HIV prevention research.

\section{Guiding Theoretical Frameworks}

\section{Developmental Lifespan Perspectives}

When conceptualizing HIV and related health disparities that exist among Hispanic young adults, it is important to take prominent developmental lifespan perspectives into consideration (Erickson, 1968; Bronfenbrenner, 1986; Arnett, 2000). For traditional undergraduate college students (typically ages 18-24) young adulthood is not simply a brief period of transition into serious adult roles, but rather, is a distinct period of the lifespan, characterized by change and exploration (Arnett, 2000). Emerging adulthood is distinguished by relative independence from normal social roles and expectations and is often accompanied by challenges and stress (Arnett, 2000). By taking into account the unique, evolving, and complex developmental processes that take place during the transition to young adult, developmental life span theories help researchers better understand the context in which risky sexual behaviors take place. In order to create effective prevention interventions, it is essential to know that risky behavior may 
be tolerated and even promoted during this developmental time period. Because of the focus on exploration and perceived exemption to negative consequences and social expectations during this developmental phase, participation in risky behaviors is common (Sussman \& Arnett, 2014).

\section{Ethnic Minority Identity Formation}

Beyond the normative exploration, change, instability, and stress that young adults experience in the developmental lifespan perspectives, ethnic minority young adults may experience additional stressors that impact their development. Theories of ethnic minority identity provide important context for better understanding the development of ethnic minority young adults (Phinney, 1990; Umaña-Taylor et al., 2014). For example, Phinney's three-stage model describes a developmental process that moves from unawareness of one's own ethnicity to realized ethnic identity incorporation (Phinney, 1990). To date, though, there is little discussion of the relationship between ethnic minority statuses and the normative developmental lifespan processes among young adults in the U.S.

For ethnic minority young adults, the developmental period can be especially marked by complexity. During this developmental phase, individuals begin to integrate their multiple identity domains (e.g., gender, social class, career, and ethnic identities). These multiple identities become one cohesive identity. In line with Erik Erickson's (1968) stages of the psychosocial developmental process, Phinney (1990) focuses on the individual's transformational period in which the individual develops the ability to incorporate their ethnic identity. During this time frame, the ethnic minority identity is no 
longer considered in isolation, but rather is integrated into the individual's identity as a whole (Phinney, 1990).

Drawing from Bronfenbrenner's social-ecological theory (1986), it is also important to consider that individuals are embedded within multiple social contexts (e.g., family, peer, community, national, and global contexts). Ethnic minority identity formation among young adults must, therefore, be understood within the context of the multiple interconnected experiences, relationships, and processes that individuals are a part of throughout their development. Notably, migration history must be considered when studying ethnic minority identity development. Research has documented that immigrant generation, specifically whether one is native versus foreign born, is an important sociodemographic characteristic that can modify the process by which ethnic minority identity development takes place (Umaña Taylor et al., 2013). The experiences of the native-born individuals are often different from those of individuals who are foreign born and affect development and the acculturation processes (Umaña Taylor et al., 2013).

While understanding the cultural characteristics, needs, and strengths of the Hispanic community is essential for successful implementation of prevention strategies, understanding the developmental stages and ethnic identity formation of young adults is also important. Developmental factors that influence the probability of effective prevention or treatment must be considered when designing and implementing prevention programs (Wagner, 2009). Paying direct attention to the developmental status of populations of interest—and specifically tailoring prevention services accordingly— 
helps researchers design prevention programs with improved chances of success (Wagner, 2009).

\section{Empirically Tested Model and Supporting Theories}

To guide the research at hand, an Information-Motivation-Behavioral Skills Model (IMB) was utilized (Fisher \& Fisher, 1992). The IMB model is widely used among current and past efforts in HIV prevention research. The IMB model holds that HIV preventive behaviors are a function of three factors: (a) an individual's information about HIV prevention, (b) motivation to engage in HIV prevention, and (c) behavioral skills for performing the specific acts involved in prevention (Fisher, Fisher, Williams, \& Malloy, 1994). The model asserts that prevention information, motivation, and behavioral skills determine preventive behavior. For this reason, the research at hand focuses on such constructs, specifically information and behavioral skills.

The IMB model has been empirically tested by Fisher et al. (1994) using structural equation modeling with a sample of university students $(n=174)$. In the study involving the sample of university students, information regarding HIV had a direct effect on behavior. Motivation to engage in HIV preventive behavior also had a systematic, direct relationship with HIV preventive behavior (Fisher et al., 1994). The findings confirmed the model's basis that information and motivation work through behavioral skills to affect preventive behavior (Fisher et al., 1994). The IMB model is consistent with the theory of reasoned action which asserts that a person's preventive behavior is a function of his or her behavioral intention and ability to perform a preventive behavior. Behavioral intentions, in turn, are thought to be determined by one's attitudes and information about how to perform an HIV preventive behavior (Fisher et al., 
1994). Because of the empirical research supporting the IMB model among university students, and its widespread use and acceptability in HIV prevention research, it was chosen as an appropriate model to guide this study.

\section{Summary}

In sum, despite the concerning trends in the rising incidence of HIV, the development, implementation, and evaluation of prevention interventions designed to reduce the risk of HIV infection among Hispanic young adults falls short of its need. The cultural, socioeconomic, and epidemiological trends of the Hispanic population in the U.S. highlight the need to direct prevention strategies to communities at high risk of disparities and to ensure that interventions are specifically designed to meet unique needs of these communities.

While effective prevention programs and initiatives should enhance protective factors and reverse or reduce risk factors, it is also evident that programs must be tailored to address specific at-risk populations in order for prevention to be effective (National Institute on Drug Abuse, 2003). Researchers in this field have made a push for developing and testing culturally sensitive prevention strategies. Culturally sensitive and participant informed interventions are key for the acceptance of prevention efforts by Hispanic young adults and the community.

Social media based strategies are becoming increasingly attractive platforms in which to deliver sexual health prevention information to at risk communities, particularly Hispanic young adults. The multifunctionality and interactive nature of social networking sites offer potential for improved communication, where participant-engaged and participant-modified health messaging is possible. Environmental prevention strategies 
that employ innovative communication strategies to increase awareness and community support for prevention are critical for successful HIV prevention. Using social media as a new setting of communication can minimize cultural barriers between members of public health institutions and those who are in need of information and services (Ems \&

Gonzalez 2016). Further research is needed in order to explore the effectiveness of using such strategies to reach evidence based HIV prevention goals. 


\section{CHAPTER III. RESEARCH DESIGN AND METHODOLOGY}

This study expands the efforts of the "Miami Dade Partnership for Preventing Health Risks among Young Adults" by evaluating its social media based prevention campaign efforts. Utilizing a mixed method approach, this research (1) provided a systematic examination of a prevention campaign delivered via social networking sites

(i.e., Facebook, Twitter, and Instagram) and (2) examined its effectiveness on sexual health outcomes as determined by data collected from a randomly assigned sample of 60 Hispanic young adults between the ages of 18 and 24. Results are divided into an assessment of reach, engagement and effectiveness in line with literature recommendations (Lim et al., 2016). Specific Aim 1 addresses reach and engagement of the campaign and Specific Aim 2 addresses evaluating its effectiveness on influencing health outcomes. Because there are two specific aims associated with the research at hand, the methodology section is divided accordingly. As such, each specific aim will present with a unique sample, procedure, and analysis.

Specific Aim 1: Provide a systematic examination of the social based campaign content. Examine the relationship between the social media campaign inputs or presence and the responsive reach and interactivity on the campaign pages.

Specific Aim 2: Examine whether there was an impact on a participants' knowledge of locally available HIV prevention services, his/her condom use, and his/her perceived benefits and confidence of condom when exposed to the social networking campaign. 


\section{Parent Study}

Because of the need to accelerate HIV prevention strategies among Hispanic young adults in Miami, FL, this location was selected through a competitive grant application process by which Principal Investigator, Dr. Eric Wagner, was awarded 3 years of funding by SAMHSA. As noted, goals of the parent project were three-fold: to build environmental capacities for HIV prevention in Miami-Dade County, to provide point of care HIV testing to individuals at high risk of infection, and to create awareness and prevention campaigns. This research focuses on expanding the former goal of implementing a tailored and participant-informed awareness campaign that was delivered via social networking site platforms.

\section{Population and Setting}

Selected as a minority serving institution, Florida International University (FIU) is the largest Hispanic-serving university in the continental U.S. with a student body of nearly 54,000 students, of which, $61 \%$ identify as Hispanic. The university is located in Miami-Dade County which was ranked number one in terms of new HIV infections in U.S. in 2014 and remains among the counties with high rates of infection (CDC, 2015). A primary goal of the parent study was to provide free point of care testing to Hispanic individuals ages 18-24. Point of care testing screens individuals for HIV antibodies which indicate HIV infection. HIV testing is the only way to determine someone's status, and furthermore, to determine whether someone is HIV positive in order to link them with appropriate medical care. As such, in collaboration with the community based service providers, Union Positiva, the "Miami Dade Partnership for Preventing Health Risks among Young Adults" provided over 1,600 tests to 18-24 year old Hispanics between 
September 2015 and April 2017, of which, approximately half were tested for the first time. After receiving an HIV test, Hispanic young adults aged 18-24 were asked to participate in a research study by filing out a baseline and one month follow up survey. The participants in the research at hand comprise a subsample of this parent study research sample.

\section{Recruitment and inclusion criteria}

Methods of recruitment for the parent study are described here. Similar to the recruitment methods employed by Bull et al. (2011) in the "Just/Us Study," participants were recruited in a number of ways. Participants were targeted at the university campus, where members of the research team sat at a table advertising free HIV/ STD testing, a key component of the parent research project. Tabling occurred during various campus events and fairs. These events were focused at the beginning of the semester when orientation activities are common among the university. The table was strategically situated in high traffic areas of the university where a majority of students spend free time while on campus. Interested young adults were encouraged to approach the staff for more information. Recruitment was solely focused on promoting free HIV/ STD testing. Free HIV/STD testing was available to anyone over the age of 18 .

Once an individual was tested for HIV, he/she was then screened for eligibility to participate in the parent research study. In order to participate in the parent research, participants had to: 1) be between the ages of 18 and 24, 2) identify as Hispanic, and 3) agree to complete both a baseline and a one month follow up survey. After explaining the purpose and details of the study, staff obtained written consent from eligible and interested individuals, therefore, enrolling them as research participants. Once enrolled as 
a participant in the parent study, additional eligibility criteria were required for the study at hand. Further details are discussed below regarding eligibility for inclusion in the research study at hand. All study procedures were approved by the University's Institutional Review Board. (See Appendix B.)

\section{Confidentiality and Privacy}

To ensure confidentiality and privacy of participants, all research staff involved in both the recruitment and consenting of participants were trained and approved by the University's Institutional Review Board. Each staff member passed a CITI training for the protection of human subjects and was bound by measures of confidentiality, including protecting the anonymity of those participants enrolled in the study. Survey information was kept private and was handled by approved staff only. All records were stored securely in the locked drawer of the research center storage room.

\section{Protection of Human Subjects}

Because prevention research conducted online takes place in a new environment that presents with unique challenges and opportunities, additional institutionalized measures were taken to promote the protection of human subjects. When implementing prevention strategies on social networking sites, participants are actively engaged using their personal accounts in receiving and exchanging messages, making it impossible to truly protect anonymity among participants. In consideration, the online prevention campaign accounts on Facebook, Twitter, and Instagram were established as community pages or accounts instead of accounts designed for individuals, limiting the amount of information participant profiles shared with the researchers. Furthermore, no sensitive data was collected from personal pages. Rather, only demographic and publicly available 
data were included and considered in the analysis. Last, a predetermined protocol was developed to ensure that the use of social media based efforts were implemented in an ethical and consistent manner. A comment policy protocol was developed to guide and protect individuals who interact with the online sites and also to provide transparency for actions taken by researchers on the site. (See Appendix C for a copy of the comment protocol). Guidelines included the right for researchers to remove any offensive, misleading or incorrect posts that could result in potentially harmful conversations or information for participants and guidelines were based off of those upheld by federal institution's use of social media. This protocol was uploaded to the campaign Facebook page, as this was the only social networking site that provided the opportunity and location to include such a policy. The policy was upheld across activities that took place on all three social networking sites.

\section{Data Collection Location}

Furthermore, as a part of the parent study goals, environmental prevention capacities were established to support the provision of free services to students on campus, as well as the facilitating of the research study. This included (but was not limited to) the securing of a testing lab space where community service providers, Union Positiva, had a consistent and secure testing location on campus to conduct the free HIV testing each week. Testing rooms included sufficient counter space where testing materials could be placed and tests could be administered by testing counselors. An additional room in the lab was secured where consent of participants was drawn by research staff. Consent rooms included two comfortable chairs and a desk where research 
staff could meet with participants and participants could comfortably and confidentially fill out the baseline survey.

\section{Contributions of researcher to the parent study}

The above procedures from the parent study were all included in the current research study. In order to address research questions focusing on the associated social media prevention campaign, additional steps were taken to gather a subsample from the larger, parent study. In addition to the parent study inclusion criteria, the criteria for the study at hand included having an active Facebook, Twitter, or Instagram account and subscription (i.e., liking or following) to the social networking campaign site if randomly assigned to the exposure group.

\section{Overview of Design and Procedures}

This study employed a mixed method research design that included two phases in order to address the study research questions. The first phase involved a mixed methods data gathering process to answer Specific Aim 1, which provided a systematic evaluation of the activity that took place online on the campaign's Facebook, Twitter, and Instagram pages. This phase contributed to social media evaluation knowledge by exploring the strengths and weaknesses of conceptual measurements which are currently in use to evaluate such efforts (i.e., key performance metrics). Furthermore, this phase included thematic classification of campaign content to explore whether there was relationship between campaign inputs and subsequent user interactivity.

The second phase of this study involved a solely quantitative data collection process and employed an experimental design to answer Specific Aim 2, which evaluated the effectiveness of social networking site exposure on self-reported health outcomes. 
Data from a randomly assigned subsample $(n=60)$ was collected in order to determine whether exposure to the online campaign had any effect on a participants' knowledge of locally available HIV preventive services, his/ her perceived benefits and confidence of using condoms during their next sexual act, and his/ her self-reported condom use at the 4 week follow up.

Because of the unique and evolving nature of both conducting health promotional campaigns online and evaluating those efforts, a mixed method design and mixed sample approach were employed in this study. Thus, both quantitative and qualitative data were gathered and analyzed from the social media campaign page (Creswell et al., 2003).

Using quantitative and qualitative methods, in combination, allowed for a more complete and rich analysis of this new and emerging field of research.

\section{Identification of survey}

The survey utilized was created uniquely for the parent SAMHSA-funded study. Questions were modeled after items found in national surveys including Monitoring the Future Survey (MTF) (Johnston et al., 2015) and from validated measures such as those utilized by Grimley et al., (1996), and Parsons, Halkitis, Bimbi, and Borkowski (2000). A team of expert researchers, including the principal investigator and three coinvestigators, drafted and adapted survey questions in order to fit the project population and location. In total, the survey of the parent study included 35-items that utilized a combination of Likert-type scales (responses ranging from strongly agree, to strongly disagree), dichotomized response options (yes or no), and fill-in response options for open ended questions. Once drafted, the survey was sent to the funding source, SAMHSA, for approval. 
Table 1.

Mixed Method Research Design Overview

\begin{tabular}{|c|c|c|c|}
\hline & Method & Procedure & Product \\
\hline $\begin{array}{l}\text { Phase } 1 \\
\text { Systematic } \\
\text { examination of existing } \\
\text { campaign content }\end{array}$ & $\begin{array}{l}\text { Address Specific Aim } 1 \\
\text { Secondary Data Analysis } \\
\text { Mixed Methods: } \\
\text { Quantitative \& Qualitative } \\
\text { Data }\end{array}$ & $\begin{array}{l}\text { Screen captures of } \\
\text { activity on the } \\
\text { campaign's } \\
\text { Instagram, Facebook, } \\
\text { and Twitter page } \\
\text { during progression of } \\
\text { study ( } 3 \text { month } \\
\text { period) } \\
\text { Gathering: } \\
\text {-Quantitative data } \\
\text { (i.e., demographic, } \\
\text { key metrics) } \\
\text {-Text (qualitative) } \\
\text { data } \\
\text { content analysis } \\
\text { - Coding \& thematic } \\
\text { analysis }\end{array}$ & $\begin{array}{l}\text { Frequencies and } \\
\text { Descriptive } \\
\text { statistics } \\
\text { Integrative analysis } \\
\text { of both quantitative } \\
\text { and qualitative data }\end{array}$ \\
\hline $\begin{array}{l}\text { Phase } 2 \\
\text { Efficacy of delivering } \\
\text { HIV prevention } \\
\text { program on SNS }\end{array}$ & $\begin{array}{l}\text { Address Specific Aim } 2 \\
\text { Primary Data Collection } \\
\text { Quantitative Data }\end{array}$ & $\begin{array}{l}\text { Random Assignment } \\
2 \text { group condition } \\
(\mathrm{n}=30 \text { in control } \\
\text { condition; } \mathrm{n}=30 \\
\text { exposure condition; } \\
\text { total } \mathrm{N}=60) \\
\text { Administer Baseline } \\
\& 1 \text { month follow up } \\
\text { Assessment } \\
\text { Collect: } \\
\text {-Survey data }\end{array}$ & $\begin{array}{l}\text { Descriptive } \\
\text { statistics } \\
\text { Mixed ANOVA } \\
\text { repeated measure } \\
\text {-Between group } \\
\text { effects (exposure vs. } \\
\text { control group) } \\
\text { Impact of Treatment } \\
\text { over Time }\end{array}$ \\
\hline
\end{tabular}

\section{Aim 1}

\section{Sample}

The sample of Aim 1 consisted of those individuals who liked or followed the campaign's Instagram, Facebook, or Twitter pages over a three month study period between January and April 7, 2017. For the purpose of this research, these individuals are referred to as "subscribers." The individuals that make up the sample pertaining to Aim 2 
are referred to as "participants." It is important to note that, although they overlap, the considered sample for Aim 1 is distinct from that of the sample considered for Aim 2, thus involving a mixed sample. Below is a brief discussion of the justification for why this distinction was utilized in order to better inform the research.

When conducting social media research in health promotion, balancing real world application and scientific rigor to evaluate effectiveness is a challenge. It has been noted that the benefits of social media as a tool to promote engagement contradict its utility as a program delivery and research evaluation platform (Lim et al., 2016). For example, social networking health promotion programs promote broad uptake and dissemination, however, researchers Lim et al. (2016) note, By not tightly controlling access to the intervention, the rigor of the evaluation's ability to determine effectiveness [impact on health and behavior change] is diminished given the complexities of being able to accurately measure and attribute impact or causality based on an individuals' exposure. (p. 188)

Tightly controlled or "closed" research designs can provide more accurate measures of engagement, including exposure to messaging which can aid researchers in attributing effectiveness, but these closed designs may have little practical implications of social media use or uptake in a real world or natural setting (Lim et al., 2016). Thus, this research aimed to mitigate this juxtaposition by involving both a closed and open design where Specific Aim 1 (open design) and Specific aim 2 (closed design) involved different samples. These methodologies were chosen to best balance evaluation of real-world uptake and rigorous assessment of effectiveness. 


\section{Qualitative data}

In order to address Specific Aim 1, qualitative data were extracted from the campaign pages. Qualitative data included all of the content that the social media campaign produced (i.e., the social media campaign's input). Considered campaign inputs were not limited to text content. That is, images were included in the thematic labeling of campaign content. This is a method of communication evaluation that has been utilized in other studies of community based organizations' use of social media for health promotion (Ramanadhan, Mendez, Rao, \& Viswanath, 2013). Provided below is a table which was adapted from a classification of content chart that was developed by Ramanadhan et al. (2013) for community based organizations' (CBO) use of social media in health promotion.

Table 2.

\section{Classification of Content}

\begin{tabular}{|l|l|}
\hline Classification of Content & Definition \\
\hline Human Interest & $\begin{array}{l}\text { Content that shares a personal story about a } \\
\text { given health topic or public health initiative. }\end{array}$ \\
\hline Health Education & $\begin{array}{l}\text { Educational information or news articles on a } \\
\text { range of health topics (e.g., health tips, policy } \\
\text { decisions that relate to health, and scientific } \\
\text { findings). }\end{array}$ \\
\hline Non Informational & $\begin{array}{l}\text { Content that is meant to maintain connections, } \\
\text { but serves no informational, promotional, or } \\
\text { persuasive purpose, e.g., holiday greetings or } \\
\text { inspirational quotes. }\end{array}$ \\
\hline Campaign Promotion & $\begin{array}{l}\text { Content that advertises or builds the image of } \\
\text { the organization sponsoring the account (e.g., } \\
\text { organization-specific news, event/program } \\
\text { updates, service offerings, and summaries of } \\
\text { past events). }\end{array}$ \\
\hline
\end{tabular}

(Ramanadhan et al., 2013). 
This classification of content table served as the guiding framework for examining the themes and categories for the existing campaign inputs.

\section{Quantitative data}

Using the guidelines of metrics for coding state health departments' use of social media that are provided by Thackeray et al (2012), the following data was quantitatively gathered to address Specific Aim 1.

Table 3. Social Media Key Performance Metrics

\begin{tabular}{|l|l|l|}
\hline Term & Defined & Quantitative Metric \\
\hline Presence & $\begin{array}{l}\text { existence of particular social } \\
\text { media feature or the inputs of } \\
\text { the campaign on a social } \\
\text { media page }\end{array}$ & $\begin{array}{l}\text { Number of posts, videos, } \\
\text { views, events, discussions, } \\
\text { notes, and videos released by } \\
\text { the campaign }\end{array}$ \\
\hline Interactivity & $\begin{array}{l}\text { Audience members posting } \\
\text { content, comments, or likes }\end{array}$ & $\begin{array}{l}\text { Number of comments, likes, } \\
\text { dislikes, posts, replies to } \\
\text { posts, replies to comments, or } \\
\text { clicks on posts }\end{array}$ \\
\hline Reach & $\begin{array}{l}\text { Number of people the } \\
\text { campaign connected with } \\
\text { through the social media } \\
\text { campaign }\end{array}$ & $\begin{array}{l}\text { Number of page likes or page } \\
\text { views }\end{array}$ \\
\hline
\end{tabular}

(Thackeray et al., 2012)

Additionally, metric data sets available on each social networking site platform were extracted in order to harness the analytics available on each site. These quantitative metrics, as well as available demographic data, were gathered in order to answer Specific Aim 1, examining the relationship between campaign inputs and responsive reach and interactivity. 


\section{Procedure}

In order to provide a systematic examination of the social based campaigns, all content and activity on the campaign's Instagram, Twitter, and Facebook page was included in analysis. Screen captures were taken of all the content on each social media site (i.e., Facebook, Twitter, and Instagram). Data available from each site was exported and organized. This included metric data that differed slightly from site to site and demographic characteristics of users that also differed some site to site.

Screen captures of the campaign's Facebook page wall were taken of all content over the proposed study period. Using Facebook analytics, page and post data was exported using the "data export" function. Screen shots of each Instagram post were taken which included analytics provided by Instagram for each post. Similarly, screen captures of the Twitter page were extracted including the analytics page provided by Twitter. Prior to analysis, any participant names and profile photos that were included in the screen captures were removed in order to maintain the participant's privacy while blinding the researchers. See Appendix for an example of screen captures across sites.

Reach and interactivity were chosen as key performance metrics (Veale et al., 2015). Reach was defined as the size of the user base (Veale et al., 2015). For Facebook, reach included anyone who liked the campaign page. For Twitter, reach included anyone who followed the campaign account. For Instagram, reach included anyone who followed the campaign account. Interactivity was used as a measurement of engagement and was defined as any interaction that occurred between users or between a user and the prevention campaign social networking site. All interactivity metrics were summed as has been done in previous reviews by Veale et al. (2015) and this sum was considered the 
measure of engagement. Summation included liking, commenting, or clicking on any part of the campaign post. Each action was considered to be on equal value and every time an individual interacted with the site in any way, a score (1) was added to the interactivity count.

Next, two coders independently coded all the content that was posted by the campaign over the total study period, in which participants in the exposure group were each exposed for 4 weeks before completing the follow up. Coders first assigned a brief description to each campaign input. Next, using the definition and guidelines from the classification of content list (Ramanahan et al., 2013), each post description was reviewed and was assigned a broader theme.

\section{Aim 1 analysis}

Each post generated by the campaign (input or presence) was considered a unit for analysis. Because the text used in a post and the image used in the same post were often different, post texts and post images were coded individually. Each unit (i.e., text and image) was coded for the presence of a theme using the classification of content list, therefore, it was possible that a unit was coded for more than one theme (e.g., a post text could have contained content related to both campaign promotion and health education).

The thematic labeling of campaign inputs involved both an inductive and deductive approach where the proposed code list found in Table 2 aided in classification. After independently coding all inputs produced by the campaign, the two coders met together to discuss assigned codes and themes. Coders checked for agreement with appropriate thematic and categorical labels of content. Discrepancies were addressed until a consensus among coders was obtained, thus employing a consensual qualitative 
research approach (Hill, Thompson, \& Williams, 1997). There were few discrepancies among coders and all discrepancies reached a consensus. Discrepancies were concerning whether to add additional themes to codes or whether to leave the theme that seemed the most relevant or appropriate using the existing code list provided by Ramanahan et al. (2013).

This code list was dynamic and analysis was solely data driven, reflecting an inductive approach, but the classification of content chart served as a guide, reflecting a deductive coding process. Such an analysis is referred to as axial coding, a dynamic process where a predetermined code list is constantly compared against data (Strauss \& Corbin, 1998). During axial coding the researcher is responsible for adding or building on a conceptual model and for determining whether sufficient data exists to support the existing interpretation (Hoepfl, 1997). By using such an approach, the researcher is able to determine whether the initial categories of content identified need to be revised, expanded, or re-conceptualized (Hoepfl, 1997). This coding and analysis process was specifically chosen to complement the state of the research in a field which is still largely underdeveloped. Using excel software to organize the qualitative data, frequency percentages for themes were calculated.

\section{$\operatorname{Aim} 2$}

\section{Sample}

In order to address Specific Aim 2, a sub-sample of 60 participants from the larger, parent study was utilized. As noted previously, after being tested at the lab center for HIV, participants were screened for the following eligibility criteria. Participants had to be: 1) between the ages of 18 and 24,2) identify as Hispanic, and 3) agree to complete 
both a baseline and a one month follow up survey. If individuals met these criteria, they were invited to participate in the study.

Once determined that an individual was eligible and interested in participating in the current research study, he/she was randomly assigned to an experimental group unknowingly. In order to determine randomization, participants were assigned a unique identifier using a random number generator which assigned them to either of the two experimental conditions: exposure group or control group. Individuals in both groups were treated the same and were administered the same baseline, but those participants assigned to the exposure group were asked to "like" or "follow" one of the campaign sites on either Facebook, Instagram, or Twitter, as a final criteria to participate in the study.

If participants were assigned to the control group, they filled out the baseline survey and were not instructed to follow the associated social media campaign site for more information. Thus the control condition was considered the "condition as usual" group. All participants were asked at baseline and follow up if they currently liked or followed the campaign on any of the available social networking sites. In order to avoid contamination, those participants who were randomly assigned to the control group but already followed or liked any of the associated social networking sites for the campaign were excluded from the sample. Similarly, those who consented into the control group and reported following or liking the social networking site at follow up were also excluded from the final analysis. Finally, those who were assigned to the exposure group who did not have active social media accounts were excluded from the sample. 


\section{Procedure}

The survey was administered at baseline and 4 week follow up to participants from both the control and exposure group ( $n=30$ exposure group; $n=30$ control group; total $n=60$ ). This survey was administered in person for the baseline and, later, delivered electronically via email for the 4 week follow up using a Qualtrics link (fiu.qualtrics.com). In order to facilitate participation, a \$10 cash incentive and a \$20 electronic gift card was provided to participants for the baseline and follow-up assessments respectively across both conditions. The baseline and follow up survey each took approximately 15 minutes to complete.

Participants in the exposure group were asked to be actively subscribed (i.e., like or follow) to the associated campaign page for a 4 week period. Participants in the exposure group were free to choose which social media site they would subscribe to for

the 4 week period, depending on participant use and preference. Campaign content posted on each media site was consistent.

Exposure group participants were encouraged to view and interact with the social media page as he/she normally would in their typical online behavior. Participants were told that they were not required to interact with the site in any way as a part of the study. This was purposefully stated at consent in order to allow for interactions with the site to occur as naturally as possible. If participants chose, they could click on their newsfeed updates to get more detail, whereupon they will be linked to the campaign page for access to further prevention information.

Participants in the exposure group received updates (at a minimum) three times a week when they logged on to their proper social networking account. 
In order to minimize performance bias, researchers did not mention purpose of the study or reveal conditional group design to participants. Further, research staff were not involved in the producing of the random sequence which assigned participants to respective groups, allowing for allocation sequence concealment during consent of participants. In order to track compliance, participants in the exposure group were asked at follow up whether they were still actively subscribed to the campaign page. All participants who met this compliance were included in the final sample of exposure participants, regardless of how often they read or thought about the posts. This was done in order to provide a realistic understanding of the feasibility and uptake of HIV prevention efforts delivered via social media platforms and to promote practical interpretation and implications of findings.

\section{Quantitative data}

In order to answer the research questions at hand, the following survey questions were considered in this study:

- Do you know where you can get tested for HIV in Miami-Dade county?"

- " $\quad$ Are you aware of any HIV prevention programs at FIU?"

- "Are you aware of any HIV prevention programs in Miami-Dade county?

These questions were uniquely created to address awareness of available HIV prevention services, both on site (in the university) and off site (in the community). Responses were dichotomized as yes or no (no $=0$, yes $=1)$.

- "The advantages/ benefits of using condoms during sexual intercourse are?" 
The perceived benefits of condom use question was modeled after a question from a previous study conducted by Parsons et al., (2000) which found that perceived benefits of using condoms were predictive of stage of change for condom use. Responses to this question ranged from not at all important to very important using a Likert type scale.

- "Indicate how confident you are that you could use a condom correctly during your next sex act."

This question was modeled after a question from a scale validated by Grimley et al. (1996) and Parsons et al. (2000). Confidence, a characteristic of self-efficacy, has been identified as an important component in the practice of safer sex behaviors and condom use. Responses to this question ranged from not at all confident to very confident using a Likert type scale.

- "In the past year, when you had sex with your current primary partner, how often did you use condoms?"

- "In the past year, when you had sex with someone other than your current primary partner, how often did you use condoms?"

These questions were modeled after questions from the MTF National Survey which assesses risk behavior related to HIV infection among young adults in the U.S. (Johnston et al., 2015). Responses to frequency of protected sex acts questions ranged from never to always using a Likert type scale. (See Appendix A for a copy of the full assessment.)

\section{Aim 2 analysis}

In order to address Aim 2, examining the impact of exposure to the social media campaign for a 4 week period on a participants' knowledge of locally available HIV 
preventive services, his/her perceived benefits and confidence of using condoms during their next sexual act, and his/her self-reported condom use at the 4 week follow up, mixed ANOVAs were conducted using the statistical software, IBM SPSS 2.0 (IBM Corp, 2011). This allowed researchers to determine whether the knowledge, thoughts, and behaviors of participants in the exposure group changed more over time than those of the participants in the control group. A power analysis using G* Power Data Analysis software, revealed that a total sample of 34 participants was sufficient using a .8 level of statistical power. Therefore, a sample of 60 total participants allowed for proper analysis of effects.

Descriptive analysis including frequencies were conducted for demographic and background characteristics across the entire sample. Descriptive analysis were conducted for the entire sample as well as for both conditions separately. In order to assess whether randomization was effective, one-way ANOVAs (analysis of variance) were performed. This allowed researchers to determine whether statistically significant differences existed among randomized groups at baseline.

Because the interest was in the impact of treatment over time across two groups, mixed ANOVAs were deemed appropriate for analysis. A mixed ANOVA allowed the researcher to determine the effect of the intervention, by using a repeated measure mixed design, examining condition $\mathrm{X}$ time interactions. Time (baseline vs. follow up) was considered the within subject factor and condition (exposure vs. control group) was considered the between subject factor. Repeated measures of data were used to model main effects of exposure to the online prevention campaign and time by treatment interaction. All outcomes were modeled in terms of the main effect of changes over time, 
the main effect of treatment, and the interaction between treatment and time. An interaction between time and treatment was considered evidence of an impact of the intervention (Mason, Benotsch, Way, Kim, \& Snipes, 2014).

For binary outcome variables, binary linear logistic regressions were performed to determine whether group predicted outcome. Additionally, McNemar tests in SPSS were conducted to determine differences in baseline and follow up responses across conditions for binary variables. 


\section{CHAPTER IV. RESULTS}

This chapter presents the findings from the evaluation surrounding Specific Aim 1 and Specific Aim 2. Results begin with Specific Aim 1 which provide an overview of the online prevention campaign that took place on Facebook, Twitter, and Instagram. Later, results for Specific Aim 2 are presented which include the exploratory analysis results from data collected through a randomly assigned sample of participants who were asked to "like" or "follow" the online prevention campaign.

Specific Aim 1: Provide a systematic examination of the social media based campaign content. Explore the relationship between the social media campaign inputs or presence and the responsive reach and interactivity on the campaign pages.

\section{Aim 1 Quantitative Results}

The study concluded after a three month period (97 days ranging from January 1April 7, 2017). This was determined by the amount of time it took to recruit the sample of participants required to address Specific Aim $2(\mathrm{n}=60)$.

A review of the three social networking sites revealed 42 unique posts distributed by the campaign across each platform during this 97 day period. Posts were consistent across each social networking site platform and differed only slightly in terms of length of text in order to accommodate character limitations for each site. Each participant in the exposure group was exposed to content for at least a 4 week period, resulting in total exposure of 12 posts or 3 posts per week.

\section{Facebook}

The campaign Facebook page was registered as a community page. This type of page allows visibility to all users on Facebook, regardless of whether they like the page 
or not. This type of page was chosen by researchers to foster broad uptake of the campaign page. The page content included community outreach and awareness content, information and referrals of substance abuse and HIV services, and information and referrals for onsite (university campus) and offsite community referrals.

Facebook had a total of 99 followers at the end of data collection (April 2017). The followers on this site were $60 \%$ female and $39 \%$ male; $1 \%$ was unknown. Of the female followers, 34\% were from the target age group (between 18 and 24 years old). Of the male followers, $21 \%$ were between 18 and 24 years old. Only $1 \%$ of followers were younger than age 17 . Approximately $31 \%$ of the followers were between the ages of 25 and 34 . The remaining $12 \%$ were older than 34 . The majority of followers identified as residing in Miami, FL.

Using Facebook Analytics, a free analytical program offered by Facebook, the following interactivity data was collected over the course of the 3 month study period. There were a total of 4,796 post impressions over all posts available on the page during the study period. Post impressions refers to the total number of times a post was displayed to any user. This metric is not limited to unique users, therefore, one user could account for multiple counts of the impression metric. Over the course of the study period, page posts were distributed to 2,688 unique Facebook accounts. The number of times a user interacted with any page post during this time period was 79 . This engagement metric included any time a user commented, liked, shared, or clicked upon any particular element of the post. The number of unique users who clicked anywhere on a post was 42 . Clicks on posts could be on hashtags, links to further resources, and other linked 
community pages. These metrics are not limited to followers, and therefore, Facebook users who did not follow the page are included in these numbers.

The most successful post on Facebook, in terms of user interactivity, was a video that featured two involved staff members placing prevention campaign materials around campus. This video had accompanying music and staff members appeared dancing while posting campaign signs. This video generated 7 user interactions and 213 impressions. The second, third, and fourth most successful posts on Facebook each generated 4 user interactions and 120, 85, and 63 impressions, respectively. These posts read a) "Today is the day and love is still in the air! Loving someone means being truthful. Know your status so you can be honest with others. Happy HUMP!" (Posted the day after Valentine's Day) b) "Quick Tip: Both male and female condoms are useful in preventing the spread of HIV and other STIS, but they are not meant to be used together. Choose one at a time and stick to it from start to finish," and c) "Some reading material to get your weekend started. Read here a step by step guide on how to properly use condoms (BOTH male and female ones). https://www.plannedparenthood.org/learn/birthcontrol/condom/how-to-put-a-condom-on \#plannedparenthood \#TGIF."

\section{Twitter}

At the closing of the study period, 67 individuals followed the prevention campaign Twitter page. The page was public to all Twitter users, regardless of whether they followed the account or not, in order to encourage broad uptake of campaign messaging. Due to the small number of followers, demographic information of followers was not aggregated by Twitter. Twitter requires a minimum number of followers in order 
to provide demographic data. The prevention campaign Twitter account did not meet this minimum criteria.

Over this time period, the Twitter page had 9,521 impressions, referring to the total number of times a tweet was displayed to any Twitter user. Similar to Facebook, this metric was not limited to unique users. Over the study period, users interacted with page posts 217 times. This engagement metric included retweets, likes, clicks anywhere on posts, and detail expands. Additionally, there were 14 total mentions during this time period. Mentions refer to when other accounts included the campaign handle, or account name, in their posts. The most common mention was from the university's Twitter account and these mentions contributed to the number of impressions and user interactivity. Mentions were performed using a hashtag (\#) or at (@) symbol to link users with the campaign account.

The most successful tweet (based on user interactivity) read, "Come by the GL breezeway for free prizes! There's FREE HIV/STD testing today from 10-5 (and every hump day) in AHC-5 room 104 \#camelapproved." This tweet included a "selfie" mobile photograph of two volunteers who were actively involved in on and offline campaign promotion. This post received 240 impressions and 38 user interactions. The second most successful tweet read, "Woke up hungover today? This is the effect of consuming alcohol. Make changes to start your days fresh. \#newyearnewyou," and included an image of a man with his arms raised in celebration after waking up on the new year with no hangover. This tweet received 133 impressions and 16 user interactions. The third most popular tweet read, "Wrapping up the week like...," and included an image that read, "Don't be silly, wrap your willy." This tweet received 207 impressions and 12 user 
interactions. Twitter was the second most successful platform for the prevention campaign in terms of generating user interactivity.

\section{Instagram}

Instagram was the most active (in terms of user interactivity) and popular (in terms of reach) site for the prevention campaign. By the end of the study period, 480 people followed the Instagram page. The campaign Instagram page was also registered as a community account, allowing public visibility to all Instagram users, regardless of whether they followed the account or not. This type of page was chosen by researchers to foster broad uptake of the campaign page and also to enable access to analytics provided by the site.

The majority of followers on Instagram were women (61\%). Men accounted for $39 \%$ of Instagram followers. The majority of followers also resided in Miami, FL and were between the ages of 18 and 24. Only available aggregated user data was included from each site in order to protect privacy and anonymity of online users. Aggregated demographic data provides evidence that the campaign was successful in reaching its target demographic audience.

Over the course of the study period there were 15,280 impressions and 1,474 user interactions generated on Instagram, making Instagram the most successful site of the prevention campaign by a large margin. Of the reported engagements, 1,446 were "likes". Seventeen total comments were posted on the Instagram page over the study period by users. Other actions in the engagement metric provided by Instagram include link clicks, reposts, shares, and detail expands. 
The top three posts on Instagram (in terms of user interactivity) were as follows. The post that received the most interactivity (65 user interactions and 496 impressions) read, "May your day be as fresh as these baked cookies. Treat yo self! Stop by AHC5 104 today for free HUMP day STD testing!" and included an image of cookies that are sold at the university bakery that have well known popularity among students as well as staff members on campus. The second most popular (55 user interactions and 246 impressions) read, "Best way to start the day- feeling HEALTHY. Woke up hungover today? This is a result of the physical and psychological effects of consuming alcohol. Make changes to start your day fresh," and included an image of a man with his arms raised in celebration after waking up on the new year with no hangover. This post was also successful on Twitter. The third most popular post (51 user interactions and 418 impressions) read, “Come by the GL breezeway for free prizes! There's FREE HIV/STD testing today from 10-5 (and every hump day) in AHC-5 room 104," and included the image of the two involved volunteers who posed in a "selfie" photograph. This post was also successful on Twitter.

Table 4 shows an overview of the 5 most successful posts on each platform, as determined by interactivity scores. This table also includes thematic labels assigned to each post, which capture the topics of the post delivered. 
Table 4.

Overview of Top Posts Per Social Networking Site

\begin{tabular}{|c|c|c|c|}
\hline & Facebook & Twitter & Instagram \\
\hline 1. Post Description & Staff Video & Volunteer "Selfie"* & University Cookies Image \\
\hline \multirow[t]{3}{*}{ Assigned Theme } & -Human Interest & -Human Interest & -Health Education/ News \\
\hline & -Campaign Promotion & -Campaign Promotion & -Campaign Promotion \\
\hline & & -Health Education/ News & \\
\hline Total Interactivity & 7 & 38 & 65 \\
\hline 2. Post Description & Quick Tip: Condom Use* & New Year, New You & New Year, New You \\
\hline \multirow[t]{2}{*}{ Assigned Theme } & -Health Education/ News & -Health Education/ News & -Health Education/ News \\
\hline & & -Human Interest & -Human Interest \\
\hline Total Interactivity & 4 & 16 & 55 \\
\hline 3. Post Description & Valentine's Day & Wrapping up the Week & Volunteer "Selfie" \\
\hline \multirow[t]{3}{*}{ Assigned Theme } & -Human Interest & -Non informational & -Human Interest \\
\hline & -Campaign Promotion & & -Health Education/ News \\
\hline & -Health Education/ News & & -Campaign Promotion \\
\hline Total Interactivity & 4 & 12 & 51 \\
\hline 4. Post Description & $\begin{array}{l}\text { Reading Material: Condom } \\
\text { Use }\end{array}$ & Quick Tip: Condom Use & Avoid feeling like an ass \\
\hline \multirow[t]{2}{*}{ Assigned Theme } & -Health Education/ News & -Health Education/ News & -Health Education/ News \\
\hline & -Cross Promotion & & -Campaign Promotion \\
\hline Total Interactivity & 4 & 11 & 50 \\
\hline 5. Post Description & New Year, New You* & Talk to your friend about using condoms & Find the Cody Crew \\
\hline \multirow[t]{2}{*}{ Assigned Theme } & -Human Interest & -Human Interest & -Health Education/ News \\
\hline & -Health Education/ News & -Health Education/ News & -Campaign Promotion \\
\hline Total Interactivity & 3 & 11 & 49 \\
\hline
\end{tabular}

Table 5 provides an overview of interactivity scores, reach, and impressions for each social networking site at the end of the study period.

Table 5.

Key Performance Metrics Overview of Study Period

\begin{tabular}{lrrr}
\hline & Reach & Impressions & Interactivity \\
\cline { 2 - 4 } Facebook & 99 & 4,796 & 79 \\
Twitter & 67 & 9,521 & 217 \\
Instagram & 480 & 15,280 & 1,474 \\
\hline
\end{tabular}

Note. Impressions $=$ total number of times a post was displayed to any user. 


\section{Aim 1 Qualitative Results}

The main input activities on the site included providing information about screening or testing services, offering evidence-informed risk reduction messaging in the form of "health tips," and providing research and statistics as well as referrals for prevention information. Through the use of hashtags, the campaign linked users with other established organizations with similar prevention goals during this study period. Some of these organizations were national (e.g., Planned Parenthood, CDC), while others were local or university based organizations (e.g., Campus Healthy Living Program). The campaign also posed questions to initiate conversations, encouraging users to respond. The campaign used humor, posted time relevant content, and made use of multimedia posts such as videos with audio (Veale et al., 2015). These techniques were implemented to ensure that the content was broadly relevant and engaging for the population of focus (Veale et al., 2015). All of the interactions that occurred on any of the social networking sites were organic, contrasting to paid interactions that are commonly used in business and marketing strategies which use social media technologies.

Using the existing classification of content chart (Ramanadhan et al., 2013), the following themes emerged from campaign inputs: human interest, health education/ news, campaign promotion, cross-promotion, and non-informational. The themes of materials for professionals and fundraising were not used in the coding of the prevention campaign content. These themes did not align with the prevention campaign goals and were, therefore, not present in campaign content. Few discrepancies between coders existed. Discrepancies were concerning whether to add additional themes to codes or 
whether to leave the existing theme that seemed the most relevant or appropriate. Discrepancies are detailed here and adaptations of thematic labels are noted.

The human interest classification label generated discussion. After reviewing, coders agreed that the thematic label for human interest should be extended to capture any post text or post image that mimicked what a person might say, do, or think, thus representing a human story. For example, commonly used "memes", which can be understood as an image, video, or text that uses humor and is copied and spread rapidly by Internet users, are often used by young adults on social media. These memes are often satirical accounts of how an individual may think, feel, or act and are, what the researchers interpret as, the depiction of a human story on social media sites. Similarly any post text or image that invited a person or community to share their thoughts was also considered as a part of the human interest category.

Cross promotion was also expanded to include subtle cross promotion that could have taken place through the use of a hashtag. Table 6 provides an overview of campaign input breakdown based on thematic labeling of content. The most common themes identified in posts were health education and news $(n=36)$, followed by campaign promotion $(\mathrm{n}=23)$. In line with campaign goals, elements of health education and news were present in $83 \%$ of the total number of posts during this study period. In the health education and news theme, the most often used code entailed information about HIV testing and condom use in the form of quick tips. Other health education and news posts entailed facts and tips about alcohol and drug misuse. Table 6 also presents themes of posts that were among the top 5 posts across each site. 
Table 6.

Overview of Posts per Theme

\begin{tabular}{|c|c|c|}
\hline & Number of total posts & Top 5 posts \\
\hline & $\mathrm{n}(\%)$ & $\mathrm{n}(\%)$ \\
\hline Human Interest & $11(26 \%)$ & $8(53 \%)$ \\
\hline Non Informational & $13(31 \%)$ & $1(7 \%)$ \\
\hline Campaign Promotion & $23(55 \%)$ & $7(47 \%)$ \\
\hline Cross Promotion & $11(26 \%)$ & $1(7 \%)$ \\
\hline Health Education/ News & $36(86 \%)$ & $13(87 \%)$ \\
\hline
\end{tabular}

Note. Posts can be labeled with more than one theme.

In order to complement the findings from Specific Aim 1, which provide an overview of the social networking sites of the prevention campaign, the following exploratory research was conducted to address Specific Aim 2.

Specific Aim 2: Examine the relationship between exposure to the social media campaign and a participants' knowledge of locally available HIV prevention services, his/her perceived benefits and confidence of condom use and his/her condom use.

The final sample utilized to address quantitative data analysis in Specific Aim 2 consisted of 60 participants between the ages of 18 and 24 who identified as Hispanic. Cubans (38\%) were the largest represented ethnic group in the total sample. The sample was mixed gender, with the majority of total participants identifying as male (62\%). The entire sample reported being cisgender, meaning all participants identified with the gender he/she was assigned at birth. The sample was largely heterosexual (73\%), followed by homosexual (13\%). When asked if participants had a current primary sex partner, $58 \%$ reported they did, while $40 \%$ reported they did not. Additionally, 1 individual in the total sample reported not knowing whether or not they had a primary sex partner. Finally, $95 \%$ of the total sample had been sexually active in the past year. Of the 
total sample, $62 \%$ were tested for the first time in their lifetime during project testing and $75 \%$ were tested for the first time within the present year during project testing. Demographic and background characteristics of the sample are presented in Table 7. 


\section{Table 7.}

Demographic and Background Characteristics of Sample

\begin{tabular}{|c|c|c|c|}
\hline Characteristic & $\begin{array}{c}\text { Total Sample } \\
n=60\end{array}$ & $\begin{array}{c}\text { Control Group* } \\
n=30\end{array}$ & $\begin{array}{c}\text { Exposure Group* } \\
n=30\end{array}$ \\
\hline Age (Mean (SD)) & $21(1.95)$ & $21(1.95)$ & $21(1.98)$ \\
\hline Foreign born & $20(33.3 \%)$ & $10(33.3 \%)$ & $10(33.3 \%)$ \\
\hline \multicolumn{4}{|l|}{ Hispanic Ancestry } \\
\hline Cuban & $23(38 \%)$ & $12(34 \%)$ & $11(33.3 \%)$ \\
\hline Venezuelan & $8(13 \%)$ & $2(6 \%)$ & $6(18.2 \%)$ \\
\hline Colombian & $7(12 \%)$ & $4(11.4 \%)$ & $3(9 \%)$ \\
\hline Puerto Rican & $7(12 \%)$ & $4(11.4 \%)$ & $3(9 \%)$ \\
\hline Dominican & $5(8 \%)$ & $3(8.6 \%)$ & $2(6 \%)$ \\
\hline Mexican & $3(5 \%)$ & $3(8.6 \%)$ & $0(0 \%)$ \\
\hline Peruvian & $1(2 \%)$ & $0(0 \%)$ & $1(3 \%)$ \\
\hline Argentine & $1(2 \%)$ & $0(0 \%)$ & $1(3 \%)$ \\
\hline Other & $13(19 \%)$ & $7(20 \%)$ & $6(18.2 \%)$ \\
\hline \multicolumn{4}{|l|}{ Sex assigned at birth } \\
\hline Male & $37(62 \%)$ & $21(70 \%)$ & $16(53.3 \%)$ \\
\hline Female & $23(38 \%)$ & $9(30 \%)$ & $14(46.7 \%)$ \\
\hline Cisgender & $60(100 \%)$ & $30(100 \%)$ & $30(100 \%)$ \\
\hline \multicolumn{4}{|l|}{ Sexual Orientation } \\
\hline Heterosexual & $44(73 \%)$ & $23(76.7 \%)$ & $21(70 \%)$ \\
\hline Mostly Heterosexual & $1(2 \%)$ & $0(0 \%)$ & $1(3.3 \%)$ \\
\hline Bisexual & $5(8 \%)$ & $2(6.7 \%)$ & $3(10 \%)$ \\
\hline Mostly Homosexual & $1(2 \%)$ & $1(3.3 \%)$ & $0(0 \%)$ \\
\hline Homosexual & $8(13 \%)$ & $4(13.3 \%)$ & $4(13.3 \%)$ \\
\hline Other & $1(2 \%)$ & $0(0 \%)$ & $1(3.3 \%)$ \\
\hline How important is religion to you? (Mean (SD)) & $2.49(1.1)$ & $2.6(.97)$ & $2.38(1.15)$ \\
\hline Not at all important & $15(25 \%)$ & $6(20 \%)$ & $9(30 \%)$ \\
\hline Fairly unimportant & $10(17 \%)$ & $4(13.3 \%)$ & $6(20 \%)$ \\
\hline Fairly important & $24(41 \%)$ & $16(53.3 \%)$ & $8(26.7 \%)$ \\
\hline Very important & $10(17 \%)$ & $4(13.3 \%)$ & $6(20 \%)$ \\
\hline Missing & $1(2 \%)$ & $0(0 \%)$ & $1(3.3 \%)$ \\
\hline \multicolumn{4}{|l|}{ Current primary sex partner } \\
\hline Yes & $35(58 \%)$ & $18(60 \%)$ & $17(56.7 \%)$ \\
\hline No & $24(40 \%)$ & $11(36.7 \%)$ & $13(43.3 \%)$ \\
\hline Don't Know & $1(2 \%)$ & $1(3.3 \%)$ & $0(0 \%)$ \\
\hline Have been sexually active in the past year & $57(95 \%)$ & $28(93.3 \%)$ & $29(96.7 \%)$ \\
\hline First time receiving HIV test in lifetime & $37(62 \%)$ & $19(63.3 \%)$ & $18(60 \%)$ \\
\hline First time receiving HIV test within the past year & $45(75 \%)$ & $22(73.3 \%)$ & $23(76.7 \%)$ \\
\hline
\end{tabular}


Results from a one-way ANOVA allowed researchers to determine whether significant differences in demographic and background characteristics existed among groups at baseline (i.e., exposure group versus control group). There were no statistically significant differences $(\mathrm{p}<.05)$ across conditions as determined by a one-way ANOVA. Examining statistically significant differences across conditions at baseline allowed researchers to determine that randomization was effective, as both groups did not differ significantly across means of key demographic or background characteristics.

Table 8 presents descriptive statistics of variables of interest at baseline of the sample. At baseline, the majority of the total sample reported being unaware of where to receive an HIV test in the community, unaware of HIV prevention programs on campus, and unaware of HIV prevention programs in the community $(60 \%, 53.3 \%$, and $78.3 \%$ respectively). All participants in the sample reported condom use during sexual intercourse as either fairly important (10\%) or very important (90\%). The majority of the participants across the sample also reported being very confident (80\%) in using condoms during their next sex act, followed by either fairly confident (16.7\%) or fairly unconfident $(3.3 \%)$.

When asked to report condom use, participants who did not have a primary partner reported using condoms more frequently than participants who did have a primary partner (18.3\% vs $10 \%$ reported always using condoms). Of participants who did not have a primary partner, $11.7 \%$ reported never using condoms, while $13.3 \%$ of participants who did have a primary partner reported never using condoms. 
Table 8 .

Descriptive statistics of variables of interest at baseline

\begin{tabular}{|c|c|c|c|}
\hline \multirow[t]{2}{*}{ Survey Question } & \multicolumn{2}{|c|}{ Total Sample Control Group } & \multirow{2}{*}{$\begin{array}{l}\text { Exposure Group } \\
\qquad \mathrm{n}=30\end{array}$} \\
\hline & $n=60$ & $\mathrm{n}=30$ & \\
\hline \multicolumn{4}{|l|}{ Awareness of locally available prevention services } \\
\hline Unaware of where to receive HIV test in community & $36(60 \%)$ & $17(56.7 \%)$ & $19(63.3 \%)$ \\
\hline Unaware of HIV prevention programs on campus & $32(53.3 \%)$ & $14(46.7 \%)$ & $18(60 \%)$ \\
\hline Unaware of HIV prevention programs in community & $47(78.3 \%)$ & $20(66.7 \%)$ & $27(90 \%) *$ \\
\hline \multicolumn{4}{|l|}{ Attitudes towards condom use } \\
\hline Perceived benefits of condom use during sexual intercourse (Mean (SD)) & $1.10(.30)$ & $1.1(.31)$ & $1.1(.31)$ \\
\hline Not at all important & $0(0 \%)$ & $0(0 \%)$ & $0(0 \%)$ \\
\hline Fairly unimportant & $0(0 \%)$ & $0(0 \%)$ & $0(0 \%)$ \\
\hline Fairly important & $6(10 \%)$ & $3(10 \%)$ & $3(10 \%)$ \\
\hline Very important & $54(90 \%)$ & $27(90 \%)$ & $27(90 \%)$ \\
\hline Confidence of using condom during next sexual intercourse (Mean (SD)) & $1.23(.50)$ & $1.3(.52)$ & $1.2(.48)$ \\
\hline Not at all confident & $0(0 \%)$ & $0(0 \%)$ & $0(0 \%)$ \\
\hline Fairly unconfident & $2(3.3 \%)$ & $1(3.3 \%)$ & $1(3.3 \%)$ \\
\hline Fairly confident & $10(16.7 \%)$ & $6(20 \%)$ & $4(13.3 \%)$ \\
\hline Very confident & $48(80 \%)$ & $23(76.7 \%)$ & $25(83.3 \%)$ \\
\hline \multicolumn{4}{|l|}{ Self-reported Condom use } \\
\hline When you had sex with your current primary partner, how often did you u & $1.92(1.44)$ & $1.63(1.42)$ & $2.24(1.44)$ \\
\hline Not applicable & $24(40 \%)$ & $11(36.7 \%)$ & $13(43.3 \%)$ \\
\hline Never & $8(13.3 \%)$ & $3(10 \%)$ & $5(16.7 \%)$ \\
\hline Almost never & $5(8.3 \%)$ & $2(6.7 \%)$ & $3(10 \%)$ \\
\hline Sometimes & $5(8.3 \%)$ & $4(13.3 \%)$ & $1(3.3 \%)$ \\
\hline Almost every time & $12(20 \%)$ & $5(16.7 \%)$ & $7(23.3 \%)$ \\
\hline Always & $6(10 \%)$ & $5(16.7 \%)$ & $1(3.3 \%)$ \\
\hline When you had sex with someone other than your current primary partner, & $1.55(1.41)$ & $1.61(1.50)$ & $1.50(1.36)$ \\
\hline Not applicable & $22(36.6 \%)$ & $12(40 \%)$ & $10(33.3 \%)$ \\
\hline Never & $7(11.7 \%)$ & $4(13.3 \%)$ & $3(10 \%)$ \\
\hline Almost never & $0(0 \%)$ & $0(0 \%)$ & $0(0 \%)$ \\
\hline Sometimes & $11(18.3 \%)$ & $4(13.3 \%)$ & $7(23.3 \%)$ \\
\hline Almost every time & $9(15 \%)$ & $5(16.7 \%)$ & $5(16.7 \%)$ \\
\hline Always & $11(18.3 \%)$ & $5(16.7 \%)$ & $5(16.7 \%)$ \\
\hline
\end{tabular}

One-way ANOVAs compared variables of interest by condition at baseline to determine whether statistically significant group differences existed between conditions.

There was a statistically significant difference between group means at baseline as determined by a one-way ANOVA $(\mathrm{F}(1,58)=5.057, \mathrm{p}=.028)$ for awareness of HIV prevention programs in the community between the control group $[.3(.45)]$ and the 
exposure group [.1(.31)]. Results indicate that participants in the exposure group were significantly less likely to be aware of HIV prevention programs in the community at baseline, when compared to participants in the control group.

Test of Hypothesis 1. Participants' knowledge of available prevention services will increase after 4 week exposure to the social media campaign.

Descriptive statistics compared mean scores of awareness variables at both baseline and follow up among control and exposure group participants. Follow up responses showed a slight increase in awareness at follow up among participants in the exposure group. Descriptive statistics for awareness outcome variables at baseline and follow up are presented in Table 9.

Table 9.

Descriptive Statistics for Awareness Outcome Variables

\begin{tabular}{llll}
\hline & Condition & $\begin{array}{c}\text { Baseline } \\
\text { Mean (SD) }\end{array}$ & \multicolumn{1}{c}{$\begin{array}{c}\text { Follow up } \\
\text { Mean (SD) }\end{array}$} \\
\cline { 2 - 4 } $\begin{array}{l}\text { Awareness of where to receive } \\
\text { HIV test in the community }\end{array}$ & Control & $.433(.504)$ & $.4000(0.498)$ \\
Awareness of prevention & Exposure & $.367(0.490)$ & $.4333(0.504)$ \\
services in the community & Control & $.333(.479)$ & $.3333(.479)$ \\
Awareness of prevention & Exposure & $.100(.305)$ & $.3333(.479)$ \\
services on campus & Control & $.533(.507)$ & $.7333(.450)$ \\
& Exposure & $.400(.498)$ & $.7333(.450)$ \\
\hline
\end{tabular}

Note. $0=$ no awareness; $1=$ awareness

Table 10 presents with the results of a binary logistic regression performed in order to assess the effects of exposure to the social networking site on the likelihood that participants would increase their awareness of where to get tested for HIV in the 
community. Awareness of where to get tested for HIV in the community at follow up was considered the dependent variable while condition and baseline response for each participant were included as independent variables. Condition was not a significant predictor of awareness of where to get tested for HIV in the community in this model $(\mathrm{p}>.05)$.

Table 10.

Binary Logistic Regression for awareness of where to receive HIV test in the community

\begin{tabular}{|c|c|c|c|c|c|c|}
\hline & B & S.E. & $\mathrm{df}$ & Sig. & $\operatorname{Exp}(B)$ & $95 \%$ C.I. \\
\hline Condition & 0.425 & 0.642 & 1 & 0.508 & 1.529 & $(0.435,5.38)$ \\
\hline $\begin{array}{l}\text { Awareness of community } \\
\text { HIV Test at baseline }\end{array}$ & 2.574 & 0.646 & 1 & 0 & 13.124 & $(3.702,46.533)$ \\
\hline Constant & -1.659 & 0.568 & 1 & 0.004 & 0.19 & \\
\hline
\end{tabular}

Another binary logistic regression was performed to assess the effects of condition on the likelihood that participants would increase awareness of prevention programs in the community. Awareness of prevention programs in the community at follow up was considered the dependent variable while condition and baseline response for each participant were included as independent variables. Condition was not a significant predictor of awareness of where to get tested for HIV in the community ( $p>$ $.05)$. Table 11 presents with the results from this model. 
Table 11.

Binary Logistic Regression for avareness of prevention services in the community

\begin{tabular}{|c|c|c|c|c|c|c|}
\hline & B & S.E. & df & Sig. & $\operatorname{Exp}(B)$ & $95 \%$ C.I. \\
\hline Condition & 0.662 & 0.665 & 1 & 0.32 & 1.938 & $(0.526,7.139)$ \\
\hline $\begin{array}{l}\text { Awareness of community } \\
\text { prevention services at baseline }\end{array}$ & 2.269 & 0.767 & 1 & 0.003 & 9.666 & $(2.148,43.499)$ \\
\hline Constant & -1.594 & 0.561 & 1 & 0.004 & 0.203 & \\
\hline
\end{tabular}

Note. Variable(s) entered on step 1: Condition, DADEHIVPREV. B= coefficent for the constant (intercept). S.E.= standard error. $\mathrm{df}=$ degree of freedom. $\operatorname{Exp}(B)=$ odds ratio. $C . I .=$ confidence interval.

Similarly, a binary logistic regression was performed to assess the effects of condition on the likelihood that participants would increase awareness of HIV prevention programs at the university. Awareness of HIV prevention programs at the university at follow up was considered the dependent variable while condition and baseline response for each participant were included as independent variables. Condition was not a significant predictor of awareness of where to get tested for HIV in the community ( $p>$ $.05)$. Thus, exposure to the social networking campaign was not predictive of an improvement of awareness outcomes. Table 12 presents with the results from this model. Table 12.

Binary Logistic Regression for avareness of prevention services on campus

\begin{tabular}{|c|c|c|c|c|c|c|}
\hline & B & S.E. & df & Sig. & $\operatorname{Exp}(B)$ & $95 \%$ C.I. \\
\hline Condition & 0.511 & 0.719 & 1 & 0.477 & 1.667 & $(0.407,6.818)$ \\
\hline $\begin{array}{l}\text { Awareness of campus } \\
\text { prevention services at baseline }\end{array}$ & 21.294 & 7563 & 1 & 0.998 & 176935464 & $(0,0)$ \\
\hline Constant & -0.288 & 0.54 & 1 & 0.594 & 0.75 & \\
\hline
\end{tabular}

Note. Variable(s) entered on step 1: Condition, FIUHIVPREV. B=coefficent for the constant (intercept). $\mathrm{SE} .=$ st andard error. $\mathrm{df}=$ degree of freedom. $\operatorname{Exp}(B)=$ odds ratio. $C I$. = confidence interval.

Baseline and follow up scores of awareness outcomes across the entire sample were compared. Using nonparametric tests for related samples, both baseline and follow up responses for each awareness outcome were considered for analysis. Scores for 
awareness of where to get tested for HIV in the community did not differ significantly from baseline to follow up nor did scores for awareness of HIV prevention programs in the community. McNemar's test results indicated that, at the 4 week follow up, participants across both conditions showed statistically significant improvements in awareness of HIV prevention programs at the university (baseline $\mathrm{M}=.467$; follow up $\mathrm{M}=.733$ ). Awareness of HIV prevention programs on campus was significantly higher at follow up across conditions $(\mathrm{p}<.001)$ when compared to baseline responses. Table 13 presents with test statistic results.

Table 13.

McNemar's Test Statistics for awareness variables

$\mathrm{N} \quad$ Exact Sig. (2-tailed)

Awareness of where to get tested for HIV in the community at baseline and follow up

60

60

at baseline and follow up

Awareness of HIV prevention programs on campus

Note. Binomial distribution used.

$*=\mathrm{p}<.005$

Test of Hypothesis 2: Participants' perceived benefits of condom use will increase after 4 week to the social media campaign.

Table 14 presents descriptive statistics for perceived benefits and confidence of condom use at baseline and follow up for both groups. Descriptive statistics for perceived benefits and confidence of condom use indicate little to no changes in scores from baseline to follow up across conditions. 
Table 14.

Descriptive Statistics for perceived benefits and confidence of condom use

\begin{tabular}{llrl}
\hline & Condition & $\begin{array}{c}\text { Baseline } \\
\text { Mean (SD) }\end{array}$ & $\begin{array}{c}\text { Follow up } \\
\text { Mean (SD) }\end{array}$ \\
\cline { 2 - 4 } Confidence of using condoms at & Control & $1.267(0.521)$ & $1.267(0.521)$ \\
next sex act & Exposure & $1.20(0.484)$ & $1.267(0.521)$ \\
Benefits of condom use during sex & Control & $1.10(0.305)$ & $1.167(0.379)$ \\
act & Exposure & $1.10(0.305)$ & $1.133(0.346)$ \\
\hline
\end{tabular}

1=very important, $4=$ not at all important

Results from a Mixed ANOVA revealed no statistical significance in the interaction between time and condition on a participants' perceived benefits of using condoms during his/ her next sex act. Tables 15 and 16 present with Mixed ANOVA results. Interpreting tests of within subject effects, time was not statistically significant. Interpreting tests of between subject effects, condition was not statistically significant in this sample. 
Table 15.

Tests of within-subject effects for reported benefits of condom use during sexual intercourse

\begin{tabular}{|c|c|c|c|c|c|c|c|}
\hline Source & & $\begin{array}{l}\text { Type III } \\
\text { Sum of } \\
\text { Squares }\end{array}$ & df & $\begin{array}{l}\text { Mean } \\
\text { Square }\end{array}$ & $\mathrm{F}$ & Sig. & $\begin{array}{c}\text { Partial } \\
\text { Eta } \\
\text { Squared }\end{array}$ \\
\hline \multirow[t]{4}{*}{ Time } & Sphericity Assumed & 0.075 & 1 & 0.075 & 0.803 & 0.374 & 0.014 \\
\hline & Greenhouse-Geisser & 0.075 & 1 & 0.075 & 0.803 & 0.374 & 0.014 \\
\hline & Huynh-Feldt & 0.075 & 1 & 0.075 & 0.803 & 0.374 & 0.014 \\
\hline & Lower-bound & 0.075 & 1 & 0.075 & 0.803 & 0.374 & 0.014 \\
\hline \multirow{4}{*}{$\begin{array}{l}\text { Time * } \\
\text { Condition }\end{array}$} & Sphericity Assumed & 0.008 & 1 & 0.008 & 0.089 & 0.766 & 0.002 \\
\hline & Greenhouse-Geiscer & 0008 & 1 & 0008 & 0089 & 0766 & 0002 \\
\hline & Huynh-Feldt & 0.008 & 1 & 0.008 & 0.089 & 0.766 & 0.002 \\
\hline & Lower-bound & 0.008 & 1 & 0.008 & 0.089 & 0.766 & 0.002 \\
\hline \multirow[t]{4}{*}{ Error(Time) } & Sphericity Assumed & 5.417 & 58 & 0.093 & & & \\
\hline & Greenhouse-Geisser & 5.417 & 58 & 0.093 & & & \\
\hline & Huynh-Feldt & 5.417 & 58 & 0.093 & & & \\
\hline & Lower-bound & 5.417 & 58 & 0.093 & & & \\
\hline
\end{tabular}

Note. Measure: benefits.

Table 16.

Tests of Between-Subjects Effects for reported benefits of condom use during sexual intercourse

\begin{tabular}{|c|c|c|c|c|c|c|}
\hline Source & $\begin{array}{l}\text { Type III } \\
\text { Sum of } \\
\text { Squares }\end{array}$ & $\mathrm{df}$ & $\begin{array}{l}\text { Mean } \\
\text { Square }\end{array}$ & $\mathrm{F}$ & Sig. & $\begin{array}{c}\text { Partial } \\
\text { Eta } \\
\text { Squared }\end{array}$ \\
\hline Intercept & 151.875 & 1 & 151.88 & 1156.51 & 0 & 0.952 \\
\hline Condition & 0.008 & 1 & 0.008 & 0.063 & 0.802 & 0.001 \\
\hline Error & 7.617 & 58 & 0.131 & & & \\
\hline
\end{tabular}

Note. Measure: benefits. 
Test of Hypothesis 3: Participants' confidence of condom use will increase after 4 week exposure to the social media campaign.

Similarly, results from a Mixed ANOVA did not reveal a statistically significant interaction between time and condition on a participants' perceived confidence of using condoms during his/ her next sex act. Tables 17 and 18 present with Mixed ANOVA results. Interpreting tests of within subject effects, time was not statistically significant. Interpreting tests of between subject effects, condition was not statistically significant in this sample.

Table 17.

Tests of Within-Subjects Effects for reported confidence of condom use during sexual act

\begin{tabular}{llccccccc}
\hline \multirow{2}{*}{ Source } & & $\begin{array}{c}\text { Type III } \\
\text { Sum of } \\
\text { Squares }\end{array}$ & df & $\begin{array}{c}\text { Mean } \\
\text { Square }\end{array}$ & F & Sig. & $\begin{array}{c}\text { Partial } \\
\text { Squared }\end{array}$ \\
\cline { 3 - 9 } Time & Sphericity Assumed & 0.033 & 1 & 0.033 & 0.279 & 0.599 & 0.005 \\
& Greenhouse-Geisser & 0.033 & & 1 & 0.033 & 0.279 & 0.599 & 0.005 \\
& Huynh-Feldt & 0.033 & 1 & 0.033 & 0.279 & 0.599 & 0.005 \\
& Lower-bound & 0.033 & 1 & 0.033 & 0.279 & 0.599 & 0.005 \\
Time* & Sphericity Assumed & 0.033 & 1 & 0.033 & 0.279 & 0.599 & 0.005 \\
Condition & Greenhouse-Geisser & 0.033 & 1 & 0.033 & 0.279 & 0.599 & 0.005 \\
& Huynh-Feldt & 0.033 & 1 & 0.033 & 0.279 & 0.599 & 0.005 \\
& Lower-bound & 0.033 & 1 & 0.033 & 0.279 & 0.599 & 0.005 \\
& Sphericity Assumed & 6.933 & 58 & 0.12 & & & \\
Error(Time) & Greenhouse-Geisser & 6.933 & 58 & 0.12 & & & \\
& Huynh-Feldt & 6.933 & 58 & 0.12 & & & \\
& Lower-bound & 6.933 & 58 & 0.12 & & & \\
\hline
\end{tabular}

Note. Measure: Confidence. 
Table 18.

Tests of Between-Subjects Effects for reported confidence of condom use during sexual act

\begin{tabular}{|c|c|c|c|c|c|c|}
\hline Source & $\begin{array}{l}\text { Type III } \\
\text { Sum of } \\
\text { Squares }\end{array}$ & $\mathrm{df}$ & $\begin{array}{l}\text { Mean } \\
\text { Square }\end{array}$ & $\mathrm{F}$ & Sig. & $\begin{array}{c}\text { Partial } \\
\text { Eta } \\
\text { Squared }\end{array}$ \\
\hline Intercept & 187.5 & 1 & 187.5 & 463.423 & 0 & 0.889 \\
\hline Condition & 0.033 & 1 & 0.033 & 0.082 & 0.775 & 0.001 \\
\hline Error & 23.467 & 58 & 0.405 & & & \\
\hline
\end{tabular}

Note. Measure: Confidence.

Test of Hypothesis 4: Participants' frequency of protected sexual acts will increase after 4 week exposure to the social media campaign.

Table 19 presents descriptive statistics for frequency of protected sex acts outcome variables. Descriptive statistics for condom use indicate slight increases in positive preventive behavior (wearing condoms) from baseline to follow up among participants in the exposure group.

Table 19.

Descriptive Statistics for frequency of protected sex acts

\begin{tabular}{lccc}
\hline & \begin{tabular}{c} 
Condition \\
\cline { 2 - 3 } Condom use with primary partner
\end{tabular} & $\begin{array}{c}\text { Baseline } \\
\text { Mean(SD) }\end{array}$ & $\begin{array}{c}\text { Follow up } \\
\text { Mean (SD) }\end{array}$ \\
\cline { 2 - 4 } & Control & $1.63(1.42)$ & $2.17(1.77)$ \\
Condom use with someone other & Exposure & $2.24(1.44)$ & $2.00(1.64)$ \\
than a primary partner & Control & $1.61(1.50)$ & $1.25(1.58)$ \\
& Exposure & $1.50(1.36)$ & $1.30(1.42)$ \\
\hline
\end{tabular}

Note. $1=$ always, $4=$ never

Results from a Mixed ANOVA did not reveal a statistically significant interaction between time and condition on a participants' use of condoms during his/ her next sex act 
when having sex with a current primary partner. Results indicate that those participants in the exposure group who reported frequency of condom use with a primary partner were more likely to increase positive preventive behaviors over time when compared to those in the control group, yet this interaction was not statistically significant. The interaction approached significance $(\mathrm{p}=.075)$.

Table 20.

Tests of Within-Subjects Effects for condom use with primary partner

\begin{tabular}{llrrrrr}
\hline \multirow{2}{*}{ Source } & Sphericity Assumed & $\begin{array}{c}\text { Type III } \\
\text { Sum of } \\
\text { Squares }\end{array}$ & df & $\begin{array}{c}\text { Mean } \\
\text { Square }\end{array}$ & F & Sig. \\
\cline { 3 - 7 } Time & Greenhouse-Geisser & 0.972 & 1 & 0.972 & 1.065 & 0.31 \\
& Huynh-Feldt & 0.972 & 1 & 0.972 & 1.065 & 0.31 \\
& Lower-bound & 0.972 & 1 & 0.972 & 1.065 & 0.31 \\
Time * & Sphericity Assumed & 3.09 & 1 & 3.09 & 3.384 & 0.075 \\
Condition & Greenhouse-Geisser & 3.09 & 1 & 3.09 & 3.384 & 0.075 \\
& Huynh-Feldt & 3.09 & 1 & 3.09 & 3.384 & 0.075 \\
& Lower-bound & 3.09 & 1 & 3.09 & 3.384 & 0.075 \\
Error(Time) & Sphericity Assumed & 29.219 & 32 & 0.913 & & \\
& Greenhouse-Geisser & 29.219 & 32 & 0.913 & & \\
& Huynh-Feldt & 29.219 & 32 & 0.913 & & \\
\hline & Lower-bound & 29.219 & 32 & 0.913 & & \\
\hline
\end{tabular}

Note. Measure: Condom Use with primary partner.

Tables 20 and 21 present with Mixed ANOVA results. Interpreting tests of within subject effects, time was not statistically significant. Interpreting tests of between subject effects, condition was not statistically significant in this sample. 
Table 21.

Tests of Between-Subjects Effects for condom use with

primary partner

\begin{tabular}{lrrrrr}
\hline \multirow{2}{*}{ Source } & $\begin{array}{c}\text { Type III } \\
\text { Sum of }\end{array}$ & df & $\begin{array}{c}\text { Mean } \\
\text { Square }\end{array}$ & F & \multicolumn{1}{c}{ Sig. } \\
& Squares & & & & \\
\cline { 2 - 6 } Intercept & 267.775 & 1 & 267.775 & 67.281 & 0 \\
Condition & 0.128 & 1 & 0.128 & 0.032 & 0.859 \\
Error & 127.358 & 32 & 3.98 & & \\
\hline
\end{tabular}

Note. Measure: Condom Use with primary partner.

Finally, results from a Mixed ANOVA revealed no statistical significance in the interaction between time and condition on a participants' use of condoms during his/ her next sex act when having sex with someone other than a current primary partner. Results suggest that mean changes in scores were equal over the study period. Thus, participant responses from those in the exposure group did not differ significantly from those in the control group. Tables 22 and 23 present with Mixed ANOVA results. Interpreting tests of within subject effects, time was not statistically significant. Interpreting tests of between subject effects, condition was not statistically significant in this sample. Findings from the mixed ANOVA support the null hypothesis where means between groups were equal. 
Table 22.

Tests of Within-Subjects Effects of condom use with someone other than a primary partner

\begin{tabular}{|c|c|c|c|c|c|c|}
\hline Source & & $\begin{array}{l}\text { Type III } \\
\text { Sum of } \\
\text { Squares }\end{array}$ & df & $\begin{array}{l}\text { Mean } \\
\text { Square }\end{array}$ & $\mathrm{F}$ & Sig. \\
\hline \multirow{5}{*}{ Time } & Sphericity Assumed & 0.263 & 1 & 0.263 & 0.382 & 0.547 \\
\hline & Greenhouse-Geisser & 0.263 & 1 & 0.263 & 0.382 & 0.547 \\
\hline & Huynh-Feldt & 0.263 & 1 & 0.263 & 0.382 & 0.547 \\
\hline & Lower-bound & 0.263 & 1 & 0.263 & 0.382 & 0.547 \\
\hline & Sphericity Assumed & 0.263 & 1 & 0.263 & 0.382 & 0.547 \\
\hline Time * & Greenhouse-Geisser & 0.263 & 1 & 0.263 & 0.382 & 0.547 \\
\hline \multirow[t]{2}{*}{ Condition } & Huynh-Feldt & 0.263 & 1 & 0.263 & 0.382 & 0.547 \\
\hline & Lower-bound & 0.263 & 1 & 0.263 & 0.382 & 0.547 \\
\hline \multirow{4}{*}{ Error(Time) } & Sphericity Assumed & 8.938 & 13 & 0.688 & & \\
\hline & Greenhouse-Geisser & 8.938 & 13 & 0.688 & & \\
\hline & Huynh-Feldt & 8.938 & 13 & 0.688 & & \\
\hline & Lower-bound & 8.938 & 13 & 0.688 & & \\
\hline
\end{tabular}

Note. Measure: Condom Use Other than Primary Partner.

Table 23.

Tests of Between-Subjects Effects of condom use with someone other than primary partner

\begin{tabular}{lrrrrr}
\hline \multirow{2}{*}{ Source } & $\begin{array}{l}\text { Type III } \\
\text { Sum of }\end{array}$ & df & $\begin{array}{c}\text { Mean } \\
\text { Square }\end{array}$ & F & Sig. \\
& Squares & & & & \\
\cline { 2 - 6 } Intercept & 45.015 & 1 & 45.015 & 17.39 & 0.001 \\
Condition & 0.215 & 1 & 0.215 & 0.083 & 0.778 \\
Error & 33.652 & 13 & 2.589 & & \\
\hline
\end{tabular}

Note. Measure: Condom Use Other than Primary Partner.

\section{Summary}

Across the three social networking prevention sites, Instagram was the most popular and active social networking sites among users. Instagram generated the most interactivity and user participation. Results suggests that campaign inputs were largely 
based in health education and news topics (83\%), in line with campaign goals. Results also indicate that those posts that were most successful included human interest in post elements.

In order to complement the review of the prevention campaign's reach and engagement online, data from a randomized sample of participants who were either exposed to the social networking site for a 30 day period or were not, were included to assess effectiveness on health related outcomes. Three binary logistic regressions were performed in order to accommodate binary outcome variables for awareness of HIV prevention and testing services in the community and university. No statistically significant predictors were found ( $\mathrm{p}>.05)$, thus exposure to the social networking campaign was not predictive of an improvement of awareness outcomes. Using McNemar's test statistics, participants across groups showed statistically significant increases in awareness of HIV prevention services in the university, suggesting positive improvements across conditions although not directly attributable to social networking site exposure. Participant's confidence of using condoms and perceived benefits of using condoms were high across groups at baseline and remained constant at follow up. In reported condom use, participants in the exposure group who had a primary partner were more likely to report positive change in condom use behavior, although the interaction between time and group was not statistically significant, as shown in the results from a mixed ANOVA. 


\section{CHAPTER V. DISCUSSION}

This chapter discusses the quantitative and qualitative findings, beginning with Specific Aim 1, providing a systematic examination of the social media based campaign content. Specific Aim 2, determines whether exposure to the social media campaign had an impact on a participants' knowledge of locally available HIV prevention services, his/her perceived benefits and confidence of condom use, and his/her condom use, utilizing a sample of randomly assigned participants. Implications, limitations, recommendations, and conclusions are also presented.

\section{Aim 1 Discussion}

Findings from Specific Aim 1 reveal that Instagram was the platform that had the most interactivity over the study period. Users commented on posts and made personally salient contributions to the conversations surrounding prevention. Instagram minimized barriers between researchers and young adults and messaging became participantinvolved. Facebook was the least active site among users in this study in terms of interactivity. Findings indicate common threads among those posts that were most successful in increasing user interactivity. The posts that were among the most successful across multiple sites had notable commonalities. These top posts were most successful because they either a) leveraged attention generated by individuals' social networking accounts who were actively a part of the campaign efforts or b) had an element of a human story or human interest embedded in the post. This was either in the form of tagging individuals in posts, using images that were of people, or relaying a relatable human sentiment for the target audience. Findings suggest incorporating such elements into online posts in order to drive interactivity. 
It is also important to note the reconceptualization of the human interest label for the qualitative content analysis in social networking efforts. After coding and analysis, it was determined that memes or other images imitating people or personalities with thoughts and motivations classified as human interest, as per the definition provided by Ramanadhan (2013), "content that tells a personal story about a given health topic or public health initiative" (p. 5). Reconceptualizing the human interest label might be necessary when considering content intended for online young adult audiences, primarily on social networking sites that are popularized as a result of personal profile capabilities. Using photographs, graphics, or memes that tell a story, share an opinion, or a feeling, may be appropriately labeled as human interest, even when they do not directly reflect opinions from a living or actual person. It is arguable that this style of communication is popularly used among young adults in order to provide an extra layer of anonymity that online user's desire. This could be particularly true when dealing with sensitive topics such as sexual behaviors, sexual health, and drug and alcohol use.

It is also notable that none of the posts released by the campaign during this study period were specifically geared towards a Hispanic population. That is, none of the posts mentioned the word "Hispanic" or "Latino" or used any Spanish language words. This is attributed to the findings from four focus groups that were conducted at the start of the community based project (2015), as a part of the parent study. Findings revealed that the young adults in the community at hand thought of themselves as unique in terms of their age, not their ethnicity. Incorporating these findings, researchers employed messaging that was tailored more towards age then ethnic origin. For example, posts over the study period included facts specific to young adults, college drinking, and spring break. In this 
way, posts were tailored for the population of focus. This unique adaptation based on focus groups findings presents is a progressive consideration from the traditional interpretation of cultural tailoring for audiences in HIV prevention.

Metric data utilized in Specific Aim 1 was exported from the different social networking platform sites. Because online activity leaves behind data that is collected and aggregated automatically from site to site, this data collection process occurred in a relatively effortless manner (Tufekci, 2014). This seemingly effortless data collection process on the different social networking sites, though, must be considered with caution. Overlap of terms with differing definitions can present as a challenge in both interpreting results and translating result implications from research to research (Tufekci, 2014). While there is a plethora of social media metric data available online, perhaps more useful than collecting all of the available data is identifying the metrics that are most relevant to program goals and considering consistent measurements across multiple sites, as was done in this research. This allows for a more streamlined use and interpretation of metric data, necessary for evaluation research advancement.

In this research, reach and interactivity were strategically chosen as engagement metrics based on the available social media evaluation literature in health promotion and based on exported data sets available through the social networking sites. It is important to note that the definitions for key metrics used in this research are different from the data directly exported from social networking sites. In social media based evaluation research, reach refers to the number of users or followers on a particular site (Lim, Wright, et al., 2016). This is different from what is readily available through analytics provided on Instagram. On Instagram analytics, reach refers to the number of unique accounts who 
saw any of your post or story. Thus, consideration must be given to how each platform's analytic variables are operationalized in order to ensure accurate reporting and interpretation of findings. It is necessary for researchers to be clear about how they are defining metrics in their reports and special attention should be placed on such information when interpreting the results of others. Clear distinction must be made in order to address which engagement results are reported, as was done in the study (e.g., Table 2).

\section{Aim 2 Discussion}

When considering social media as a component of larger environmental prevention efforts, the ability to single out the effects of exposure to a social networking site is particularly challenging. As is reflected in the findings pertaining to the analysis for Specific Aim 2, both groups in the randomized controlled conditions improved significantly over time, specifically regarding awareness of prevention services on campus. It is possible that other project strategies, as noted below, have influenced this positive preventive increase, though we cannot attribute this improvement specifically to exposure to the online social networking site, based on the data that is available from this sample.

The efforts of this community based partnership incorporated multiple environmental prevention strategies and channels, social networking sites being just one of many. Therefore, participants who were involved in the study may have been exposed to other environmental strategies such as the use of lawn signs, billboards, flyers, etc. with campaign prevention messaging. This multi-channel exposure presents as a challenge and suggests that the considered sample should not be thought of as a closed 
system, but rather part of a large system where information flow and influence is present through multiple avenues. This is especially true in an age and a generation that is already prone to exchanging and receiving information through multiple outlets, alternating between social networking sites, other online media, mobile phone communication, texting, face-to-face and other methods of interaction and information exchange. In applying a system approach when interpreting findings, researchers acknowledge this possibility of exposure contamination in a desired experimental conditional design.

Findings also suggest that outcome variables should continue to capture information, motivation and behavior outcome variables as each present as key constructs in successful HIV preventive behavior change (Fisher, Fisher, Williams, \& Malloy, 1994). Results from this research indicate that participants across conditions increased awareness of prevention services and were already highly confident in using condoms and perceived condom use to be very beneficial. Although there was no statistically significant interaction between time and condition for reported condom use, among those participants who had a primary partner, the interaction approached significance, making this an interesting consideration for continued research.

\section{Limitations of method and sample}

Research focused on social media based efforts presents various limitations given the rapidly changing practices, uses, and expansion of opportunities that are present online, paired with the considerable lag in its evaluation. Specific Aim 1 involved analyzing a social media campaign that is unique to a specific city, school, year, and CBO partnership. Thus, the replicability and generalizability of these findings may be limited. This researched focused on what was uniquely posted on this prevention 
campaign's social networking sites. This campaign may differ dramatically from other health promotional campaigns because of its location and tailoring. Still, the researchers believe that the results are useful to other researchers in the field and provide guidance for the future use and evaluation of tailored social media campaigns in prevention efforts.

It is important to note that all those individuals who were eligible to participate in the research survey were individuals who had already been tested for HIV. Recruitment of participants was solely focused on free HIV/ STD testing. Therefore, the sample of participants in this study was comprised of individuals who had already engaged in a positive HIV preventive behavior (i.e., HIV rapid testing). These individuals may have already been more motivated or comfortable performing HIV preventive behaviors (i.e., HIV testing) than the general population. Because of this, there is potentially some selfselection bias in our study and this likely contributed to responses that indicated both high confidence of using condoms and high-perceived benefits of condom use at both baseline and follow up.

The survey data collected at follow up was collected after only a 4 week period. Longer lasting effects of the social media campaign were unstudied. Furthermore, "dosage" of the messaging was very small, which may have made effects harder to detect. Future campaigns could consider increasing the "dosage" (i.e., frequency and cross platform saturation) of messaging. Last, the sample considered for Specific Aim 1 and the sample considered for Specific Aim 2, while overlapping, were not equivalent. Because of this, we cannot say that all the interactivity reported in Specific Aim 1 came from participants in Specific Aim 2. Tightly controlled experiments may increase the opportunity for detecting influence of exposure, yet the researchers believe offering a 
mixed sample method for this study was more appropriate, in order to foster broad uptake and reach of campaign messaging.

\section{Ethical Considerations}

Although there are many advantages to online research for both the researcher and participants, there are challenges related to ethical considerations and the protection of human subjects. Because of the nature of social media, researchers have a certain lack of control over the data collection setting and must prepare for unexpected case scenarios including the risk of misinformation. As such, researchers were prepared to deal with misinformation in a consistent manner. Researchers have an opportunity to add value to online conversation by providing accurate information and feedback, but this, too, doubles as an obligation. During this study period, no user comments, posts, or responses were taken down by researchers. Because of the nature of social media and networking that promotes and accepts honesty, the researchers avoided modification of user interactivity in order to keep the online environment as natural as possible. This included the risk of misinformation from other users (Veinot et al., 2011). Future research should include analyzing comments for topic (i.e., conducting sentiment analysis). Such research could inform researchers about what kinds of effects posts are having, for example, whether discussion is supportive of prevention messaging, in conflict, or otherwise.

In order to plan for resolutions of misinformation or any other ethical dilemma, researchers should be prepared with a panel or advisory board designated to meet if an issue were to arise. Researchers should hold the right to take down information during extreme cases where an action is inappropriate or deemed to be offensive. The advisory board for the study at hand involved researchers who formed and developed the online 
campaign, community partners, members involved in the similar prevention work in the university, as well as other researchers who were not actively involved in the implementation of the campaign. While no ethical dilemmas arose during this study period, researchers were prepared in the event that one did occur.

\section{Significance to Social Work}

As social media—specifically, social networking sites— attract users across all segments of the U.S. population, especially racial and ethnic minorities, it has become increasingly important for public health and social worker researchers to evaluate how best to leverage social media for health promotion and disease prevention initiatives, and ultimately assess their impact on health outcomes (Kontos et al., 2010). Of particular interest to social work practitioners and researchers is the ability to choose an avenue of communication that complements the lives of ethnic minority young adults. It is important for social workers to acknowledge the realities in which their clients exist and live today. By meeting young adults where they are, in this case, online, in online communities where they actively communicate, receive information, and share information, social workers are adapting prevention efforts in a way that supports young adult behavior and their consumption of information. By acknowledging that online is, indeed, a new and real environmental context in which young adults exist, researchers and service providers are applying a social work perspective that both supports young adult behavior and highlights its strengths and opportunities for positive impact.

Furthermore, by offering social media based intervention strategies, social work practitioners and researchers offer young adults HIV prevention programming in a manner by which participants can remain autonomous. In this way, participants have 
more authority and flexibility over the timing that they receive program content, the setting in which they receive content, and in their decision to interact or not interact with the content. These benefits make it an attractive platform for individuals to search and engage with information of sensitive topics. Additionally, by using such strategies, participants are given the opportunities for continuous consent. Participants can discontinue their involvement at any time, at no inconvenience to them. By selecting such an avenue, practitioners are encouraging participants to remain autonomous in their engagement and, thus, participants are less vulnerable to coercion (Pequegnat et al., 2007). This commitment to autonomy reflects a commitment to self-determination, identified in the National Association of Social Worker's (NASW) Code of Ethics (2008) as a primary responsibility to a client. In sum, while there are noted ethical risks, when used in thoughtful and systematic ways, social media can offer ethical benefits that include private, targeted messaging while actually minimizing ethical risks like privacy violations, recordability of private information, and coercion (Ems \& Gonzalez, 2016).

\section{Implications for Social Work Practice}

Reducing HIV related disparities and health inequities are at the forefront of a social worker's priorities. Research investigating the efficacy of utilizing social networking sites as avenues for health promotion guide social work researchers in their strategies to reducing the spread of HIV among ethnic minorities. The NASW Code of Ethics binds all social workers to a duty to protect social justice for all individuals, especially those who face oppression and who maintain cultural and ethnic diversity (NASW, 2008). Social workers strive to ensure access to health information, services, and resources, equality of opportunity, and meaningful participation in decision making. 
By providing relevant resources in a convenient way, social workers are working to increase access to treatment and care. The basic principles of utilizing social media based intervention strategies support these ethical standards of service provision.

Using such strategies is both an acknowledgement and a commitment to clients and their community. By engaging with people online, researchers are confirming that client opinions matter and that researcher's care and are listening (Heldman, Schindelar, \& Weaver, 2013). Social media functionality allows social workers to maximize interactions with the people they serve and allows for a more personalized avenue of information communications by being able to listen, respond, interact, and learn directly from populations of focus (Heldman, Schindelar, \& Weaver, 2013). Further, utilizing social media technologies allows the opportunity for interventions to be incorporated in people's daily routines and habits instead of being an extra burden on their already busy lives (Laranjo et al., 2014).

\section{Implications for Future Research}

The present research has contributed to a field of research that is referred to as being in the "Wild West" phase of evaluation (Ems \& Gonzalez, 2016, p. 1762). Extensive work is still required to improve and maximize the use of social media based strategies in health communication. To fully harness the benefits of using social networking sites in the dissemination of HIV prevention information, future implementation and research must include a continued push for the promotion of engagement online. This includes encouraging and soliciting users to share their stories, participate in message creation, and collaborate on ideas that can be shared on prevention campaign's social media sites. Promoting user-generated content will increase the 
authenticity and relevance of health messages and will be the method that harnesses the two-way flow of communication that is available. By engaging users to co-create content, authenticity of messages and trust can be improved and researchers and practitioners can capitalize on the capabilities of social media (Freeman, Potente, Rock, \& McIver, 2015).

In order to increase interactivity and engagement, it is recommended that motivated volunteers leverage their connections from their personal accounts to generate interactivity and reach. Recruiting motivated volunteers who can leverage their personal online connections with others appears to be more likely to generate interactivity then impersonalized messaging (Freeman, Potente, Rock, \& McIver, 2015). Furthermore, disseminating content that provides a story or a shared human sentiment may be most successful in increasing engagement. Additionally, partnering with organizations and people who already have established social media presence and following can improve reach and interactivity. These people or organizations can promote campaigns and influence others to share campaign content and take advantage of offline service offerings (Freeman, Potente, Rock, \& McIver, 2015). Other suggestions for increasing reach and interactivity include encouraging posting, sharing and tagging of photos by current users as well as creating incentives or prizes to increase followings and visibility (Veale et al., 2015).

While the prevention campaign at hand implemented consistent input across three social networking sites (i.e., Facebook, Instagram, and Twitter), it is important to recognize that each site has slightly different functions and features. Future campaign content should be tailored uniquely for the dissemination on each site. Instagram's strengths lie in the support of high quality, mobile photo uploads. Whereas, Twitter best 
supports the use of brief real-time, text-based updates. The inputs of the prevention campaign were seemingly more geared towards success on Instagram, with the incorporation of photos for each post, and, thus, generated more interactions on Instagram. Modifications can be made to better harness the strengths of each social networking site in order to increase engagement across multiple platforms. Considering the dearth of activity that took place on Facebook, the least active site over the study period, future research can consider focusing energy on the site that generates the most activity, rather than maintaining efforts on sites that have little following. Still, it is suggested that tailoring prevention messaging according to site would improve interactivity.

In order to keep up with young adult uses and preferences of social networking sites, it is recommended that researchers elicit feedback from the population of focus and incorporate findings into planning and implementation stages of campaign development. This can be done in the form of focus groups with the population of focus. It is also suggested that focus groups not only be conducted at the start of prevention programs, but rather, continuously, in order to keep up with the rapidly changing uses and preferences of social networking communication among young adults. In addition to using focus groups to better understand uses and preferences of social media technologies, focus groups can also be used to elicit feedback on how messages should be tailored to increase prevention adoption. As Hispanic young adults continue to be the fastest growing ethnic group in higher education, an accurate understanding of their attitudes and opinions surrounding HIV prevention messaging becomes increasingly critical to ensure a realistic and authentic impact in health communication. Increases in 
the number of native born Hispanics also suggest changes in the level of acculturation and subsequent cultural identity for the young adult Hispanic population in the U.S. Such changes require deliberate attention and consideration in the design and implementation of prevention campaigns.

It is also important to note that in order to be able to harness the potential of social networking sites, sufficient energy and preparation must be dedicated to the task in order to implement strategies in a responsible and high impact manner. One of the benefits of using social networking platforms to engage audiences is the ability for real time responses and dialogues. Without a staff member who is responsible for being actively focused and engaged on the site, this beneficial functionality becomes obsolete. Therefore, proper staffing is necessary for the successful implementation of such strategies. Just as in all efforts, time and effort must be dedicated in order for success. Social media based interventions are no exception. An active, ongoing effort is necessary to maintain efforts of online campaigns and to drive traffic to the site. Thus, although developing a successful social media campaign may be lower cost than a mass media campaign, it can be time and human resource intense because it requires ongoing content generation and interaction with users (Freeman, Potente, Rock, \& McIver, 2015). Appropriate allocation of resources should be a priority for successful campaigns.

Lastly, in terms of evaluation, research should continue to incorporate mixed method approaches. Whenever possible, social media data should be paired with other collected data such as the survey utilized in this study. By embedding different collected data sources (both quantitative and qualitative) into research questions, researchers can gather more formative and complete information which is critical in the formulation of 
evaluation knowledge (Creswell, 2013). Pairing social media data with surveys, interviews, or other traditional data collection methods helps balance the biases and shortcomings of each method in order to arrive at more complete analysis and understanding (Tufekci, 2014). This strategy will help researchers provide better clarity to implications between available metric datasets and desired behavioral outcome changes (Tufekci, 2014).

Finally, findings suggest that the use of social media maybe be more appropriately employed as a part of a comprehensive public health communication strategy rather than relying on social media based efforts alone. Social media can be used to enhance current efforts by increasing exposure to messaging but social media alone may not be sufficient. Findings suggest such strategies are most appropriately used in synergy with traditional methods of prevention and health promotion.

\section{Conclusions \& Recommendations}

Risks for HIV are heightened in college settings where individuals are likely to have multiple partners and inconsistent condom use. Coupled with an ethnic minority status and a location of high concentration of new incidences of HIV, Hispanic college students in a minority serving institution (MSI) in Miami, FL comprise a group that is ideally suited for the implementation of prevention messaging to decrease health disparities relating to HIV and to increase the health and well-being of marginalized populations in the United States. Although Hispanics now constitute the largest ethnic minority group in the U.S., they continue to experience serious health disparities across areas of public health, particularly HIV. 
The primary goal of the community-based social media campaign presented in this research, was to implement prevention communication efforts in an innovative and pioneering manner. This research is among the few reported interventions to date to evaluate the use of social media to accomplish HIV prevention goals utilizing an experimental design. Ultimately, the campaign aimed to relay useful and accurate information about HIV prevention in the local community in a way that was relevant and authentic for Hispanic young adults.

This study went beyond describing the potential application of social media, and offered a systematic overview and an exploratory health outcome analysis. Specifically, this research addressed gaps in the literature, by evaluating the impact of social media for health communication in a unique population, Hispanic young adults, and by assessing and exploring the effectiveness of social media for health communication and its impact on behavior change (Moorehead et al., 2013). While countless organizations and campaigns exist online, specifically, on social networking sites that are geared towards influencing a young adult audience, this study provides with a comprehensive analysis of such an effort in terms of reach, engagement, and effectiveness. Furthermore, this research supports the collaboration of public and private organizations in order to build and sustain the environmental prevention capacities needed in order to achieve a large scale, environmental response to eliminating health disparities. Educating the general public, specifically high risk groups, about prevention services and evidenced informed HIV prevention strategies is necessary to reduce, and ultimately, eliminate HIV infection.

This study sheds light on the success and opportunity that is available in using social media based strategies in implementing a tailored and participant informed 
prevention campaign. Results reflect how social media efforts can be successful in reaching specific target audiences (i.e., Hispanic young adults in Miami, FL) and how efforts can also be suited for tailored messaging (i.e., location specific, relevant timing, and developmentally appropriate). Last, this study provides an example of how social media based efforts can be used to complement biomedical and behavioral prevention efforts in order to ensure multipronged and multilevel efforts that address structural factors such as access to health information.

Findings offer guidance and directions for future and additional uses of social media, particularly social networking sites as an innovative way to engage diverse minority populations in health promotional goals. These findings help guide evidence informed social media prevention interventions focused on young adults at risk of HIV, specifically those identifying as Hispanic. Through this research, we have gained a better understanding of the relationship between social media based campaign efforts and specific outcomes in terms of reach, interactivity, and behavioral health outcomes. 


\section{REFERENCES}

Adzharuddin, N. A., \& Ramly, N. M. (2015). Nourishing healthcare information over Facebook. Procedia-Social and Behavioral Sciences, 172, 383-389.

Airhihenbuwa, C. O. (1995). Health and culture: Beyond the Western paradigm. Sage.

Alexa Internet, Inc. (2017). The top 500 sites on the web. An Amazon Company. Retrieved from https://www.alexa.com/topsites.

Arnett, J. J. (2000). Emerging adulthood: A theory of development from the late teens through the twenties. American psychologist, 55(5), 469.

Barnett, J. C., \& Vornovitsky, M. S. (2016). Health insurance coverage in the United States: 2015. US Census Bureau, Current Population Reports, Report, (P60-257).

Bennett, G. G., \& Glasgow, R. E. (2009). The delivery of public health interventions via the internet: Actualizing their potential. Annual Review of Public Health, 30, 273.

Boyd, D., \& Ellison, N. (2010). Social network sites: definition, history, and scholarship. IEEE Engineering Management Review, 3(38), 16-31.

Brown, A. (2015). U.S. immigrant population projected to rise, even as share falls among Hispanics, Asians. Pew Research Center. Retrieved from http://www.pewresearch.org/fact-tank/2015/03/09/u-s-immigrant-populationpprojected-to-rise-even-as-share-falls-among-hispanics-asians/

Bronfenbrenner, U. (1986). Ecology of the family as a context for human development: Research perspectives. Developmental Psychology, 22(6), 723.

Bull, S. S., Breslin, L. T., Wright, E. E., Black, S. R., Levine, D., \& Santelli, J. S. (2011). Case study: An ethics case study of HIV prevention research on Facebook: the Just/Us Study. Journal of Pediatric Psychology, 36(10), 1082-1092.

Bull, S. S., Levine, D. K., Black, S. R., Schmiege, S. J., \& Santelli, J. (2012). Social media-delivered sexual health intervention: a cluster randomized controlled trial. American Journal of Preventive Medicine, 43(5), 467-474.

Centers for Disease Control and Prevention. (2015). HIV among Latinos. Division of HIV/ AIDS Prevention. Retrieved from http://www.cdc.gov/hiv/pdf/risk_latino2.pdf

Centers for Disease Control and Prevention. (2015). Today's HIV/AIDS Epidemic. Division of HIV/ AIDS Prevention. Retrieved from 
http://www.cdc.gov/nchhstp/newsroom/docs/hivfactsheets/todaysepidemic508.pdf

Centers for Disease Control and Prevention. (2015). HIV/ AIDS Prevention Communication Branch. Division of HIV/ AIDS Prevention. Retrieved from https://www.cdc.gov/hiv/dhap/pcb/index.html

Centers for Disease Control and Prevention. (2015). Vital signs: HIV infection, testing, and risk behaviors among youths- United States. MMWR Mortal Weekly Report $2015 ; 64(12) ; 331$.

Centers for Disease Control and Prevention. (2016). HIV among Hispanics/ Latinos. National Center for HIV/AIDS, Viral Hepatitis, STD, and TB Prevention. Division of HIV/ AIDS Prevention. Retrieved from https://www.cdc.gov/hiv/pdf/group/racialethnic/hispaniclatinos/cdc-hivlatinos.pdf

Centers for Disease Control and Prevention. (2017). Health Disparities in HIV/AIDS, Viral Hepatitis, STDs, and TB. Retrieved from https://www.cdc.gov/nchhstp/healthdisparities/hispanics.html

Creswell, J. W., Plano Clark, V. L., Gutmann, M. L., \& Hanson, W. E. (2003). Advanced mixed methods research designs. Handbook of Mixed Methods in Social and Behavioral Research, 209, 240.

Creswell, J. W. (2013). Research Design: Qualitative, quantitative, and mixed methods approaches. Sage publications.

Duggan, M., Ellison, N., Lampe, C., Lenhart, A., \& Madden, M. (2015). Social Media Update: 2014. Pew Research Center. Retrieved from http://www.pewinternet.org/2015/01/09/social-media-update-2014/

Ems, L., \& Gonzales, A. L. (2016). Subculture-centered public health communication: A social media strategy. New Media \& Society, 18(8), 1750-1767.

Erikson, E. H. (1968). Youth and crisis. WW Norton \& Company, New York-London, 17.

Excelencia in Education (2015). The Condition of Latinos in Education: 2015 Fact Book. Excelencia in Education. Retrieved from https://www.nccpsafety.org/assets/files/library/The_Condition_of_Latinos_in_Ed ucation.pdf

Federal Interagency Forum on Child and Family Statistics. (2014). America's Young Adults: Special Issue, 2014. Washington, DC: U.S. Government Printing Office. Retrieved from http://www.childstats.gov/pdf/ac2014/YA_14.pdf 
Fisher, J. D., \& Fisher, W. A. (1992). Changing AIDS-risk behavior. Psychological Bulletin, 111(3), 455.

Fisher, J. D., Fisher, W. A., Williams, S. S., \& Malloy, T. E. (1994). Empirical tests of an Information-Motivation-Behavioral skills model of AIDS-preventive behavior with gay men and heterosexual university students. Health Psychology, 13(3), 238.

Florida Department of Health (2015). Florida HIV/AIDS Annual Report 2014. Retrieved from http://www.floridahealth.gov/diseases-and-conditions/aids/surveillance/epiprofiles/2014/hivaids-annual-morbidity-2014.pdf

Florida Department of Health. (2016). HIV Data Center. Retrieved from http://www.floridahealth.gov/diseases-andconditions/aids/surveillance/index.html

Florida Department of Health. (2016). HIV among Hispanics. Retrieved from http://www.floridahealth.gov/diseases-andconditions/aids/surveillance/_documents/fact-sheet/2015/2015-hispanic-factsheet.pdf

Freeman, B., Potente, S., Rock, V., \& McIver, J. (2015). Social media campaigns that make a difference: what can public health learn from the corporate sector and other social change marketers. Public Health Res Pract, 25(2), e2521517.

Fry, R. (2011). Hispanic College Enrollment Spikes, Narrowing Gaps with Other Groups. Pew Research Center. Retrieved from http://www.pewhispanic.org/2011/08/25/hispanic-college-enrollment-spikesnarrowing-gaps-with-other-groups/

Gibbons, M. C. (2005). A historical overview of health disparities and the potential of eHealth solutions. Journal of Medical Internet Research, 7(5).

Gold, J., Pedrana, A. E., Sacks-Davis, R., Hellard, M. E., Chang, S., Howard, S., ... \& Stoove, M. A. (2011). A systematic examination of the use of online social networking sites for sexual health promotion. BMC Public Health, 11(1), 583.

Glasgow, R. E. (2007). eHealth evaluation and dissemination research. American Journal of Preventive Medicine, 32(5), S119.

Greenwood, S., Perrin, A., \& Duggan, M. (2016). Social Media Update 2016. Pew Research Center. Retrieved from http://assets.pewresearch.org/wpcontent/uploads/sites/14/2016/11/10132827/PI_2016.11.11_Social-MediaUpdate_FINAL.pdf 
Grimley, D. M., Prochaska, G. E., Prochaska, J. O., Velicer, W. F., Galavotti, C., Cabral, R. J., \& Lansky, A. (1996). Cross-validation of measures assessing decisional balance and self-efficacy for condom use. American Journal of Health Behavior, 20(6), 406-16.

Heldman, A. B., Schindelar, J., \& Weaver III, J. B. (2013). Social media engagement and public health communication: implications for public health organizations being truly" social". Public Health Reviews, 35(1), 1.

Hill, C. E., Thompson, B. J., \& Williams, E. N. (1997). A guide to conducting consensual qualitative research. The Counseling Psychologist, 25, 517- 572.

Hoepfl, M. C. (1997). Choosing qualitative research: A primer for technology education researchers. Retrieved from http://scholar.lib.vt.edu/ejournals/JTE/v9n1/hoepfl.html

Hussar, W., \& Bailey, T. (2014). Projections of Education Statistics to 2022. U.S. Department of Education, Institute of Education Sciences. Retrieved at https://nces.ed.gov/pubs2014/2014051.pdf

IBM Corp. (2011). IBM SPSS Statistics for Windows, Version 20.0 [Computer software]. Armonk, NY.

Jaganath, D., Gill, H., K., Cohen, A., Carl, \& Young, S., D. (2012). Harnessing online peer education (HOPE): Integrating C-POL and social media to train peer leaders in HIV prevention. AIDS Care, 24(5), 593-600. doi:10.1080/09540121.2011.630355.

Jones, S. G., Patsdaughter, C. A., Jorda, M. L., Hamilton, M., \& Malow, R. (2008). SENORITAS: An HIV/Sexually transmitted infection prevention project for latina college students at a Hispanic-serving university. Journal of the Association of Nurses in AIDS Care, 19(4), 311-319. doi:http://dx.doi.org/10.1016/j.jana.2008.04.002

Johnston, L., O'Malley, P., Bachman, J., Schulenber, J., \& Patrick, M., Miech, R. (2015).Monitoring the Future: HIV/AIDS Risk and Protective Behaviors among Adults Ages 21 to 40 in the U.S. Retrieved from http://www.monitoringthefuture.org/pubs/monographs/mtf-hivaids_2011.pdf

Kann, L., Kinchen, S., Shanklin, S. L., Flint, K. H., Kawkins, J., Harris, W. A., Zaza, S. (2014). Youth risk behavior surveillance--United States, 2013. Morbidity and Mortality Weekly Report. Surveillance Summaries (Washington, D.C.: 2002), 63 Suppl 4, 1. 
Kontos, E. Z., Emmons, K. M., Puleo, E., \& Viswanath, K. (2010). Communication inequalities and public health implications of adult social networking site use in the United States. Journal of Health Communication, 15(sup3), 216-235.

Korda, H., \& Itani, Z. (2013). Harnessing social media for health promotion and behavior change. Health Promotion Practice, 14(1), 15.

Krogstad, J., Passel, J., \& Cohn, D. (2017). 5 facts about illegal immigration in the U.S. Pew Research Center. Retrieved from http://www.pewresearch.org/fact$\operatorname{tank} / 2017 / 04 / 27 / 5$-facts-about-illegal-immigration-in-the-u-s/

Krogstad, J., \& Lopez, M. (2014). Hispanic Nativity Shift. Pew Research Center. Retrieved from http://www.pewhispanic.org/2014/04/29/hispanic-nativity-shift/

Laranjo, L., Arguel, A., Neves, A. L., Gallagher, A. M., Kaplan, R., Mortimer, N., ... \& Lau, A. Y. (2014). The influence of social networking sites on health behavior change: a systematic review and meta-analysis. Journal of the American Medical Informatics Association, 22(1), 243-256.

Lim, M. S., Wright, C. J., Carrotte, E. R., \& Pedrana, A. E. (2016). Reach, engagement, and effectiveness: a systematic review of evaluation methodologies used in health promotion via social networking sites. Health Promotion Journal of Australia, 27(3), 187-197.

Lopez, M., \& Fry, R. (2013). Among recent high school grads, Hispanic college enrollment rate surpasses that of whites. Pew Research Center. Retrieved from http://www.pewresearch.org/fact-tank/2013/09/04/hispanic-college-enrollmentrate-surpasses-whites-for-the-first-time/

Maher, C. A., Lewis, L. K., Ferrar, K., Marshall, S., De Bourdeaudhuij, I., \& Vandelanotte, C. (2014). Are health behavior change interventions that use online social networks effective? A systematic review. Journal of Medical Internet Research, 16(2), e40.

Mann, L., Alonzo, J., Downs, M., Abraham, C., Miller, C., \& Reboussin, B. A. (2014). Innovations in HIV prevention research and practice through community engagement (pp. 135-160). S. D. Rhodes (Ed.). Springer New York.

Marín, B. V. (2003). HIV prevention in the Hispanic community: Sex, culture, and empowerment. Journal of Transcultural Nursing, 14(3), 186-192.

Mason, M., Benotsch, E. G., Way, T., Kim, H., \& Snipes, D. (2014). Text messaging to increase readiness to change alcohol use in college students. The Journal of Primary Prevention, 35 (1), 47-52. 
Moorhead, S. A., Hazlett, D. E., Harrison, L., Carroll, J. K., Irwin, A., \& Hoving, C. (2013). A new dimension of health care: systematic review of the uses, benefits, and limitations of social media for health communication. Journal of Medical Internet Research, 15(4), e85.

National Association of Social Workers (2008). Code of Ethics. Retrieved form https://socialwork.utexas.edu/dl/files/academic-programs/other/nasw-code-ofethics.pdf

National Institute on Drug Abuse. (2003). Preventing Drug Use among Children and Adolescents. Retrieved from https://www.drugabuse.gov/publications/preventingdrug-abuse-among-children-adolescents-in-brief/prevention-principles

Neiger, B. L., Thackeray, R., Burton, S. H., Giraud-Carrier, C. G., \& Fagen, M. C. (2012). Evaluating social Media's capacity to develop engaged audiences in health promotion settings. Health Promotion Practice, 14(2), 157.

Office of Management and Budget (1997). Revisions to the Standards for the Classification of Federal Data on Race and Ethnicity. Retrieved from https://www.whitehouse.gov/omb/fedreg_1997standards

Paek, H. J., Hove, T., \& Cole, R. T. (2013). A Multimethod Approach to Evaluating Social Media Campaign Effectiveness. In System Sciences (HICSS), 2013 46th Hawaii International Conference on (pp. 1570-1579).

Parsons, J. T., Halkitis, P. N., Bimbi, D., \& Borkowski, T. (2000). Perceptions of the benefits and costs associated with condom use and unprotected sex among late adolescent college students. Journal of Adolescence, 23(4), 377-391.

Patten, E. (2016). The Nation's Latino Population Is Defined by Its Youth. Pew Research Center. Retrieved from http://www.pewhispanic.org/2016/04/20/the-nationslatino-population-is-defined- by-its- youth/

Pequegnat, W., Rosser, B. S., Bowen, A. M., Bull, S. S., DiClemente, R. J., Bockting, W. O., ... \& Konstan, J. (2007). Conducting Internet-based HIV/STD prevention survey research: considerations in design and evaluation. AIDS and Behavior, 11(4), 505-521.

Perrin, A. (2015). Social Media Usage: 2005-2015. Pew Research Center. Retrieved from http://www.pewinternet.org/2015/10/08/social-networking-usage-2005-2015/

Phinney, J.S. (1990). Ethnic identity in adolescents and adults: review of research. Psychological Bulletin, 108(3), 499. 
Ramanadhan, S., Mendez, S. R., Rao, M., \& Viswanath, K. (2013). Social media use by community-based organizations conducting health promotion: A content analysis. BMC Public Health, 13, 1129.

Rotheram-Borus, M. J., Swendeman, D., \& Chovnick, G. (2009). The past, present, and future of HIV prevention: Integrating behavioral, biomedical, and structural intervention strategies for the next generation of HIV prevention. Annual Review of Clinical Psychology, 5, 143-167. doi:10.1146/annurev.clinpsy.032408.153530 [doi]

Sánchez, J., De La Rosa, M., \& Serna, C.,A. (2013). Project Salud: Efficacy of a community-based HIV prevention intervention for Hispanic migrant workers in south Florida. AIDS Education and Prevention: Official Publication of the International Society for AIDS Education, 25(5), 363.

Satterwhite, C. L., Torrone, E., Meites, E., Dunne, E. F., Mahajan, R., Ocfemia, M. C. B. \& Weinstock, H. (2013). Sexually transmitted infections among US women and men: prevalence and incidence estimates, 2008. Sexually Transmitted Diseases, 40(3), 187-193.

Sexuality Information and Education Council of the United States. (2012). Position statement on sexual health. Retrieved from http://www.siecus.org/index.cfm?fuseaction=Page.viewPage\&pageId=494\& parentI $\mathrm{D}=472$.

Smith, M., \& Denali, D. (2014). Social media in health education, promotion, and communication: Reaching rural Hispanic populations along the USA/Mexico border region. Journal of Racial and Ethnic Health Disparities, 1(3), 194.

Strauss, A., \& Corbin, J. (1998). Basics of qualitative research: Techniques and procedures for developing grounded theory. Sage Publications, Inc.

Substance Abuse and Mental Health Services Administration. (2016). Prevention Approaches. Retrieved at http://www.samhsa.gov/capt/practicing-effectiveprevention/prevention-approaches

Sussman, S., \& Arnett, J. J. (2014). Emerging adulthood: developmental period facilitative of the addictions. Evaluation \& the health professions. Retrieved at http://ehp.sagepub.com/content/early/2014/02/02/0163278714521812.full.pdf

Taylor, P., Gonzalez-Barrera, A., Passel, J., \& Lopez, M. (2012). An Awakened Giant: The Hispanic Electorate is Likely to Double by 2030. Retrieved from http://www.pewhispanic.org/2012/11/14/an-awakened-giant-the-hispanicelectorate-is-likely-to-double-by-2030/ 
Thackeray, R., Neiger, B. L., Hanson, C. L., \& Mckenzie, J. F. (2008). Enhancing promotional strategies within social marketing programs: Use of web 2.0 social media. Health Promotion Practice, 9(4), 338.

Thackeray, R., Neiger, B. L., Smith, A. K., \& Van Wagenen, S. B. (2012). Adoption and use of social media among public health departments. BMC Public Health, 12(1), 242.

Thomas, T. L., Yarandi, H. N., Dalmida, S. G., Frados, A., \& Klienert, K. (2015). Crosscultural differences and sexual risk behavior of emerging adults. Journal of Transcultural Nursing, 26(1), 64 .

Tienda, M., \& Mitchelle, F. (2006). Hispanics and the Future of America. Introduction: Epluribus Plures or E Pluribus Unum? Retrieved from http://www.ncbi.nlm.nih.gov/books/NBK19892/

Tufekci, Z. (2014). Big Questions for Social Media Big Data: Representativeness, Validity and Other Methodological Pitfalls. ICWSM, 14, 505-514.

Umaña-Taylor, A. J., Quintana, S. M., Lee, R. M., Cross, W. E., Rivas-Drake, D., Schwartz, S. J., ... \& Seaton, E. (2014). Ethnic and racial identity during adolescence and into young adulthood: An integrated conceptualization. Child Development, 85(1), 21-39.

United States Census Bureau (2016). Miami-Dade QuickFacts. Retrieved from https://www.census.gov/quickfacts/fact/table/miamidadecountyflorida/RHI72521 6

U.S. Census Bureau. (2016). Hispanic Heritage Month 2016. Retrieved from https://www.census.gov/newsroom/facts-for-features/2016/cb16-ffl6.html

U.S. Department of Education. (2012). Degrees conferred by sex and race: The Condition of Education 2012. Retrieved from https://nces.ed.gov/fastfacts/display.asp?id=72

U.S. Department of Health and Human Services. (2013). National standards for culturally and linguistically appropriate services in health and health care: A blueprint for advancing and sustaining CLAS policy and practice. Office of Minority Health. Retrieved from https://www.thinkculturalhealth.hhs.gov/pdfs/EnhancedCLASStandardsBlueprint. pdf

U.S. Department of Health and Human Services \& Office of Disease Prevention and Health Promotion. (2010). Healthy people 2020. 
U.S. Department of Health and Human Services. (2011). Health Equity and Disparities. Retrieved from http://minorityhealth.hhs.gov/npa/templates/browse.aspx?lvl=1\&lvlid=34

U.S. Department of Health and Human Services. (2013). AIDS.gov U.S. Statistics. Retrieved from http://aids.gov/hiv-aids-basics/hiv-aids-101/statistics/

Veale, H. J., Sacks-Davis, R., Weaver, E. R., Pedrana, A. E., Stoové, M. A., \& Hellard, M. E. (2015). The use of social networking platforms for sexual health promotion: identifying key strategies for successful user engagement. BMC Public Health, 15(1), 85.

Vega, W. A., Rodriguez, M. A., \& Gruskin, E. (2009). Health disparities in the Latino population. Epidemiologic Reviews, 31(1), 99-112.

Veinot, T. C., Campbell, T. R., Kruger, D., Grodzinski, A., \& Franzen, S. (2011). Drama and danger: The opportunities and challenges of promoting youth sexual health through online social networks. AMIA ...Annual Symposium Proceedings / AMIA Symposium, 2011, 1436.

Voisin, D., Shiu, C., Chan Tack, A., Krieger, C., Sekulska, D., \& Johnson, L. (2013). In their own words: Racial/ethnic and gender differences in sources and preferences for HIV prevention information among young adults. AIDS Care, 25(11), 1407.

Wagner, E. F. (2009). Improving treatment through research: Directing attention to the role of development in adolescent treatment success. Alcohol Research \& Health, 32(1), 67.b

Warner, L. A., Valdez, A., Vega, W. A., De la Rosa, M., Turner, R. J., \& Canino, G. (2006). Hispanic drug abuse in an evolving cultural context: An agenda for research. Drug and Alcohol Dependence, 84, S8-S16.

World Health Organization (2017). Global Health Observatory data: HIV/AIDS. Retrieved from http://www.who.int/gho/hiv/en/

Wilson, K., Durantini, M. R., Albarracín, J., Crause, C., \& Albarracín, D. (2012). Reducing cultural and psychological barriers to Latino enrollment in HIVprevention counseling: Initial data on an enrollment meta-intervention. AIDS Care, 25(7), 881.

Yager, A. M., \& O'Keefe, C. (2012). Adolescent use of social networking to gain sexual health information. The Journal for Nurse Practitioners, 8(4), 294-298. 
Young, S. D., Cumberland, W. G., Lee, S. J., Jaganath, D., Szekeres, G., \& Coates, T. (2013). Social networking technologies as an emerging tool for HIV prevention: a cluster randomized trial. Annals of internal medicine, 159 (5), 318-324.

Zeglin, R. J., \& Stein, J. P. (2015). Social determinants of health predict state incidence of HIV and AIDS: A short report. AIDS Care, 27(2), 255. 
APPENDICES 


\section{Appendix A}

\section{Copy of Assessment}

Baseline Survey

ID \#

This survey will take about 15 minutes to complete. Please answer each item as honestly as you can. This is not a test, there are no right or wrong answers. Your information will be kept private and will be protected by the researchers. Research records will be stored securely and only the research team will have access to the records. You will receive $\$ 10$ cash after completing the survey.

1. Where were you born? (circle one)

$\begin{array}{lllll}\text { U.S. } & \text { Puerto Rico } & \text { Cuba } & \text { Venezuela } & \text { Colombia } \\ \text { Mexico } & \text { Dominican Republic } & \text { Peru } & \text { Argentina } & \text { Chile }\end{array}$

Other:

Puerto Rico

2. How old were you when you came to the US? (check one)

$\square$ N/A

$\square 10$ or younger

$\square \quad 11$

$\square \quad 12$

ㄴ 13

$\square \quad 14$

$\square \quad 15$

$\square 16$

$\square \quad 17$

$\square \quad 18$ or older

3. What is your age?

4. What best describes your Hispanic ancestry? (circle all that apply)

$\begin{array}{llll}\text { Puerto Rican } & \text { Cuban } & \text { Venezuelan } & \text { Colombian } \\ \text { Dominican } & \text { Peruvian } & \text { Argentine } & \text { Chilean }\end{array}$

Dominican

Peruvian Argentine

Chilean

Mexican

Other:

5. What is your preferred language? (check one)

$\square$ English all the time

(a) English most of the time

English/ Spanish equally

(1) Spanish most of the time

- Spanish all the time

6. What best describes your current housing status?

$\square$ Campus Residence Hall

F Fraternity or Sorority House

$\square$ Other University Housing

- Parent/ Guardian home

$\square$ Independent Apartment/ Home Rental

$\square$ Other:

7. What is your current marital status? (check one)

$\square$ Single

$\square$ Living Together/ Cohabitating

- Married

$\square$ Civil Union/ Partnership

$\square$ Separated 
Divorced

$\square$ Widowed

8. Sexual orientation- Please check the description that best fits how you think about yourself:

$\square$ Heterosexual (Straight)

$\square$ Mostly heterosexual (Straight), but somewhat attracted to people of your own sex

$\square$ Bisexual- attracted to men and women equally

$\square$ Mostly homosexual (Gay/ Lesbian), but somewhat attracted to people of the opposite sex

$\square$ Homosexual (Gay/ Lesbian)

$\square$ Other

9. What sex were you assigned at birth on your original birth certificate ? Male Female

10. Do you consider yourself to be transgender? Yes

No

11. How important is religion to you? Not at all important Fairly unimportant Fairly important Very important

12. Have you ever been tested for HIV prior to today?

Yes

No

13. Have you been tested for HIV in the past year?

Yes

No

14. If this was your first time being tested, why have you NOT been tested before? (select all that apply)

$\square \quad$ N/A

Not likely to have HIV infections

$\square$ Afraid to find out that I am infected

$\square$ Prefer not to think about HIV

$\square$ Do not like needles or blood drawing

$\square$ Worried that test results would not remain confidential

A Afraid of losing job, family, housing, friends if found to be infected

Not sure how to tell spouse or other sexual partner if infected

$\square$ Do not know where to be tested and counseled

$\square$ Other:

15. Do you know where you can get tested for HIV at FIU? Yes No

16. Do you know where you can get tested for HIV in Miami-Dade County? Yes

No

17. Are you aware of any HIV/AIDS prevention programs at FIU? Yes No

18. Are you aware of any HIV/AIDS prevention programs in Miami-Dade County? Yes No

19. What is your HIV status? (circle one) Positive Negative Don't know 
20. In the past year, has your sex partner or partners been: Have not been sexually active in the past year Exclusively male Both male and female

21. Do you have a current primary partner?
Yes
No
Don't Know

If yes, in the past year, when you had sex with your current primary partner, how often did you use condoms?

N/A Never Almost never Sometimes Almost every time Always

22. In the past year, when you had sex with someone other than your current primary partner, how often did you use condoms?

N/A Never Almost never Sometimes Almost every time Always

23. In the past year, with how many different people (other than your current primary partner if you have one) have you had vaginal sexual intercourse?

$\begin{array}{lllllllllll}0 & 1 & 2 & 3 & 4 & 5 & 6 & 7 & 8 & 9 & 10 \text { or greater }\end{array}$

24. In the past year, with how many different people (other than your current primary partner if you have one) have you had anal sexual intercourse?

$\begin{array}{lllllllllll}0 & 1 & 2 & 3 & 4 & 5 & 6 & 7 & 8 & 9 & 10 \text { or greater }\end{array}$

25. In the past year, how often did you have unprotected sex while drinking or using drugs? Never Almost never Sometimes Almost every time Always

26. In the past year, how often did you get into a sexual situation that you later regretted because you had been drinking?

Never Almost never Sometimes Almost every time Always

27. In the past year, how often did you get into a sexual situation that you later regretted because you had been using drugs?

Never Almost never Sometimes Almost every time Always

28. The advantages/benefits of using condoms during sexual intercourse are:
Not at all important
Fairly unimportant
Fairly important
Very important

29. Indicate how confident you are that you could use a condom correctly during your next sexual intercourse act:

Not at all confident Fairly unconfident Fairly confident Very confident

30. Do you and your friends ever talk about using condoms?

Yes No

31. Do your friends use condoms?

Yes

No 
32. How did you hear about HIV testing here at FIU? (check all that apply)

$\square$ Flyer

口 Palm Cards

L Lawn Sign

- Jumbo Screen

- Social media, please specify:

- Table event in GC

a Friend

$\square$ Fraternity

$\square$ Sorority

$\square$ Other, please specify:

33. What is your overall impression of the HIV testing service?

34. Where did your testing take place? (circle one)

Mobile testing unit Lab in AHC 5

A) Next time you get tested, would you prefer to get an HIV test in the mobile unit or in a classroom in AHC 5? Briefly explain your answer.

35. Did you come with someone else?

Yes

No

If yes, what is their relation to you:

36. Would you recommend us to your friends?

Yes

No

37. Please provide any suggestions that you may have for future HIV testing events. 
Social Media Campaign-

38. Have you ever visited the Cody the Camel page on any of the following (Check all that apply):
- Facebook
Instagram
$\square$ Twitter
$\square \quad$ N/A

39. Do you currently "like" or follow the Cody the Camel Facebook page?

Yes

No

a. If yes, how often do you read the page posts?

Never

Almost never

Sometimes

Very often

Always

N/A

b. If yes, how often do you think about the posts after you read them?

$\begin{array}{lllll}\text { Never } & \text { Almost never } & \text { Sometimes } & \text { Very often } & \text { Always }\end{array}$

c. If yes, what do you like about the posts?

d. If yes, what do you dislike about the posts?

As a part of this study, we will be sending you a similar online survey 1 month from now. This survey

will be sent via email. Please be sure to provide an accurate email address to the FIU research staff before leaving. You will receive a $\$ 20$ gift card to Starbucks electronically after completing the 1 month follow up survey. 


\title{
Appendix B
}

\author{
Institutional Review Board Approval
}

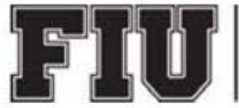

FLORIDA

INTERNATIONAL

Office of Research Integrity

UNIVERSITY

Research Compliance, MARC 414

\section{MEMORANDUM}

To:

Dr. Eric Wagner

CC:

From:

File

Date:

Maria Melendez-Vargas, MIBA, IRB Coordinator

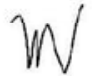

Protocol Title: "Miami-Dade Partnership for Preventing Health Risks Among Young

Adults- Testing Implementation"

The Health Sciences Institutional Review Board of Florida International University has re-approved your study for the use of human subjects via the Full Board Review process. Your study was found to be in compliance with this institution's Federal Wide Assurance (00000060).

IRB Protocol Approval \#:

IRB-15-0236

IRB Approval Date: $\quad 05 / 25 / 16$

TOPAZ Reference \#: 103657

IRB Expiration Date: 05/25/17

As a requirement of IRB Approval you are required to:

1) Submit an IRB Amendment Form for all proposed additions or changes in the procedures involving human subjects. All additions and changes must be reviewed and approved by the IRB prior to implementation.

2) Promptly submit an IRB Event Report Form for every serious or unusual or unanticipated adverse event, problems with the rights or welfare of the human subjects, and/or deviations from the approved protocol.

3) Utilize copies of the date stamped consent document(s) for obtaining consent from subjects (unless waived by the IRB). Signed consent documents must be retained for at least three years after the completion of the study.

4) Receive annual review and re-approval of your study prior to your IRB expiration date. Submit the IRB Renewal Form at least 30 days in advance of the study's expiration date.

5) Submit an IRB Project Completion Report Form when the study is finished or discontinued.

Special Conditions: N/A

For further information, you may visit the IRB website at http://research.fiu.edu/irb.

$\mathrm{MMV} / \mathrm{em}$ 


\title{
Appendix C
}

\section{Copy of Comment Policy}

\author{
Cody the Camel Comment Policy
}

This project participates in social networking sites in order to engage individuals and organizations in health promotion. We provide content on Facebook, Instagram, and Twitter to enhance information sharing, encourage participation with our science-based messages and discussion of positive health behaviors. We welcome your comments, opinions, and questions. Please follow these guidelines when posting

\section{Stay Focused}

All viewpoints are welcome, but comments should remain relevant to the website, page, video, photo, or post to which you're commenting. If you would like to contact FIU-BRIDGE about another topic, please email us at samhsafiubridge@gmail.com

\section{Be Respectful}

Constructive interaction is welcome. Personal attacks, foul language, and aggressive commenting are not. Please review comment approval for more information.

Tell the Truth

Spreading misleading or false information is not permitted.

\section{Do Not Spam}

Repeated posting of identical or very similar content is not permitted. This media site is for informative discussion. Do not send posts that aggressively promote services or products

Protect yourself

We encourage you to share your comments and ideas. But to protect your privacy, please do not disclose personally identifiable information, such as an e-mail address, home address or phone number for yourself or others. If you choose to interact with this site, any information that you provide is voluntarily contributed by you.

Comment Approval

FIU-BRIDGE keeps records of unapproved comments to limit inappropriate postings. Comments will not be approved if they contain:

- Commercial endorsements

- Discriminatory, racist, offensive, obscene, unlawful, or otherwise objectionable language or content

- Hate speech, profanity, or vulgarity, name calling and/or personal attacks

- Other topics that the team deems inappropriate.

Disclaimer

Posted comments and images do not necessarily represent the views of FIU-BRIDGE. External links on this site do not constitute official endorsement on behalf of FIU-BRIDGE. While we encourage followers to share thoughts and opinions on the page, we expect that this will be done in a respectful and focused manner. Our goal is to share ideas and information with as many individuals as possible and our policy is to accept the majority of comments made to our profile.

Please note, though, that all links posted as comments on posts will be reviewed and may be deleted. Repeated violations of the comment policy may cause the author to be blocked from the Facebook page.

Privacy

We will not collect personally identifiable information such as your name, address, or telephone number from thirdparty websites such as Facebook. We will not contact you directly via phone, mail, or email attempting to solicit information from you. We may use information that visitors make available on Facebook and other third-party websites to improve our programs and better serve the public (for example, improving our education and outreach materials and activities). We will maintain any such information in accordance with federal law.

NOTE: This Comment Policy is based on the policies held by federal institutions' use of social networking sites (i.e. SAMHSA, CDC). The FIU. BRIDGE Comment Policy is subject to change without notice. Please review this policy periodically for changes. If you have any questions, please contact wagnere@fiu.edu . For media inquiries, please contact. sofernan@fu.edu. 
Appendix D

Example of Screen Captures

Instagram

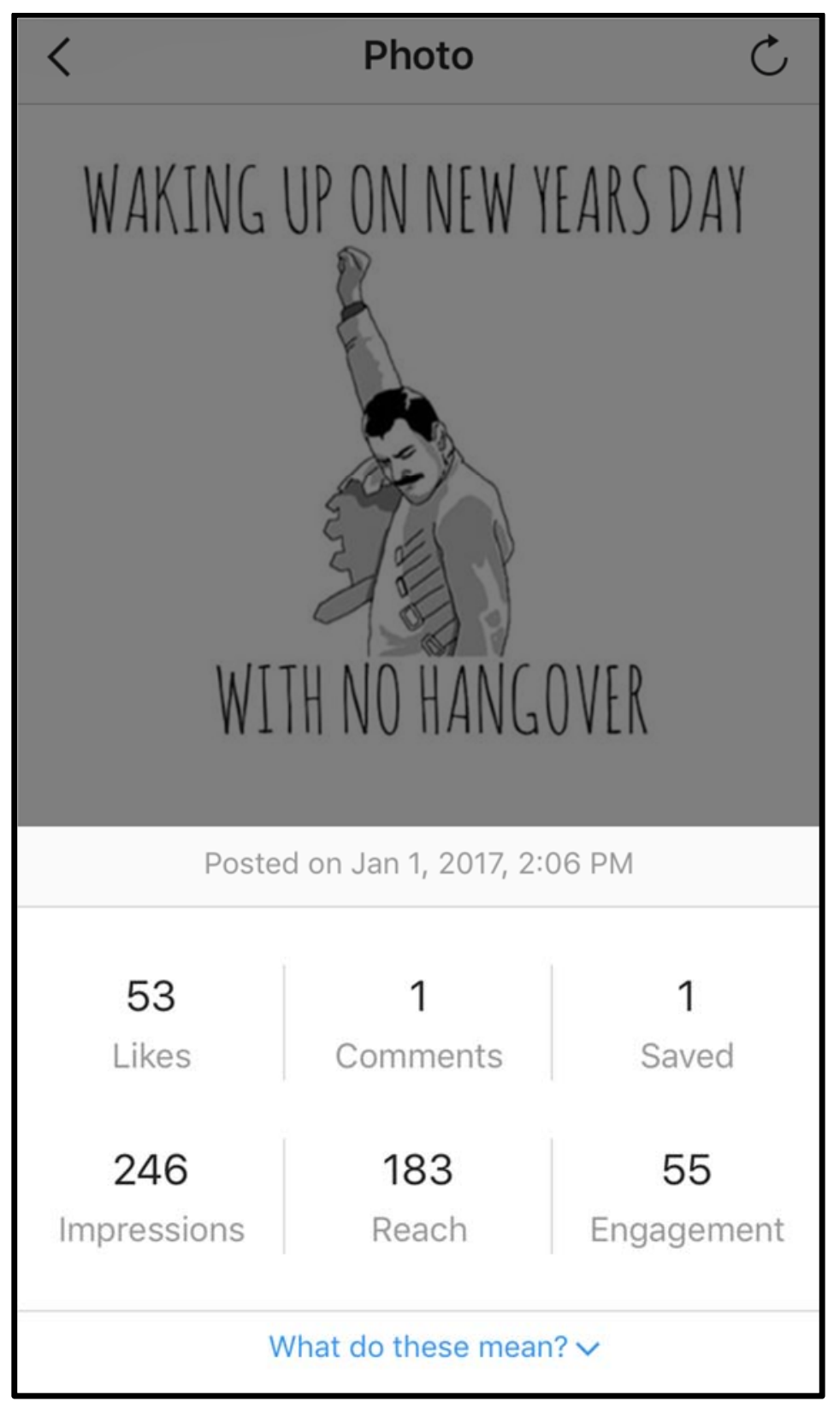




\section{Facebook}

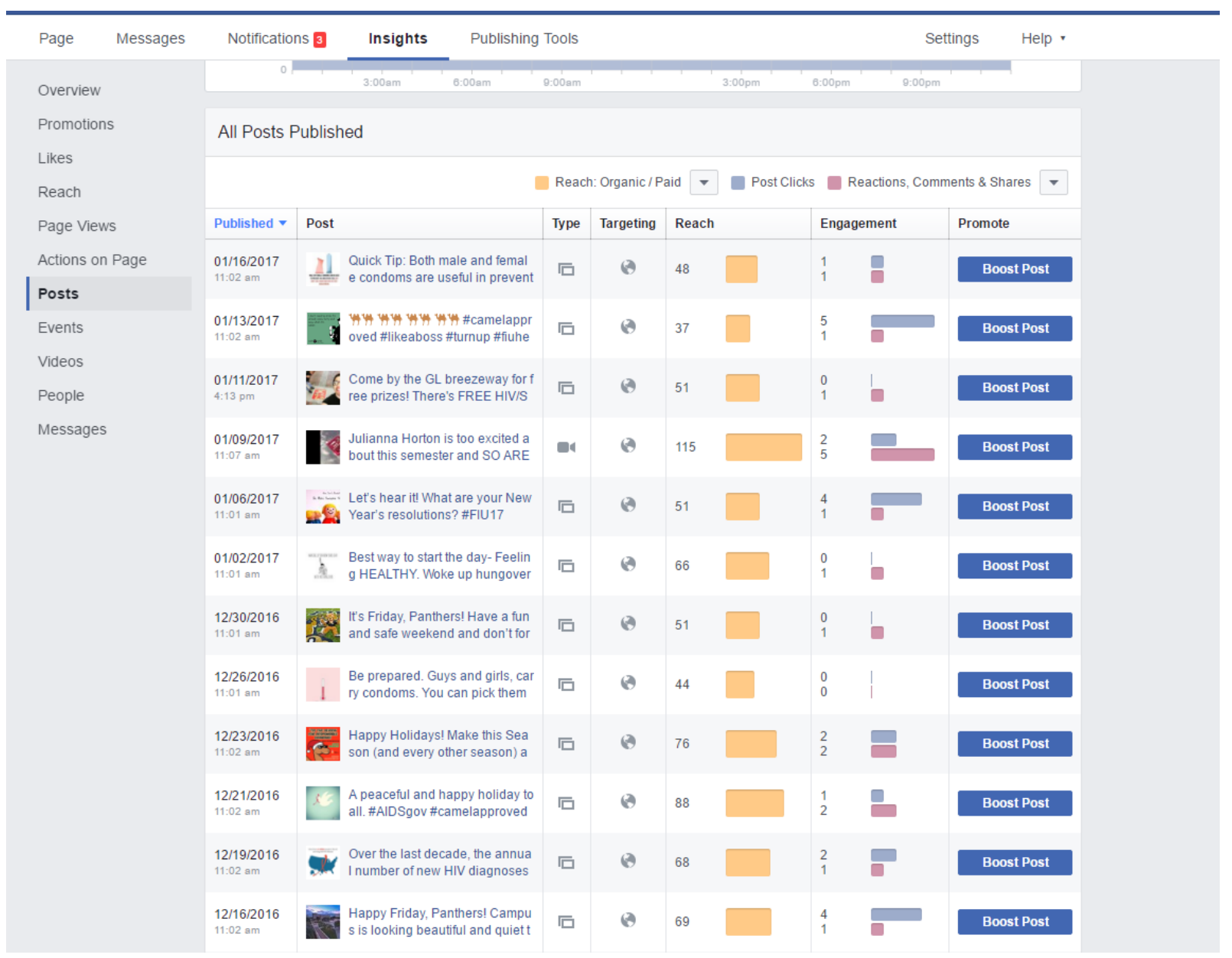




\section{Twitter}

1. Analytics Home Tweets Audiences Events More v

Jan $2017 \cdot 31$ days

TWEET HIGHLIOHTS

Top Tweet earned 165 impressions

Come by the GL breezeway for free prizes! There's FREE HIVISTD testing today from 10-5 (and every hump day) in AHC-5 room 104 \#camelapproved pic.twitter.com/liu5luhmdO

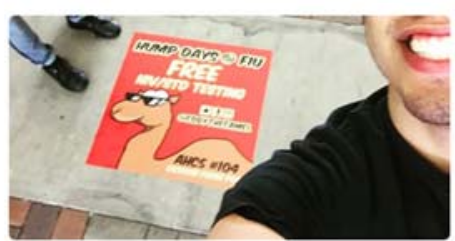

571 $* 3$

View Tweet activity View all Tweet activity

Top Follower followed by

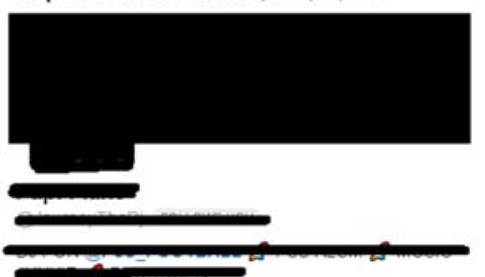

271 23

View Tweet
Codythecamel $\vee 58$ Sion up for Twitter Ads

JAN 2017 SUMMARY

13

2,725

FIU

Join @CodytheCamel for free STD \& HIV testing today \& every Wednesday in AHC5 in room 104 from 10am-5pm!

\#CodytheCamel

1
320

New followers

7

Top media Tweet earned 146 impressions

Let's hear it! What are your New Year's resolutions? \#FIU17

pic.twitter.com/rBGIvhdX65

New Year's Resdution \#1:

Be More Awesome than last year.

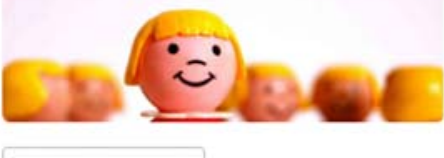

View Tweet activity

View all Tweet activity 
VITA

SOFIA B. FERNANDEZ

2013

2013

2014

2014

2014- Present

2016-2017
B.S.W., Social Work

Florida State University

Tallahassee, FL

College of SW Humanitarian of the Year Florida State University

Tallahassee, FL

M.S.W., Social Work

Florida State University

Tallahassee, FL

Graduate Research Assistant

Florida International University

Miami, FL

Project Coordinator

FIU-BRIDGE

Miami, FL

Doctoral Candidate

Florida International University

Miami, FL

\section{PUBLICATIONS AND PRESENTATIONS}

Howard, M., Fernandez, S.B., Graziano, J., Hospital, M., Morris, S., \& Wagner, E. (2017, November). Getting their foot in the door: Communication cues to action for HIV test takers at a Hispanic-serving institution (HSI). American Public Health Association Annual Meeting and Expo. Atlanta, GA.

Huang, H., Rhoden, M., Fernandez, S.B. (2016, April). Mental Health Status among Former Child Welfare Youth in College. Florida Public Health Association South Florida Regional Conference. Miami, FL.

Huang, H., Rhoden, M., \& Fernandez, S.B. (2016, November). Serving Former Foster Youth and Homeless Students in College: A Mixed-Method Approach. Council of Social Work Education $62^{\text {nd }}$ Annual Program Meeting. Atlanta, GA. 
Huang, H., Rhoden, M., \& Fernandez, S.B. (2017, January). Early Engagement in College Support Programs: the Key to Academic Success among Former Child Welfare Youth and Homeless Students. Society for Social Work Research. New Orleans, LA.

Huang, H., Rhoden, M., Fernandez, S.B., \& Joseph, R. (2017, October). Mental health diagnosis among former foster youth and homeless students in college. Council on Social Work Education $63^{\text {rd }}$ Annual Program Meeting. Dallas, TX.

Fernandez, S.B., Wagner, E., Hospital, M., Morris, S., Howard, M., \& Graziano, J. (2016) Direct and indirect Strategies for reducing alcohol use in emerging adult clinical and community samples: Social Media-Based Prevention for Reducing Alcohol Use Problems among Emerging Adults. Alcoholism: Clinical and Experimental Research. Volume 40, Supplement: S1.

Fernandez, S.B., Wagner, E., Hospital, M., Morris, S., Howard, M., \& Graziano, J. (2015, December). \#MissHIVaria: Social Media Engagement for Expanding HIV Testing Among Hispanic Young Adults. The National HIV Prevention Conference, Atlanta, GA.

Wagner, E., Hospital, Morris, S., M., Howard, M., Graziano, J., \& Fernandez, S.B. (2016, April). Social media engagement for sexual health promotion among Hispanic young adults. The International Society for Research on Internet Interventions, Seattle, WA.

Wagner, E., Hospital, M., Howard, M., \& Graziano, J., Fernandez, S.B. (2016, April). HIV Testing strategies for reaching Urban Hispanic Young Adults: A UniversityCommunity Partnership. 13th International Conference on Urban Health, San Francisco, CA.

Wagner, E. \& Fernandez, S.B. (2016, June). Direct and indirect strategies for reducing alcohol use in emerging adult clinical and community samples: Social Media-Based Prevention for Reducing Alcohol Use Problems among Emerging Adults. The Research Society on Alcoholism, New Orleans, LA.

Wagner, E., Hospital, M., Howard, M., \& Graziano, J., Fernandez, S.B. (2015, April) Community- Based Research Partnerships for Preventing Health Risks Among Urban Young Adults. Abstract accepted for 85 minute Panel Discussion at the $45^{\text {th }}$ Annual Urban Affairs Association Conference, Miami, FL. 